\title{
Report on Geophysical Surveys in the 300-FF-1 Operable Unit
}

\author{
G. A. Sandness
}

March 1991

Prepared for the U.S. Department of Energy under Contract DE-AC06-76RLO 1830

Environmental Management Operations

Operated for the U.S. Department of Energy by Battelle Memorial Institute 


\section{DISCLAIMER}

This report was prepared as an account of work sponsored by an agency of the United States Government. Neither the United States Government nor any agency thereof, nor Battelle Memorial Institute, nor any of their employees, makes any warranty, expressed or implied, or assumes any legal liability or responsibility for the accuracy, completeness, or usefulness of any information, apparatus, product, or process disclosed, or represents that its use would not infringe privately owned rights. Reference herein to any specific commercial product, process, or service by trade name, trademark, manfacturer, or otherwise does not necessarily constitute or imply its endorsement, recommendation, or favoring by the United States Government or any agency thereof, or Battelle Memorial Institute. The views and opinions of authors expressed herein do not necessarily state or reflect those of the United States Government or any agency thereof.

ENVIRONMENTAL MANAGEMENT OPERATIONS operated by

BATTELLE MEMORIAL INSTITUTE for the

UNITED STATES DEPARTMENT OF ENERGY under Contract DE-AC06-76RLO 1830 


\section{DISCLAIMER}

This report was prepared as an account of work sponsored by an agency of the United States Government. Neither the United States Government nor any agency Thereof, nor any of their employees, makes any warranty, express or implied, or assumes any legal liability or responsibility for the accuracy, completeness, or usefulness of any information, apparatus, product, or process disclosed, or represents that its use would not infringe privately owned rights. Reference herein to any specific commercial product, process, or service by trade name, trademark, manufacturer, or otherwise does not necessarily constitute or imply its endorsement, recommendation, or favoring by the United States Government or any agency thereof. The views and opinions of authors expressed herein do not necessarily state or reflect those of the United States Government or any agency thereof. 


\section{DISCLAIMER}

Portions of this document may be illegible in electronic image products. Images are produced from the best available original document. 
REPORT ON GEOPHYSICAL SURVEYS IN THE 300-FF-1 OPERABLE UNIT

March 1991

Prepared for

the U.S. Department of Energy under Contract DE-AC06-76RLO 1830

Environmental Management Operations Pacific Northwest Laboratories

Richland, Washington 99352 


$$
\checkmark
$$




\section{PREFACE}

This report summarizes the geophysical surveys, Tasks $1 . b$ and $1 . c$ of the Phase I Remedial Investigation for the 300-FF-I operable unit on the Hanford Site, near Richland, Washington. The purpose of the Remedial Investigation is to determine the nature and extent of the risk presented by releases of hazardous substances from the operable unit. The purpose of this task was, first, to confirm the locations of abandoned process sewers and radioactive liquid waste sewers as shown on existing maps or to otherwise accurately determine their locations, and second, to attempt to identify locations of possible leaks.

Westinghouse Hanford Company was responsible for coordinating Phase I efforts. The information presented in this report was collected by Pacific Northwest Laboratory, for Battelle, Pacific Northwest Division's Environmental Management Operations, at the request of Westinghouse Hanford Company. The Westinghouse Hanford Company technical coordinator for these activities was Larry C. Hulstrom. The Environmental Management Operations program manager was Donald A. Kane, and the Pacific Northwest Laboratory project manager was George V. Last. 


$$
\nabla
$$




\section{SUMMARY}

This report describes a set of geophysical surveys performed by the Pacific Northwest Laboratory at selected locations within the 300-FF-1 Operable Unit at Hanford. Field work and preliminary data processing activities were initiated in September 1989. These actions were terminated by the Westinghouse Hanford Company before completion in December 1989. Work was reinitiated in October 1990, to complete the processing of the data that had already been collected and to report the results. Because the field work was only partially completed, the task objectives, as presented in the Statement of Work, could not be fully met. This report is, therefore, a progress report covering the work performed through December 11, 1989.

This task involved 1) ground-penetrating radar surveys of the 618-4 and 618-5 Burial Grounds, and 2) ground-penetrating radar and electromagnetic induction surveys along the assumed routes of the abandoned process sewers and radioactive liquid waste sewers in the 300-FF-1 Operable Unit. The surveys in the burial grounds were intended to identify burial trenches and pits, to determine the depth of fill, and to locate waste materials, including any that might be outside the perimeter fences. The surveys along the sewer routes were intended, first, to confirm the locations of the sewers as shown on existing maps or to otherwise accurately determine their locations, and second, to attempt to identify locations of possible leaks.

Initial geophysical surveys were performed at 10 locations, or survey areas, that covered most of the sewer sections that were included in this task as well as the outer perimeter of the 618-5 Burial Ground. Surveys of the other parts of the burial-ground sites could not be completed in the time available. The resulting data have been processed and analyzed.' Preliminary maps showing the interpreted results are included in this report.

The data collected at the 618-5 Burial Ground indicated that some scattered man-made materials are present in the ground outside the perimeter fence. The surveys along the sewer routes clearly defined segments of the sewers and other nearby pipelines. Additional ground-penetrating radar 
surveys are needed in certain areas to obtain improved spatial resolution and/or to detect sections of the sewers that might be deeper than the penetration depth of the initial surveys. 


\section{CONTENTS}

PREFACE

SUMMARY

1.0 INTRODUCTION $\ldots \ldots \ldots \ldots \ldots \ldots$

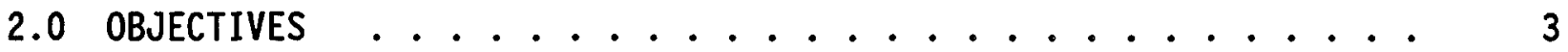

3.0 SITE DESCRIPTIONS ........................ 5

4.0 GEOPHYSICAL SURVEY METHODS . . . . . . . . . . 11

4.1 GROUND-PENETRATING RADAR PROFILING ............ 11

4.2 EMI GROUND CONDUCTIVITY PROFILING . . . . . . . . 12

4.3 DATA COLLECTION PROCEDURES . . . . . . . . . . . 12

4.4 DATA PROCESSING PROCEDURES ................... 13

5.0 RESULTS ............................... 17

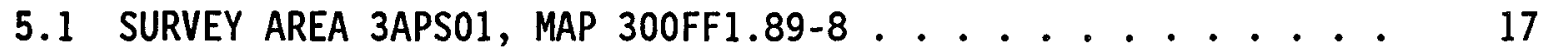

5.2 SURVEY AREA 3APSO2, MAP 300FF1.89-9 ........... 18

5.3 SURVEY AREA 3APRS1, MAP 300FF1.89-10 . . . . . . . 19

5.4 SURVEY AREA 3APRS3, MAP 300FF1.89-10 . . . . . . . . 19

5.5 SURVEY AREA 3APRS2, MAP 300FF1.89-10 .......... 20

5.6 SURVEY AREA 3APRS4, MAP 300FF1.89-10 . . . . . . . 21

5.7 SURVEY AREA 3APRS2, MAP 300FF1.89-11 ............ 21

5.8 SURVEY AREAS 3ARSI AND 3ARS2, MAP 300FFI.89-12 . . . . . 22

5.9 SURVEY AREA 618-5 BURIAL GROUND, MAP 300FF1.89-13 . . . . 23

6.0 FINAL COMMENTS . . . . . . . . . . . . . . 25

7.0 REFERENCES . . . . . . . . . . . . . . . . 27

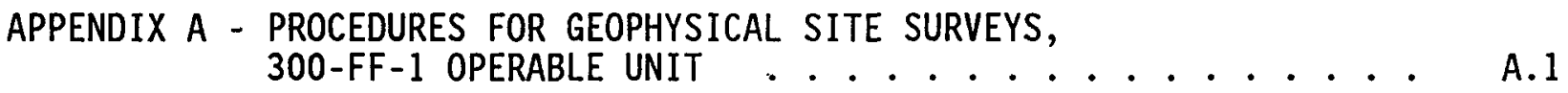
APPENDIX B - SURVEY-AREA MAPS .............. B.I 
APPENDIX C - GPR PROFILES . . . . . . . . . . . . . C.I

APPENDIX D - LARGE-SCALE SUMMARY MAPS . . . . . . . . . . . . . D.

APPENDIX E - EMI PROFILES . . . . . . . . . . . . . . . . . . E.1

APPENDIX F - GEOPHYSICAL SURVEYS TO LOCATE BURIED LITHIUM

ALUMINATE RODS .................... F.l 


\section{FIGURES}

$1300-F F-1$ Operable Unit . . . . . . . . . . . . . 6

2 General Layout of the 300 Area . . . . . . . . . . . . 7

3 Abandoned Radioactive Liquid Waste Sewer System . . . . . . 8

\section{TABLES}

1 Summary of Geophysical Surveys . . . . . . . . . . . . 9

2 Summary of Data Profiles . . . . . . . . . . . . . 15 


\subsection{INTRODUCTION}

This report describes a set of geophysical surveys performed by the Automation and Measurement Sciences Department of the Pacific Northwest Laboratory $(\mathrm{PNL})^{(a)}$ at selected locations within the 300-FF-1 Operable Unit at Hanford. The surveys were performed for the Westinghouse Hanford Company (WHC) as a task under the 300-FF-1 Phase 1 Remedial Investigation Project. The surveys were performed in accordance with the Fiscal Year 1989 Statement of Work for work orders ED9399 and ED9458.

Field work and preliminary data processing activities were initiated in September 1989. Work was terminated by WHC, prior to its completion, in December 1989. Work was restarted in October 1990, to complete the processing of the data that had already been collected and to report the results. Because the field work was only partially completed, the task objectives, as presented in the Statement of Work, could not be fully met. This report is, therefore, a progress report covering the work performed through December 11 , 1989.

This is the second of three primary products, or deliverables, that are to be submitted to WHC by PNL during the course of this work. The first of these products was a set of formal Work Procedures, which were submitted to WHC prior to the initiation of field work. Copies of these Work Procedures are appended to this report as Appendix A. They are also contained in PNL6894 (PNL 1989, Sections SG-1 through SG-4). The third product consists of the project file records and the geophysical data collected in this study. This assortment of materials will be submitted to WHC.

The text in the remainder of this report is divided into five sections. Section 2.0 outlines the objectives of the geophysical surveys. Section 3.0 provides a brief introduction to the sites at which the geophysical surveys were performed. Section 4.0 briefly describes the geophysical methods that were used. Section 5.0 discusses the results of the geophysical surveys.

(a) Pacific Northwest Laboratory is operated for the U.S. Department of Energy by Battelle Memorial Institute. 
Section 6.0 contains some final comments relating to the significance of the results and to the need for additional work to fully meet the task objectives. Finally, the results of interpretations of the collected geophysical data are presented on a set of 16- $x$ 21-in. maps included as an appendix at the back of this report. 


\subsection{OBJECTIVES}

As outlined in the Statement of Work (DOE 1990), the geophysical surveys

were intended to address two parts of Task 1, Source Investigation. The first part, Task 1.b, involved ground-penetrating radar (GPR) surveys of Burial Grounds 618-4 and 618-5. The objectives of these surveys were

- to determine the depths of fill

- to identify subsurface structures such as trenches and pits

- to detect and map buried waste materials and other significant features inside the burial grounds and within a narrow zone along the outside of the perimeter fences.

The second part, Task $1 \mathrm{c}$, was initially planned to consist of electromagnetic induction (EMI) surveys of the process sewers (active and inactive) and radioactive liquid waste (RLW) sewers within the 300-FF-1 Operable Unit. The scope of this task was expanded by PNL and WHC to include GPR surveys along the assumed paths of these sewers because it was expected that the high density of pipelines, cables, buildings, and other conductive structures in the areas to be surveyed would seriously degrade the ability of the EMI method to detect the sewers in an interpretable and unambiguous manner. The objectives were

- to determine the exact locations of the sewers

- to identify the locations of possible leaks. 


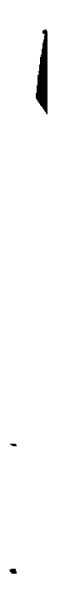

. 


\subsection{SITE DESCRIPTIONS}

Figure 1 is a map showing the major features of the 300-FF-1 Operable Unit, including the locations of the 618-4 and 618-5 Burial Grounds and the active and abandoned process sewers in that operable unit. Figure 2 is a similar map that encompasses the entire 300 Area. It does not show the locations of the process sewers or the RLW sewers, but it does show the specific areas in which we performed our geophysical surveys. These are indicated in a generalized way by heavy black line segments. Figure 3 is a schematic diagram of the RLW sewer system in the 300 Area.

The specific areas in which geophysical surveys were performed prior to the termination of field work are shown at a larger scale on a set of surveyarea maps. These 8.5- x 11-in. maps (map nos. 300FFl.89-1 through 300FF1.89-6) are contained in Appendix B. They show the locations, directions, and coordinates of the sets of survey lines along which the GPR and EMI measurements were made.

Each of the survey areas was given a label to facilitate the handling of data files during our data acquisition and data processing activities. These labels are shown on the survey-area maps.

The areas to be covered by our geophysical surveys at the burial grounds were defined by grids established by Kaiser Engineers Hanford. These grids were marked by wooden stakes at intervals of $8 \mathrm{~m}$. Each of the other survey areas was defined by a set of survey lines measured and marked by PNL prior to the collection of the geophysical data. The survey lines were established by measuring distances with a steel tape and by marking line locations with spray paint. To ensure that the lines could be relocated later, we recorded reference coordinates relative to permanent features or structures. Distance units of feet were used for all measurements except for those at the burial-ground sites. Table 1 briefly describes the survey areas and summarizes the geophysical surveys in terms of the types of measurements that were made, the spacing of the survey lines, and the traverse directions for each of the geophysical survey methods. 


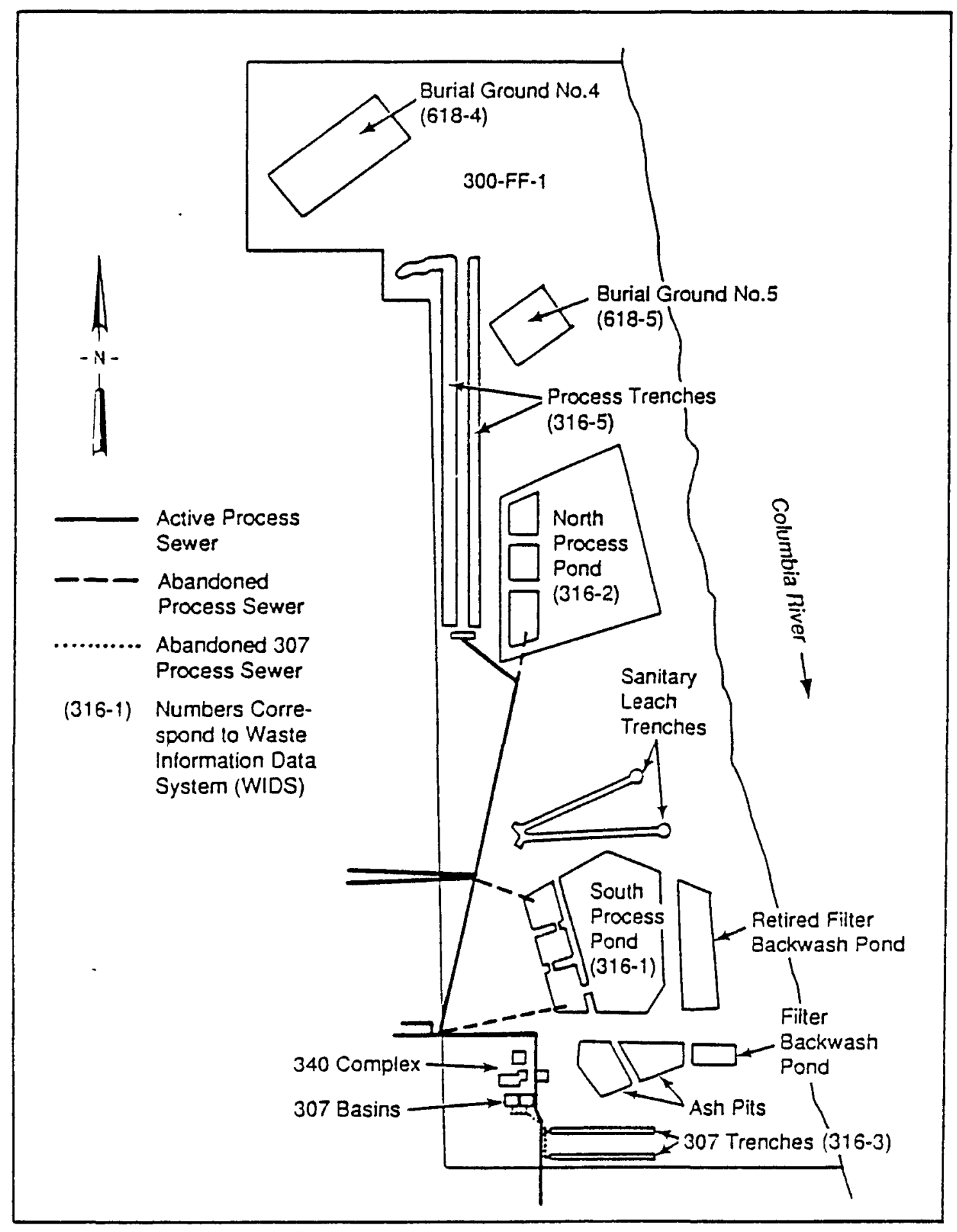

FIGURE 1. 300-FF-1 Operable Unit 


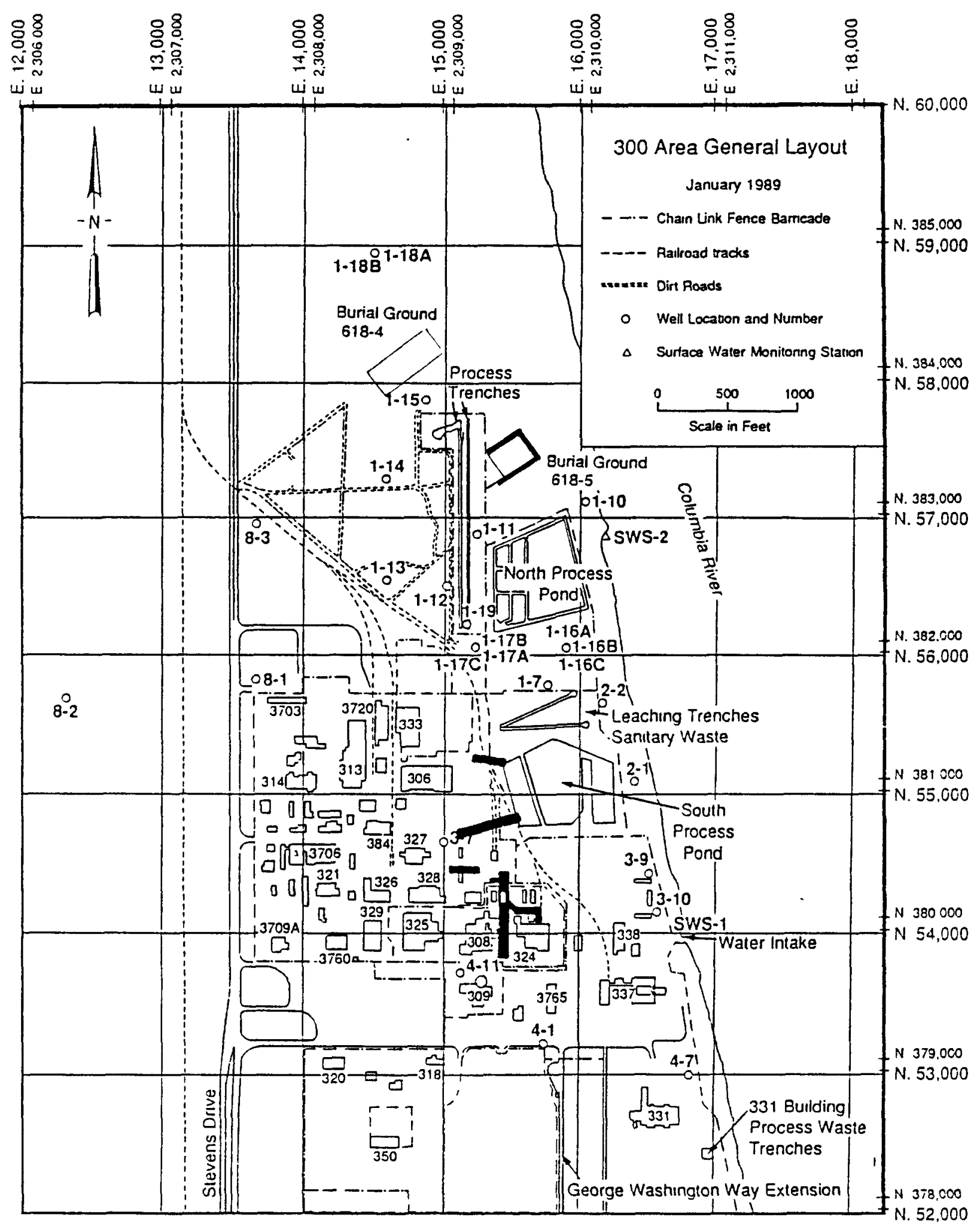

FIGURE 2. General Layout of the 300 Area. The heavy lines show the areas where the geophysical surveys were performed. 


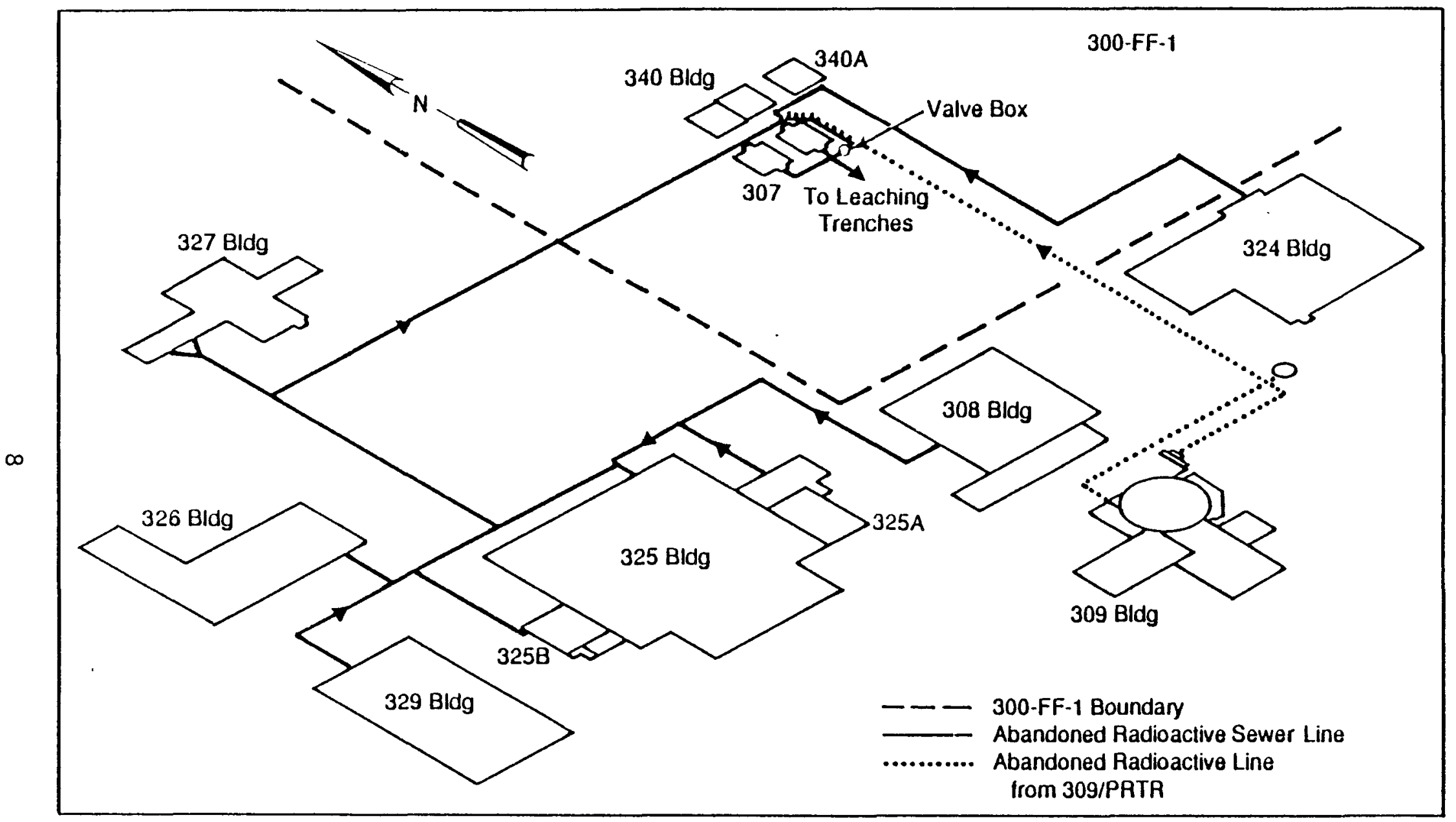

FIGURE 3. Abandoned Radioactive Liquid Waste Sewer System (from Young et al. 1990) 
TABLE 1. Summary of Geophysical Surveys

\begin{tabular}{|c|c|c|}
\hline Survey Area & $\begin{array}{l}\text { Line } \\
\text { Spacing (ft) }\end{array}$ & Survey Method (dir) \\
\hline $\begin{array}{l}\frac{3 A P S 01}{\text { Pond } 3} \text { (S. Process Sewer to } \\
\text { Process Pond) }\end{array}$ & $\begin{array}{l}25 \\
25\end{array}$ & $\begin{array}{ll}\text { EMI } & (N N W-S S E) \\
\text { GPR } & \text { (NNW-SSE) }\end{array}$ \\
\hline $\begin{array}{l}\frac{3 \text { APSO2 }}{\text { Pond } 1 \text { Process Sewer to }} \text { (S. Process Pond) } \\
\text { Prose }\end{array}$ & $\begin{array}{l}25 \\
25\end{array}$ & $\begin{array}{l}\text { EMI (NNE-SSW) } \\
\text { GPR (NNE-SSW) }\end{array}$ \\
\hline$\frac{3 A P R S 1}{324 \text { BT } d g}-$ RLW Sewer from & $\begin{array}{l}5 \\
5\end{array}$ & $\begin{array}{l}\text { EMI }(W-E, S-N) \\
\text { GPR }(W-E, S-N)\end{array}$ \\
\hline $\begin{array}{l}\frac{3 A P R S 2}{309 \&}-\text { RLW Sewers from } \\
\text { Sewer from } 324 \text { Bldg }\end{array}$ & $2.5,5$ & $\begin{array}{l}\text { EMI }(W-E, N-S) \\
\text { GPR }(W-E, N-S)\end{array}$ \\
\hline$\frac{3 A P R S 3}{324 \text { BT } d g}-$ RLW Sewer from & $\begin{array}{l}5 \\
5\end{array}$ & $\begin{array}{l}\text { EMI }(N E-S W) \\
\text { GPR }(N E-S W)\end{array}$ \\
\hline $\begin{array}{l}\frac{3 A P R S 4}{309 \text { B1 }}-\text { RLW Sewer from } \\
\text { from } 324 \text { Bldg }\end{array}$ & $\begin{array}{r}25 \\
5\end{array}$ & $\begin{array}{l}\text { EMI }(W-E) \\
\text { GPR }(W-E)\end{array}$ \\
\hline $\begin{array}{l}\frac{3 A P R S 5}{\text { Sewers }}-\text { RLW and Process } \\
307 \text { Ponds }\end{array}$ & 2.5 & GPR $(E-W, S-N)$ \\
\hline $\begin{array}{l}\frac{3 \text { ARS1 }}{\text { the } 3762 \text { Bld Sewer East of }}\end{array}$ & 2.5 & GPR $(S-N)$ \\
\hline $\begin{array}{l}\frac{3 \text { ARS2 }}{\text { the } 3762 \text { RLW Sewer West of }} \\
\text { Bldg }\end{array}$ & 5 & GPR $(S-N)$ \\
\hline 618-5 Burial Ground & $(13.1 \mathrm{ft})$ & $\begin{array}{l}\text { GPR (NW-SE, SW-NE, } \\
\text { and SE-NW) }\end{array}$ \\
\hline
\end{tabular}

Note that Table 1 and some of the EMI and GPR data display products (described below) give the directions of the survey lines in a more accurate form than do the maps of the survey areas. For example, al though the base line of Survey Area 3APSO1 was actually oriented in a NNE-SSW direction, the survey line coordinates are simply designated as $O E, 25 E$, etc. on the map. Although a totally consistent scheme for noting line directions has not been used in the various parts of this report, Table 1 will clarify the actual line directions. 


\subsection{GEOPHYSICAL SURVEY METHODS}

The sensors and procedures that correspond to the GPR and EMI survey methods are described briefly in the following paragraphs. Additional instrument specifications and operational details have been presented in the procedures documents contained in Appendix A.

\subsection{GROUND-PENETRATING RADAR PROFILING}

The GPR system used in these surveys was a Model SIR System 7, manufactured by Geophysical Survey Systems, Inc. (North Salem, New Hampshire). It operates by transmitting a short $(3-n s e c)$ electromagnetic pulse into the ground, then detecting the signals that are backscattered or reflected from buried objects or interfaces. In principle, reflected signals are produced by any object (metallic or non-metallic) or interface that has a dielectric constant or electrical conductivity different from that of the surrounding earth. Examples of detectable targets include metal or plastic waste containers, metal and plastic pipe, sand and clay layers or lenses, bedrock, and the edges of backfilled trenches. The radar operates in the time-domain reflectometry mode, where the depth of a reflective target or interface is proportional to the travel time of the reflected signal.

At the beginning of this task, it was assumed that pipelines, possible cables, and other features in the survey areas would be located at depths ranging from $1 \mathrm{ft}$ to approximately $20 \mathrm{ft}$. Thus, to begin the GPR surveys, an antenna was used that transmitted signals with a frequency spectrum centered at approximately $300 \mathrm{MHz}$. This antenna provided reasonably good spatial resolution as well as an effective penetration depth of at least $15 \mathrm{ft}$ in most survey areas. Given the results of initial surveys with this antenna, we had planned to perform follow-on surveys using a higher-frequency antenna $(500 \mathrm{MHz})$ to obtain higher-resolution data where greater near-surface detail was needed, and using a lower-frequency antenna (120 MHz) where greater depth penetration was needed. Unfortunately, the premature termination of work made it impossible to return to any of the survey areas to perform this follow-on work. 


\subsection{EMI GROUND CONDUCTIVITY PROFILING}

A Geonics (Mississauga, Ontario) EM31 ground conductivity meter was used to perform the EMI surveys. This is a portable instrument that uses the electromagnetic induction principle to measure the apparent electrical conductivity of the ground. It contains two coils mounted at opposite ends of a 12-ft-long support tube. An alternating magnetic field produced by the transmitter coil induces electrical currents in the ground and in any conductive waste materials that may be present in the ground. These currents, in turn, produce a secondary magnetic field that is detected by the receiver coil. The ratio of the secondary and primary field components is measured and electronically scaled to derive the desired conductivity value. The resulting analog signal is displayed to the operator by means of a meter on the unit's control pane1. An electrical output connector permits the signal to be recorded by an external data logger.

\subsection{DATA COLLECTION PROCEDURES}

The basic procedure for data collection at each site was to separately carry or pull the geophysical sensors along the survey lines. The conductivity meter was carried by the operator, and its output was recorded in digital form by means of a small, battery-powered data recorder. The GPR antenna unit was mounted on wheels and was manually pulled across the ground surface. The GPR control unit and digital data acquisition system were contained in a nearby vehicle.

The EMI data were collected along the survey lines at a constant normal walking speed, yielding an along-track data spacing of approximately 12 in. The GPR data were collected with a slightly slower constant traverse speed and a higher data collection rate, yielding an along-track data spacing of approximately 3 in.

Each time the operator crossed a selected distance mark or grid stake, he pressed a switch that entered a marker code into the data record. These markers provided fixed points within each data record at which the locations of the measurements were precisely known. They ensured that the collected EMI data could be accurately associated with field coordinates. 


\subsection{DATA PROCESSING PROCEDURES}

The recorded, digital, EMI data sets, or files, were downloaded in the field from the data recorder to a. portable personal computer, then copied to a 3.5-in. floppy disk. The first step in the data processing procedure involved a linear interpolation of the data to adjust the along-track data spacing to a predetermined value. This value was set at 1 or $1.5 \mathrm{data} / \mathrm{ft}$ for all of the EMI surveys. The accuracy of the interpolation algorithm was enhanced by utilizing the marker codes in the data records to divide the data file into segments corresponding to the distance between stakes or other position markers. Thus, each end of a specified data interval was precisely correlated with a known field location.

The second step in the processing of the EMI data sets was the production of graphs, or data profiles, that show the amplitude of the recorded signal as a function of distance along the survey lines. These profiles are presented in Appendix B. As a final step, the profiles were visually interpreted to determine the locations of the buried waste materials. The results were plotted on a series of output summary maps, which constitute the final products of the geophysical surveys.

The GPR data files were initially recorded on digital tape cartridges. These files were transferred to the hard disk of a DEC (Digital Equipment Corporation, Maynard, Massachusetts) 11/23 minicomputer. A descriptor file containing information such as the number of digitized data in each received signal (scan), the number of scans in each survey line, and the nominal length and direction of each survey line was associated with each data file. The first step in processing a given data file was to edit the descriptor file, modifying the parameters as needed to correspond to the actual values (e.g., the actual length of a survey line may differ from the nominal length that was initially recorded). Using the parameters of the edited descriptor file, the data file was then interpolated by a linear method equivalent to that used to interpolate the EMI data. This procedure yielded data sets that had a fixed scan density (i.e., a predetermined number of scans per unit length). This parameter was set at 4 scans/ft for all of the GPR data files recorded in this task. The interpolated files were written to 9 -track magnetic tape to 
facilitate the transfer of the data to a DEC VAX computer and to provide for long-term storage of the data. The VAX was used to perform the final data processing and display operations.

The last data processing step involved the removal of unchanging signal components from the GPR data. These unwanted components consist of reflections from the ground surface and from within the radar system. In a video or photographic display of the radar data, these components appear as horizontal stripes that extend from one end of the image to the other. They were removed from the data files by computing an average amplitude at each depth increment, or row in the two-dimensional data set, then subtracting that average from each datum in the row. Eliminating the largest positive and negative data from the average prevented the average from being biased by exceptionaliy strong localized reflections.

Hardcopy images (profiles) of the GPR data were produced with the aid of a Dicomed (Minneapolis, Minnesota) D47 digital film recorder. Copies of these profiles in the form of intensity-modulated black and white images are presented in Appendix C. Each image in these prints corresponds to a survey line. The horizontal dimension in each profile corresponds to distance along the survey line. The vertical dimension corresponds to the two-way travel time of the radar signals or, equivalently, to the depth of the reflective materials. Estimated depth scales are shown on several of the photographic pages. These depth scales were calculated using a value of 9.0 for the relative dielectric constant of the ground materials. This value is consistent with values determined previously at other nearby sites. The depth scales can be easily adjusted if excavations at the current sites show that the actual depths of buried objects are different from the depths given on the radar profiles.

Because the radar waveforms oscillate between positive and negative values, the amplitude modulation was adjusted to display large negative data values as black and large positive values as white. The presence of a reflective buried object is usually indicated by a hyperbolic pattern of white and black tones. For a concentration of reflective objects, the reflection 
pattern may be quite complex; however, such a pattern is usually distinctive and distinguishable from the more regular or subdued patterns produced by und isturbed ground.

Table 2 summarizes the plots and photographs that display the collected data.

The numbers shown on the vertical axes of the EMI profiles are the raw data values produced by the 12-bit analog-to-digital convertor in the data logger. These numbers can be multiplied by a scale factor to obtain the approximate value of the electrical conductivity of the ground in units of mmhos/m, but the resulting values are meaningful only in areas where the ground is relatively undisturbed and are not related in any simple way to the

\section{TABLE 2. Summary of Data Profiles}

\begin{tabular}{|c|c|c|}
\hline Site & $\begin{array}{c}\text { EMI Profiles } \\
\text { (pages) }\end{array}$ & $\begin{array}{l}\text { GPR Profiles } \\
\text { (pages) }\end{array}$ \\
\hline$\frac{3 \text { APSO1 }}{\text { Pond } 3}$ - Process Sewer to & 4 & 2 \\
\hline$\frac{3 \text { APSO2 }}{\text { Pond } 1}$ - Process Sewer to & 2 & 1 \\
\hline$\frac{3 A P R S 1}{324 \text { B1dg }}-$ RLW Sewer from & 1 & 2 \\
\hline $\begin{array}{l}\frac{3 A P R S 2}{309 \&} 324 \text { Bldgs, Process } \\
\text { Sewer from } 324 \text { B } 1 \text { dg }\end{array}$ & 2 & 2 \\
\hline$\frac{3 A P R S 3}{324 \text { B1dg }}-$ RLW Sewer from & 1 & 1 \\
\hline $\begin{array}{l}\frac{3 A P R S 4}{309 \text { B }} \text { - RLW, Process Sewer from } \\
\text { from } 324 \text { Bldg }\end{array}$ & 2 & 1 \\
\hline $\begin{array}{l}\frac{3 A P R S 5}{\text { Sewers at } 307 \text { Ponds }}\end{array}$ & 0 & 2 \\
\hline $\begin{array}{l}\frac{3 A R S 1,2}{\text { and West of the } 3762 \text { Bldg }}\end{array}$ & 0 & 1 \\
\hline
\end{tabular}


properties of buried objects. A11 of the useful information relating to the locations of pipes is contained in the raw, or relative, data values shown on the profiles.

The horizontal axes of the EMI profiles show distances in units of feet along the survey lines. The location and direction of each profile are indicated by labels printed on the profile. To understand these labels, refer to the survey-area maps (Appendix B) that show the survey lines. The combination of labels and maps should make it easy to locate the starting and ending points of the profiles. 


\subsection{RESULTS}

The locations of the buried pipelines or waste materials in each survey area were derived by visually interpreting the EMI and radar profiles. The results are shown on the enclosed set of six large-scale $(1 \mathrm{in.}=40 \mathrm{ft}$ ) summary maps included as Appendix D. Solid heavy lines show the locations of detected pipelines that we considered to be well defined by the EMI and/or GPR data. Heavy dashed lines show the locations of pipelines or segments of pipelines that were poorly defined by the data. The estimated depth of a given pipe in units of feet is given by a number near the corresponding line on the map. An indicated depth of $2 \mathrm{ft}$ should be understood to mean 0 to $2 \mathrm{ft}$. This is because the GPR receiver is saturated by the transmitted pulse for a time period approximately equivalent to a 2-ft depth. Each map, or survey area, is discussed separately in the following paragraphs.

\subsection{SURVEY AREA 3APSO1, MAP 300FF1.89-8}

The target of interest in this survey area is the abandoned process sewer that terminates at Pond 3 (southwest segment of the South Process Pond). According to HEDL Drawing M-3904, Sheet 3, this sewer is a clay tile structure buried at a depth of approximately 8 to $13 \mathrm{ft}$. As shown on the map, five east-west-oriented pipelines were detected by the EMI and GPR sensors. The locations of four of these conform closely to the locations of pipelines shown on the HEDL drawing. We found two closely spaced pipelines at the location where the HEDL drawing shows an abandoned ash sluice line. The third pipeline shown on our map is an active process sewer from the 340 Complex. The fourth is probably an abandoned ash sluice line. The fifth, located approximately $20 \mathrm{ft}$ north of our baseline origin (at E15091.0, N54628.3) is unidentified.

The expected location of the abandoned process sewer is shown by a dashed line on our map. This pipeline was not detectable in the data produced by either the EM31 sensor or the GPR system. The reason for this is not clear. A non-metallic pipe can be expected to be more difficult to detect by either sensing method than a metallic pipe; however, the active process sewer mentioned above was easily detected by both methods. We assume that the west 
half of the pipeline was probably masked by the shallower pipes that overlie it, and that the east half was deeper than the maximum depth setting used for the GPR survey at this location (approximately $11 \mathrm{ft}$ ). Prior to the termination of work, we had planned to perform additional GPR surveys at this site, first adjusting the system for deeper penetration, and second, using a higherfrequency antenna for improved resolution. These measures would probably have detected the abandoned process sewer.

\subsection{SURVEY AREA 3APSO2, MAP 300FF1.89-9}

The target at this site was an abandoned clay tile process sewer that terminates at Pond 1 (South Process Pond). This pipeline appears to be detectable, although weakly expressed, in the GPR profiles at a location that corresponds closely to the expected location derived from HEDL Drawing M-3904, Sheet 3. This location also conforms to the result of visual observation of the ends of the pipeline (a diversion box at the west end and the exposed west end at Pond 1).

The process sewer was not detected by the EM31 survey. The EMI data at this site were virtually useless due to the presence of metallic buildings, railroad tracks, a fence, and surface debris. As shown on Page 2 of the EMI profile plots for this survey area (Appendix E), we tested the possibility that alternative orientations of the EM31 sensor might be more responsive to the sewer. This test was performed at the $200 \mathrm{E}$ survey line. The profile on Page 1 of the profile plots corresponds to the normal orientation of the EM31 sensor. The notation "ROT. 90H" on Page 2 means that the sensor was rotated 90 degrees about its horizontal axis. Similarly, "ROT. 90V" indicates a rotation of 90 degrees about the sensor's vertical axis, and "ROT. 9OHV" indicates a 90-degree rotation about the horizontal and vertical axes. Although the shape of a small anomaly at $20 \mathrm{ft}$ north changed according to the orientation of the sensor, there was no indication that the detectability of the pipeline was improved by any of the alternative orientations. (The small anomaly corresponds, at least predominantly, to a metal object at or near the ground surface. See the corresponding GPR profile for the $200 E$ survey 7 ine in Appendix C.) 


\subsection{SURVEY AREA 3APRS1, MAP 300FF1.89-10}

This survey area is an asphalt-covered area north of the 324 Building. The target of interest is an L-shaped segment of the 4-in.-diameter, stainless. steel, abandoned RLW sewer that originates near the northeast corner of the 324 Building. The expected location of this sewer is shown as a dashed line on the survey-area map, 300FF1.89-3, and as a solid line on the corresponding larger-scale summary map, 300FF1.89-10. EMI profiles were recorded along the south-north profiles between $200 \mathrm{~W}$ and $30 \mathrm{~W}$. These profiles provide lowresolution indications of east-west pipelines at approximately $15 \mathrm{~S}$ and $38 \mathrm{~S}$. According to HEDL Drawing M-3904, the latter corresponds to the expected location of the RLW sewer, and the former corresponds to the location of three closely spaced retention process sewer lines.

The south-north and west-east GPR profiles confirm the locations of these pipelines. They also show the presence of several other underground pipelines. All of the pipelines detected by the EMI and GPR methods are shown on the summary map.

\subsection{SURVEY AREA 3APRS3, MAP 300FF1.89-10}

This survey area adjoins Area 3APRS1 and covers a segment of the abandoned RLW sewer that was described in the preceding paragraphs (the RLW sewer from the 324 Building). This segment apparently runs toward the 3718-C Building from a cleanout riser near the northwest corner of the 324 Building.

Several pipes, including sections of the currently active RLW sewer, are evident in the GPR profiles and are shown on the output map. Most of these correspond to pipes shown on Drawing M-3904. In particular, the location of the abandoned RLW sewer, although not well defined in the profiles, appears to conform reasonably well to that shown on the HEDL drawing (shown as a dashed line on our map). The retention process sewer lines identified in Survey Area 3APRS1 are also evident in the expected location. 
The EMI profiles for this survey area clearly show that subsurface conductors are present, but no meaningful information can be extracted from them. This is what one would expect, given the complex distribution of pipes in this relatively small area.

\subsection{SURVEY AREA 3APRS2, MAP 300FF1.89-10}

The two main sections of this survey area are adjacent to the east and north sides of the 3718-C Building. Three of the west-east survey lines (115N-120N) actually extend under the roof of the building. According to Drawing M-3904, the abandoned RLW sewers from the 309 and 324 Buildings, a retention process sewer, and an active process sewer from the 324 Building are all located near or under the east side of the 3718-C Building.

The GPR profiles show several underground pipes and possible electrical cables in this congested area. However, the sewers of interest cannot be unambiguously identified. The abandoned RLW (PRTR) sewer from the 309 Building is expected to cross this survey area at the coordinate 16W. Radar reflections are present at approximately that location, but they are discontinuous and occur at depths ranging from 6 to $12 \mathrm{ft}$. No reflections can be reasonably associated with the other three sewers. It is probable that their depths (possibly greater than $17 \mathrm{ft}$ ) are greater than the effective detection depth of the GPR system as it was set up for this survey. To obtain improved data in this survey area, it would be appropriate to use a higher radar frequency range to achieve improved resolution at shallow depths, and to use a lower frequency and deeper range settings to obtain information about greater depths.

EMI data were collected along the west-east survey lines located to the north of the 3718-C Building and along the north-south lines located to the east of the 3727 Building. It was hoped that the first of these two data sets would detect the RLW sewers, the process sewer, and the retention process sewer that are discussed in the preceding paragraph. The second data set was collected as an attempt to detect the two abandoned process sewers that transferred liquid wastes to the 307 Trenches that are located to the west of the 


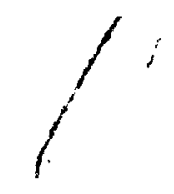

3718-E Building. Neither data set exhibits any interpretable anomalies that could help to define the locations of the pipelines that are assumed to be present in this survey area.

\subsection{SURVEY AREA 3APRS4, MAP 300FF1.89-10}

This survey area is approximately centered on the assumed location (as shown on HEDL Drawing M-3904) of the abandoned RLW sewer that originates at the 309 Building. EMI data were collected along a set of west-east survey lines that covered the entire length of the survey area (see survey-area map 300FF1.89-3). The survey lines were spaced $25 \mathrm{ft}$ apart. GPR data were collected only along the more closely spaced lines ( $5 \mathrm{ft}$ ) at the north end of the survey area.

As indicated on the summary map, the abandoned RLW sewer was detected by the GPR data at the expected location and at a depth of approximately $8 \mathrm{ft}$. The process sewer and retention process sewer were probably detected at a depth of approximately 14 to $15 \mathrm{ft}$, but could not be resolved as individual pipes. A shallow pipe or cable was also detected at the coordinate $40 \mathrm{E}$.

Except for a short section at the south end of the survey area, the EMI profiles do not provide a useful indication of the presence of underground pipes. The presence of the RLW sewer is suggested by anomalies in the profiles recorded between $100 \mathrm{~N}$ and $150 \mathrm{~N}$.

\subsection{SURVEY AREA 3APRS5, MAP 300FF1.89-11}

This survey area was planned to cover all sides of the 307 Ponds. However, because of the premature termination of field work, only parts of the south and east sides of the area were actually surveyed. Only the GPR method was used at this site because of the known complexity of the subsurface piping around the ponds.

As shown in the summary map, several pipelines were detected by the GPR survey. The three south-north pipes located near coordinate $130 \mathrm{E}$ are assumed to be, from west to east: a segment of the active process sewer $(128 \mathrm{E}, 11 \mathrm{ft}$ deep), the abandoned RLW sewer (131E, $4 \mathrm{ft}$ deep), and the abandoned PRTR 
(309-Building) RLW sewer (134E, $5 \mathrm{ft}$ deep). The locations of these three pipelines, as determined from the GPR profiles, are approximately 2 to $3 \mathrm{ft}$ east of the locations shown on Drawing M-3904. Four sections of the active process sewer converge at a manhole located at coordinates $127 \mathrm{E}, 3 \mathrm{~N}$. The section to the east of the manhole could not be reliably identified in the GPR profiles. The section to the west of the manhole seems to have been detected (at $8 \mathrm{~N}$, approximately $40 \mathrm{E}$ to $112.5 \mathrm{E}, 9 \mathrm{ft}$ deep) and is shown on the summary map. Several other north-south and east-west pipeline segments are also shown on that map. Some of these correspond to pipelines shown on Drawing M-3904, others do not.

The fragmentary nature of the detected pipelines and the failure to detect certain pipelines is consistent with the use of the $300-\mathrm{MHz}$ antenna and the complexity of the subsurface at this site. As in other survey areas, more-complete and more-detailed results would have been obtained by follow-on GPR surveys with both the higher-and lower-frequency antennas.

\subsection{SURVEY AREAS 3ARS1 AND 3ARS2, MAP 300FF1.89-12}

These survey areas are located to the west and east of the 3762 Building. They are approximately centered on a section of the abandoned RLW sewer that apparently passes under the 3762 Building before terminating at the 340 Complex. The middle part of Area 3ARS2 was inaccessible because of obstructions on the surface. Only a GPR survey was performed in these survey areas. The middle part of Area 3ARS2 was inaccessible because of surface obstructions.

As shown in the summary map, a pipeline was detected at a depth of 8 to $10 \mathrm{ft}$ at the coordinate $20 \mathrm{~N}$. This is approximately the expected location of the RLW sewer. Drawing M-3904 shows a retention process sewer adjacent to the RLW sewer and at approximately the same depth. If these two pipelines are as close together as suggested by the drawing, they might both be represented by the line shown at coordinate $20 \mathrm{~N}$ on our summary map. (The resolution of the GPR profile might not have been sufficient to resolve them.) A second pipeline (or possible cable) was detected at a depth of approximately $4 \mathrm{ft}$ at the coordinate $13 \mathrm{~N}$. This might correspond to the retention process sewer, but 
it is several feet south of the expected location and is at a depth that might be too shallow. The GPR profiles show a third apparent pipeline or cable at the extreme south end of the survey area (coordinate $O N$ ). The depth of this feature is approximately $2 \mathrm{ft}$.

\subsection{SURVEY AREA 618-5 BURIAL GROUND, MAP 300FF1.89-13}

The GPR survey at this site was limited to a set of survey lines located outside the outer fence. It was intended that the GPR survey would also include all of the area inside that fence; however, we were unable to work inside the fence because the required radiological survey was not completed before our work was terminated. As mentioned above, most of the survey grid at this site was emplaced by Kaiser Engineers Hanford, using a node, or stake, spacing of $8 \mathrm{~m}$. Before beginning our GPR survey, we added a line of stakes along the southeast and northeast sides of the original grid (at coordinates $S 24$ and E144). (As noted in Section 3.0, direction designations of $S$ and $E$ were used by Kaiser although the actual directions of the grid lines were southwest-northeast and southeast-northwest.) The additional stakes expanded our coverage of the area surrounding the burial ground and made the survey lines more usable.

As shown on the summary map, some apparently man-made material was detected along the three accessible sides of the burial ground fence. Most of these materials are at a depth of $2 \mathrm{ft}$ or less. Depth indications are shown on the map only in a few locations where deeper materials seem to be present. Because of the 4-m spacing of the survey lines, it was not possible to determine whether the subsurface materials found along one line are contiguous with those found along an adjacent line. Further, it could not be determined whether these materials are hazardous waste materials or benign debris. Some buried radioactive waste materials have been found in this general area by an earlier GPR survey (Appendix F) and by the radiological survey performed by PNL as part of the current work. 


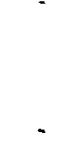

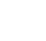




\subsection{FINAL COMMENTS}

The results discussed above fall short of meeting the objectives of this task as stated in Section 3.0. This is because of the termination of work prior to the completion of the necessary geophysical surveys. In addition, the planned GPR surveys of the burial grounds could not be performed in the available time because required radiological surveys were not completed. The survey performed around the exterior of Burial Ground 618-5 identified buried materials that appear to be man-made and that could be hazardous. The depth of fill and the location of trenches and pits inside the perimeter fences could not be determined by surveys performed outside the fences.

Surveys designed to determine the exact locations of the abandoned process and RLW sewers are a necessary prerequisite to any surface-based geophysical procedure for detecting possible leaks in those pipelines. The leak-detection procedure to be attempted or investigated in this task involved EMI and/or GPR profiling along, and adjacent to, the centerlines of the sewers after the sewers had been accurately mapped by the initial geophysical surveys.

EMI surveys, as expected, proved to be of 1 imited value for detecting and tracing either the steel RLW sewers or the clay tile process sewers. The inherently low spatial resolution of the EMI method, combined with the generally high density of pipes, cables, and other subsurface features along the routes of those sewers, makes the EM31 instrument insensitive to the targets or features of interest. In a less complex environment, an EMI-based approach might be effective for mapping pipelines and for detecting conductivity anomalies that might be associated with leaks.

Analysis of the GPR data collected in our 1989 field work indicated that the GPR method can accurately identify and map the RLW and process sewers in the 300-FF-1 Operable Unit. Equally important, the GPR method can detect and map other pipelines and other features that might cross the sewers or that might be located nearby. This result is consistent with the proven performance of PNL's GPR system in many pipe- and cable-mapping applications at other locations at the Hanford Site. 
The complexity of the subsurface environment in the survey areas associated with this task, and the wide depth range at which the pipelines are located, made it difficult to obtain the desired, accurate, pipe-location information with just the one GPR survey that we were able to perform in each survey area. As mentioned in Section 4.1, the spatial resolution or penetration depth of a GPR survey can be enhanced by an appropriate selection of antennas or frequency bands. To complete this task, it will be helpful to perform additional GPR surveys at most locations. Surveys using a frequency band centered at approximately $500 \mathrm{MHz}$ would yield high-resolution maps of pipes that are somewhat shallower than the useful depth range of the $300-\mathrm{MHz}$ system that we used. Similarly, additional surveys using a frequency band centered at approximately $100 \mathrm{MHz}$ would help to detect pipelines that are too deep to have been reliably detected by our $300-\mathrm{MHz}$ surveys.

As a final comment, we would like to point out that accurate, definitive, geophysical mapping of subsurface pipelines in a highly developed industrial environment like that of the $300-F F-1$ Operable Unit is a demanding task that requires a great deal of time and effort. The total effort required to fully meet the objectives defined in Section 2.0 is probably substantially greater than the original 1989 estimate. 


\subsection{REFERENCES}

DOE (Department of Energy). 1990. Remedial Investigation/Feasibility Study Work Plan for the 300-FF-1 Operable Unit, Hanford Site, Richland, Washington. DOE/RL 88-31, U.S. Department of Energy-Richland Operations, Richland, Washington.

PNL (Pacific Northwest Laboratory). 1989. Procedures for Ground-Water Investigations. PNL-6894, Pacific Northwest Laboratory, Richland, Washington.

Young, J. S., R. M. Fruland, and J. S. Fruchter. 1990. Data Compilation Task Report for the Source Investigation of the 300-FF-1 Operable Unit Phase 1 Remedial Investigation. PNL-7241, Pacific Northwest Laboratory, Richland, Washington. 


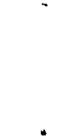




\section{APPENDIX A}

PROCEDURES FOR GEOPHYSICAL SITE SURVEYS, 300-FF-1 OPERABLE UNIT 
PNL TECHNICAL PROCEDURE

SG-1 USING GROUND-PENETRATING RADAR FOR GEOPHYSICAL SITE SURVEYS

\section{$\underline{1.0 \quad \text { APPLICABILITY }}$}

This geophysical sensing method measures variations in electromagnetic fields to detect and characterize natural or manmade features, objects, or materials in the ground. To provide this characterization, electromagnetic waves are backscattered from objects or interfaces in the ground. This procedure may be used instead of borehole sampling when time and funding for site characterization efforts are minimal, quality and quantity of site assessment data must be maximized, and other methods might compromise personnel safety.

\subsection{DEFINITIONS}

ATV--all-terrain vehicle.

\subsection{RESPONSIBLE STAFF}

Technical staff.

\subsection{PROCEDURE}

\subsection{Prerequisites}

\subsubsection{Equipment}

The following equipment is required to conduct surveys using ground-penetrating radar:

- Geophysical Survey Systems, Inc. (GSSI) ground-penetrating radar system, operator's manual, and circuit diagrams

- digital data acquisition unit and operator's manual

- all-terrain vehicle (ATV)

- GSSI P731 calibrator.

Written descriptions of the geophysical field work will be recorded in field notebooks. The contents of these notebooks will include site descriptions, explanations of the work being performed, general field procedures, a list of the instruments used in the work, records of instrument settings, notations of anomalous occurrences, and descriptive details relating to data collection (e.g., line numbers, traverse directions, obstructions, deviations, data record numbers, and data file names). A separate notebook will be used by each individual or group that is performing independent field work.

\begin{tabular}{|c|c|c|c|}
\hline Concurregce, & $\begin{array}{l}\text { Date } \\
\text { B/16/89 }\end{array}$ & Approval & Date \\
\hline Prepared by & $8 / 16 / 89$ & QAD congurgerces 1 Ramber & $\begin{array}{l}\text { Date } \\
816189 \\
\end{array}$ \\
\hline Procedstr-g No & & Effective Date & 1 of 3 \\
\hline
\end{tabular}




\subsubsection{Safety Precautions}

Do not operate the small ATV used for ground-penetrating radar surveys on steep slopes or embankments that, in the judgement of the operator, cannot be safely negotiated.

The SITE SAFETY OFFICER shall evaluate safety issues related to potential chemical or radioactive contamination of the site and to the possibility of ground subsidence over collapsing waste materials or containers before initiation of geophysical field work.

\subsection{Step-by-Step Instructions}

\subsubsection{Calibrating and Preparing the Equipment}

1. Before operation of the survey system, inspect and, if needed, clean the cables, connectors, and tape recorder heads. Inspect and, if needed, charge the battery. (During operation, battery status is indicated by a voltmeter and indicator lights on the radar control unit.)

2. Inspect the ATV for adequate gas and oil levels and tire pressure.

3. Record performance of steps 1 and 2 in the field notebook.

4. Record a travel-time calibration record, utilizing the P731 calibrator, at least once per day during field operations and whenever a change is made in the timing parameters of the radar system. This will be a special data record on the recording medium used for the rest of the radar field data (digital magnetic tape or disk).

5. Record the performance of the calibration procedure and the location of the calibration data in the recorded data set in the operator's field notebook.

\subsubsection{Defining and Mapping Boundaries}

1. Before the geophysical survey can be conducted, boundaries and survey lines must be in place. Plant survey stakes a maximum of $100 \mathrm{ft}$ apart along straight lines to mark the nodes of a rectangular grid.

NOTE: Geophysical survey lines are not always coincident with the grid lines for at least two reasons: 1) it may be more appropriate to collect geophysical data along lines that are more closely spaced than the grid lines, and 2) the stakes are obstructions that make it impossible to maneuver survey vehicles and certain geophysical instruments directly along the grid lines. Instead, data may be collected along lines that are offset from the grid lines. The amount of offset and direction relative to the grid should be recorded in the field notebook and accounted for in the subsequent data analysis. Other major obstructions on the ground surface (bushes, rocks, surface debris, pipes, fences, posts, buildings, fixed machinery, etc.) should also be

Procedure No. Revision No. Effective Date Page 
recorded in the field notebook. Record only those obstructions greater than the lateral spatial resolution of the survey instrument or the subsurface feature to be detected.

\subsubsection{Collecting the Data}

NOTE: The survey system may be towed by the ATV or pulled by the operator. If towed, a footage counter mounted on the ATV provides position data that are inserted into the data records. If pulled, no footage counter is provided.

1. Activate the equipment and allow it to warm up for 1 min.

2. Adjust the system parameters such as time scale, gain, filter, sampling rate, and signal frequency rate (antenna selection) to correspond to site conditions. Record all instrument settings in the operator's field notebook.

3. Position the survey system along the survey line and transport the instrument along the line at a constant speed of 2 to $5 \mathrm{ft} / \mathrm{sec}$. This will allow an along-track data spacing of $1 \mathrm{ft}$ or less. It is generally not cost effective to attempt to obtain a fixed data spacing. Record pertinent data (e.g., direction, location, track number, obstructions) relating to each traverse in the operator's field notebook.

4. Record radar data in digital form on magnetic tape cartridges or disks.

5. Repeat steps 3 and 4 until all survey lines have been traversed.

6. Label and date each data disk.

7. Transfer the data to the laboratory computer for processing. Record the unprocessed data on 9-track magnetic tape for long-term storage and transmittal to WHC.

\subsubsection{Data Processing}

1. Process the radar data using a PC or DEC VAX computer. Processing steps may include clutter removal, filtering, synthetic aperture focusing, and image enhancement. Intermediate output products will normally be amplitude-modulated radar profiles in the form of photographic prints. The final product will normally be a site map showing the interpreted locations, depths, and characteristics of waste materials and other wasterelated features. This map may include the results of the other types of geophysical surveys performed at the site. Procedure No. Revision No. Effective Date 


\section{SG-3 USING ELECTROMAGNETIC INDUCTION FOR GEOPHYSICAL SITE SURVEYS}

\subsection{APPLICABILITY}

This geophysical sensing method measures variations in electromagnetic fields to detect and characterize natural or manmade features, objects, or materials in the ground. To provide this characterization, measurable secondary magnetic fields are induced in conductive objects by an alternating magnetic field source at or above the ground surface. This procedure may be used instead of borehole sampling when time and funding for site characterization efforts are minimal, quality and quantity of site assessment data must be maximized, and other methods might compromise personnel safety.

\subsection{DEFINITIONS}

\section{$\mathrm{N} / \mathrm{A}$}

\subsection{RESPONSIBLE STAFF}

Technical staff.

\subsection{PROCEDURE}

\subsection{Prerequisites}

\subsubsection{Equipment}

The following equipment is required to perform electromagnetic induction:

- Geonichs EM34-3 or EM-31 ground conductivity meter, operator's manual, and circuit diagrams

- digital data acquisition unit (for EM-31)

- size C internal batteries.

Written descriptions of the geophysical field work will be recorded in field notebooks. The contents of these notebooks will include site descriptions, explanations of the work being performed, general field procedures, a list of the instruments used in the work, records of instrument settings, notations of anomalous occurrences, and descriptive details relating to data collection (e.g., line numbers, traverse directions, obstructions, deviations, data record numbers, and data file names). A separate notebook will be used by each individual or group that is performing independent field work.

\begin{tabular}{|c|c|c|c|}
\hline concurrence & $8 / 14 / 89$ & Approval & Date \\
\hline $2+1=5$ & $\begin{array}{l}\text { Date, } \\
8116189\end{array}$ & QAD Concarrenges & $8 / 16 / 89$ \\
\hline Procedure No. & Revision No. & Effectivebate & 1 of 3 \\
\hline
\end{tabular}




\subsubsection{Safety Precautions}

The SITE SAFETY OFFICER shall evaluate safety issues related to potential chemical or radioactive contamination of the site and to the possibility of ground subsidence over collapsing waste materials or containers before initiation of geophysical field work.

\subsection{Step-by-Step Instructions}

\subsubsection{Calibrating and Preparing the Equipment}

NOTE: The ground conductivity meter is factory calibrated.

1. Before operation of the ground conductivity meter, inspect and, if needed, clean the cables, connectors, and tape recorder heads. Inspect and, if needed, charge the battery.

2. Conduct equipment functional tests as specified in the operator's manual.

3. Check the long-term stability before use at the site by measurements at a selected test location (currently a parking lot at the 2400 Stevens facility). Make any needed adjustments according to the procedures listed in the operator's manual.

4. Record the performance of steps 1,2 , and 3 in the operator's field notebook.

\subsubsection{Collecting the Data}

NOTE: The instrument is carried by the operator.

1. Activate the instrument and allow it to warm up for $1 \mathrm{~min}$.

2. Carry the instrument along the predetermined survey lines at a constant speed of 3 to $5 \mathrm{ft} / \mathrm{sec}$. Data will be automatically recorded in digital form at a rate of several samples per second.

3. Record pertinent data related to each survey line in the operator's field notebook.

4. Transfer the recorded data to floppy disks and label (site, data set name), date, and back up the disks.

Procedure No. $S G-3$
Revision No.

0
Effective Date

Page
2 of 3 


\subsubsection{Data Processing}

1. Process the data using a PC or DEC VAX computer. Processing steps may include interpolation and filtering. Output products may include conductivity (apparent) profiles, contour maps, and color-coded maps. The primary output product will normally be a site map showing the interpreted locations of detected waste materials or subsurface structures. These results may be included on a more general site map that contains the results of other geophysical surveys. 
SG-2 USING MAGNETOMETERS TO CONDUCT GEOPHYSICAL SITE SURVEYS

\section{$\underline{1.0 \quad \text { APPLICABILITY }}$}

This geophysical sensing method measures variations in magnetic field to detect and characterize natural or manmade features, objects, or materials in the ground. To provide this characterization, magnetic materials produce measurable anomalies in the ambient (earth's) magnetic field. This procedure may be used instead of excavating or borehole sampling when time and funding for site characterization efforts are minimal, quality and quantity of site assessment data must be maximized, and other methods might compromise personnel safety.

\subsection{DEFINITIONS}

The term "gradiometer" refers to a particular type of magnetometer that uses two sensors separated by a fixed distance to estimate the gradient of a magnetic field.

\subsection{RESPONSIBLE STAFF}

Technical staff.

\subsection{PROCEDURE}

\subsection{Prerequisites}

\subsubsection{Equipment}

The following equipment is required to perform magnetometer surveys:

- cesium vapor magnetometer, operator's manual, and circuit diagrams $O R$ proton precession magnetometer and operator's manual $O R$ fluxgate gradiometer and operator's manual.

- digital recorder and operator's manual

- PC computer

- 6-V gel-cell battery pack (if using cesium vapor magnetometer)

- size $C$, non-magnetic internal batteries (if using proton precession magnetometer).

Written descriptions of the geophysical field work will be recorded in field notebooks. The contents of these notebooks will include site descriptions, explana

\begin{tabular}{|c|c|c|c|}
\hline Concurrence & $8 / 16 / 49$ & Approval & Date \\
\hline Prepar & $8 / 16 / 89$ & QAD Goncurrerger fousen & 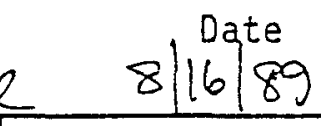 \\
\hline Procedure No. & Revision No. & Effective date & Page \\
\hline
\end{tabular}


tions of the work being performed, general field procedures, a list of the instru-ments used in the work, records of instrument settings, notations of anomalous occurrences, and descriptive details relating to data collection (e.g., line numbers, traverse directions, obstructions, deviations, data record numbers, and data file names). A separate notebook will be used by each individual or group that is performing independent field work.

\subsubsection{Safety Precautions}

The SITE SAFETY OFFICER shall evaluate safety issues related to potential chemical or radioactive contamination of the site and to the possibility of ground subsidence over collapsing waste materials or containers before initiation of geophysical field work.

\subsection{Step-by-Step Instructions}

\subsubsection{Calibrating and Preparing the Equipment}

1. Before operation of the magnetometer, inspect and, if needed, clean the cables, connectors, and tape recorder heads. Inspect and, if needed, charge the battery. (During operation, low battery voltage is indicated on the front panel display of the magnetometer.)

NOTE: The calibration of cesium vapor and proton precession magnetometers is determined by fundamental physical constants and is not adjustable by the user. A correct reading of the known ambient magnetic field indicates that the instrument is functioning correctly.

2. Check short-term stability of the magnetometer daily by a 1-min sequence of measurements at a fixed field location.

3. Check long-term stability of the magnetometer by repeating at least one survey line at each site.

4. Monitor diurnal variations in the earth's magnetic field by making periodic measurements at a fixed location at an interval of $1 \mathrm{hr}$ or less (these measurements are not necessary if the fluxgate gradiometer is used).

5. Record the performance of steps $1,2,3$, and 4 in the operator's field notebook.

\subsubsection{Collecting the Data}

NOTE: The magnetometer is carried by the operator.

1. Before beginning the survey, ensure that the operator is not carrying or wearing any ferromagnetic object (e.g., knife, steel belt buckle, or steel-reinforced boots) that can affect the magnetic measurement.

Procedure No.

Revision No.

Effective Date 2 of 3 


\section{PNL TECHNICAL PROCEDURE}

2. Activate the instrument and allow it to warm up for $5 \mathrm{~min}$.

3. Carry the magnetometer along the predetermined survey lines at a constant speed of 3 to $5 \mathrm{ft} / \mathrm{sec}$. Data will be automatically recorded in digital form at a rate of several samples per second.

4. Transfer the data stored in the digital data recorder to floppy disk using the onsite PC. Label (site, data set name), date, and back up each floppy disk.

5. Record any pertinent data (e.g., direction, location, track number, obstructions) relating to each traverse in the operator's field notebook.

\subsubsection{Data Processing}

1. Process the magnetic data using a PC or DEC VAX computer. Processing steps may include interpolation, filtering, correction for diurnal variations, and subtraction of the ambient field. Output products may include magnetic profiles, contour maps, and color-coded maps of magnetic amplitudes. The primary output product will normally be a site map showing the interpreted locations of magnetic waste materials. These results may be included on a more general site map that contains the results of other geophysical surveys. 
SG-4 USING A METAL DETECTOR FOR GEOPHYSICAL SITE SURVEYS

\section{$\underline{1.0 \quad \text { APPLICABILITY }}$}

This geophysical sensing method measures variations in electromagnetic fields to detect and characterize natural or manmade features, objects, or materials in the ground. To provide this characterization, measurable secondary magnetic fields are induced in conductive objects with a sensor specialized to detect metallic objects. This procedure may be used instead of borehole sampling when time and funding for site characterization efforts are minimal, quality and quantity of site assessment data must be maximized, and other methods might compromise personnel safety.

\subsection{DEFINITIONS}

N/A

\subsection{RESPONSIBLE STAFF}

Technical staff.

\subsection{PROCEDURE}

\subsection{Prerequisites}

\subsubsection{Equipment}

The following equipment is required to conduct surveys using a metal detector:

- Fisher M-scope pipe and cable locator and operator's manual

Written descriptions of the geophysical field work will be recorded in field notebooks. The contents of these notebooks will include site descriptions, explanations of the work being performed, general field procedures, a list of the instruments used in the work, records of instrument settings, notations of anomalous occurrences, and descriptive details relating to data collection (e.g., line numbers, traverse directions, obstructions, deviations, data record numbers, and data file names). A separate notebook will be used by each individual or group that is performing independent field work.

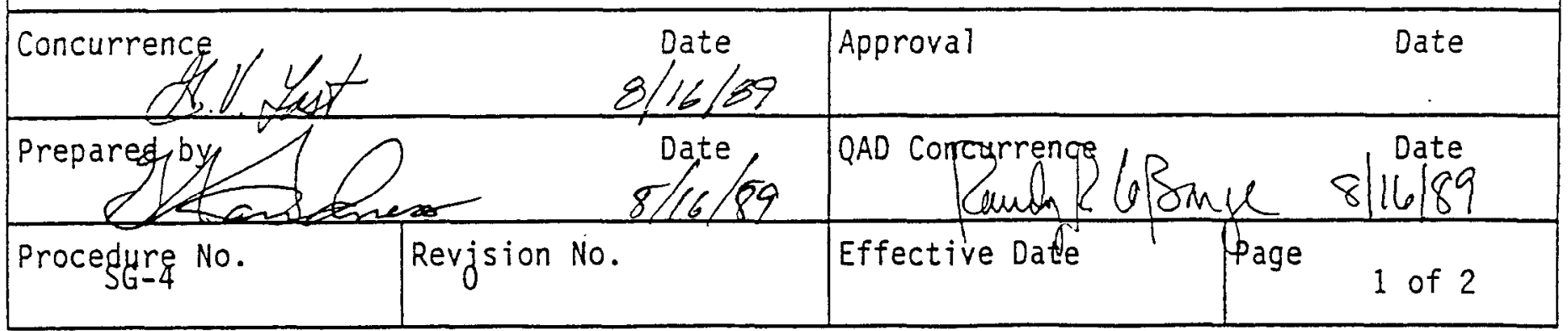




\subsubsection{Safety Precautions}

The SITE SAFETY OFFICER shall evaluate safety issues related to potential chemical or radioactive contamination of the site and to the possibility of ground subsidence over collapsing waste materials or containers before initiation of geophysical field work.

\subsection{Step-by-Step Instructions}

\subsubsection{Calibrating and Preparing the Equipment}

NOTE: The locator is an uncalibrated instrument used for indication only. Frequent adjustments are required onsite to ensure good sensitivity. These are normaliy made by maximizing the response to a known target such as a buried pipeline or a metal plate placed on the ground surface. Record the performance of this procedure in the operator's field notebook.

1. Before operating the instrument, check the battery using the instrument's front-panei, battery-check function switch. Replace the battery if iow voltage is indicated.

\subsubsection{Collecting the Data}

NOTE: The instrument will be carried by the operator.

1. Activate the instrument and allow it to warm up for $1 \mathrm{~min}$.

2. Carry the instrument along a survey line at a constant speed of 1 to $5 \mathrm{ft} / \mathrm{sec}$ until a response is obtained.

3. Move the instrument in an areal pattern to define the boundaries of the detected object or material.

4. Mark the boundaries on the ground (e.g., spray paint, marks in the dirt, rocks).

5. Record the location in the operator's field notebook.

\subsubsection{Data Processing}

1. Replot the field records and present them either as a separate map or as a component of a more general site map containing the results of other geophysical surveys.

\begin{tabular}{|l|l|l|l|}
\hline Procedure No. & $\begin{array}{l}\text { Revision No. } \\
\text { S }-4\end{array}$ & Effective Date & Page \\
\hline
\end{tabular}




\section{APPENDIX B}

SURVEY-AREA MAPS 


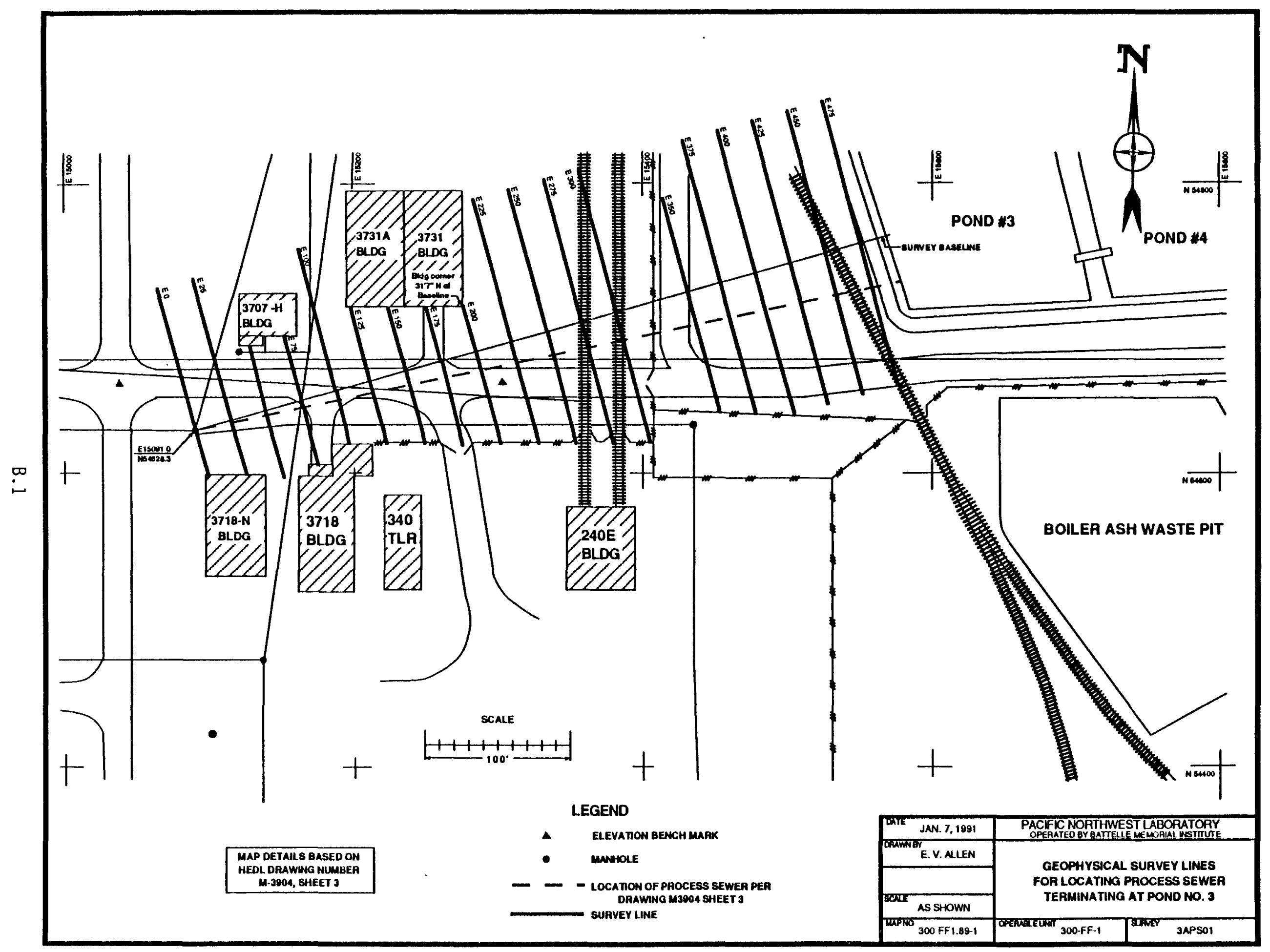




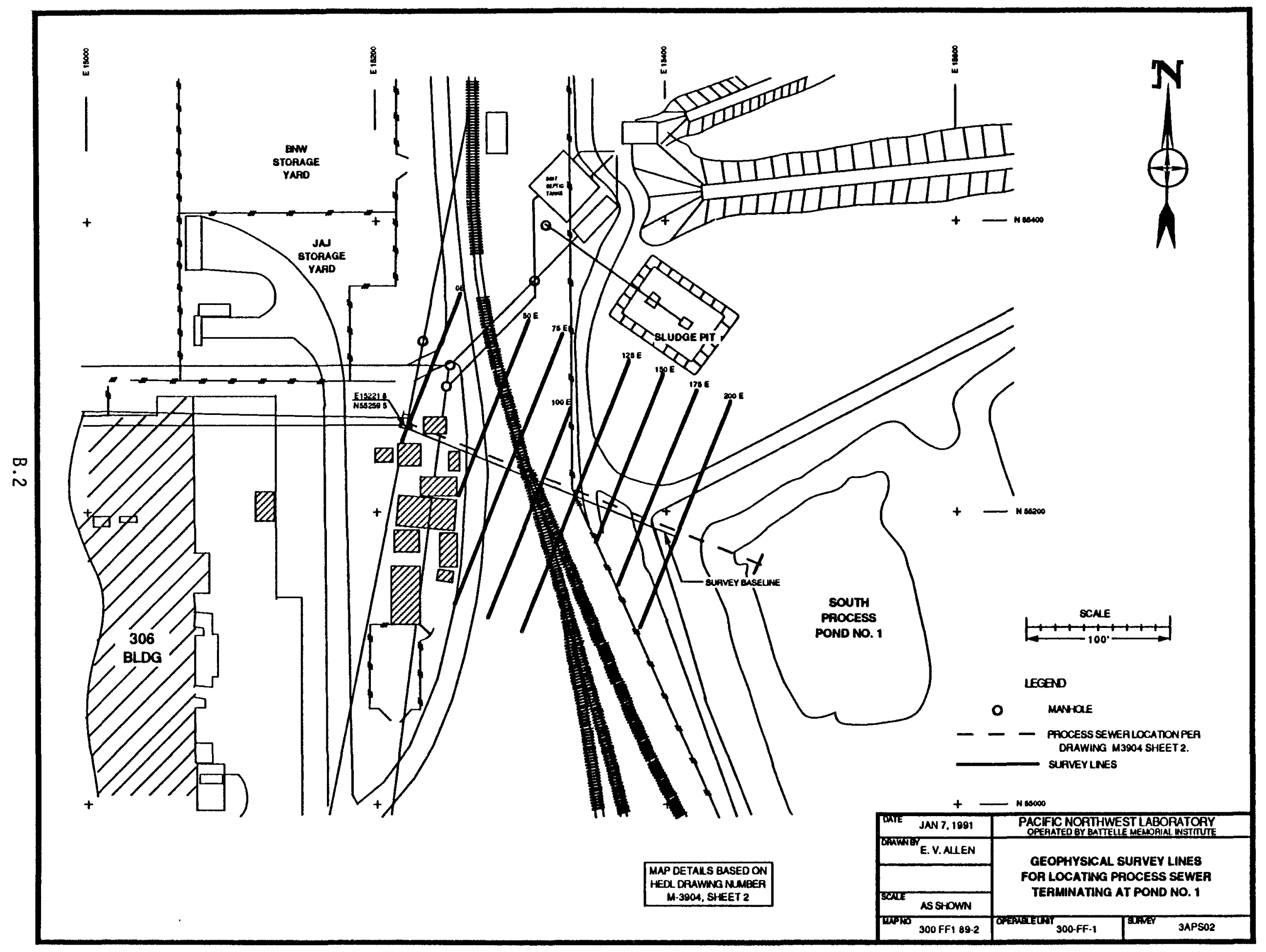




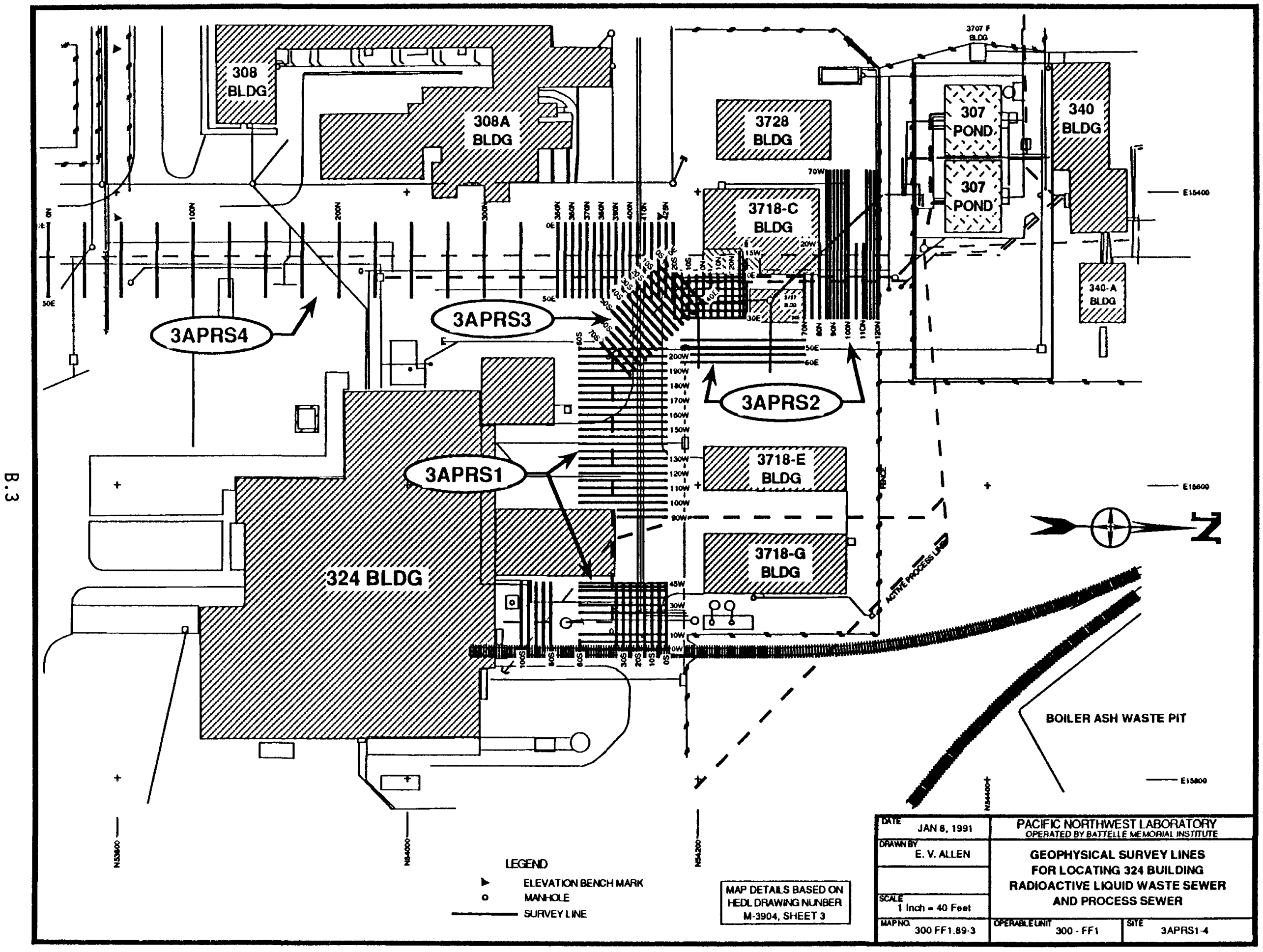




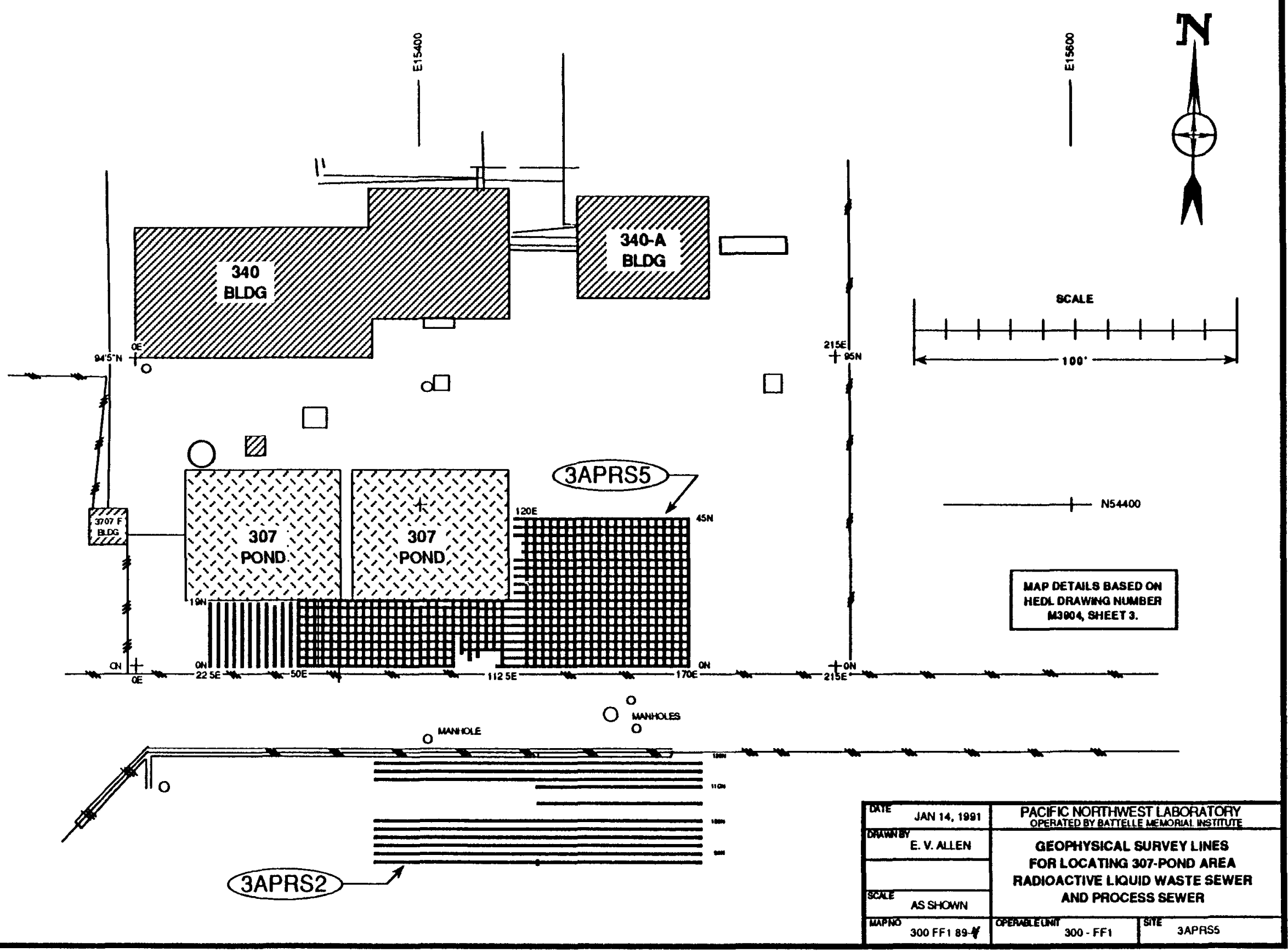




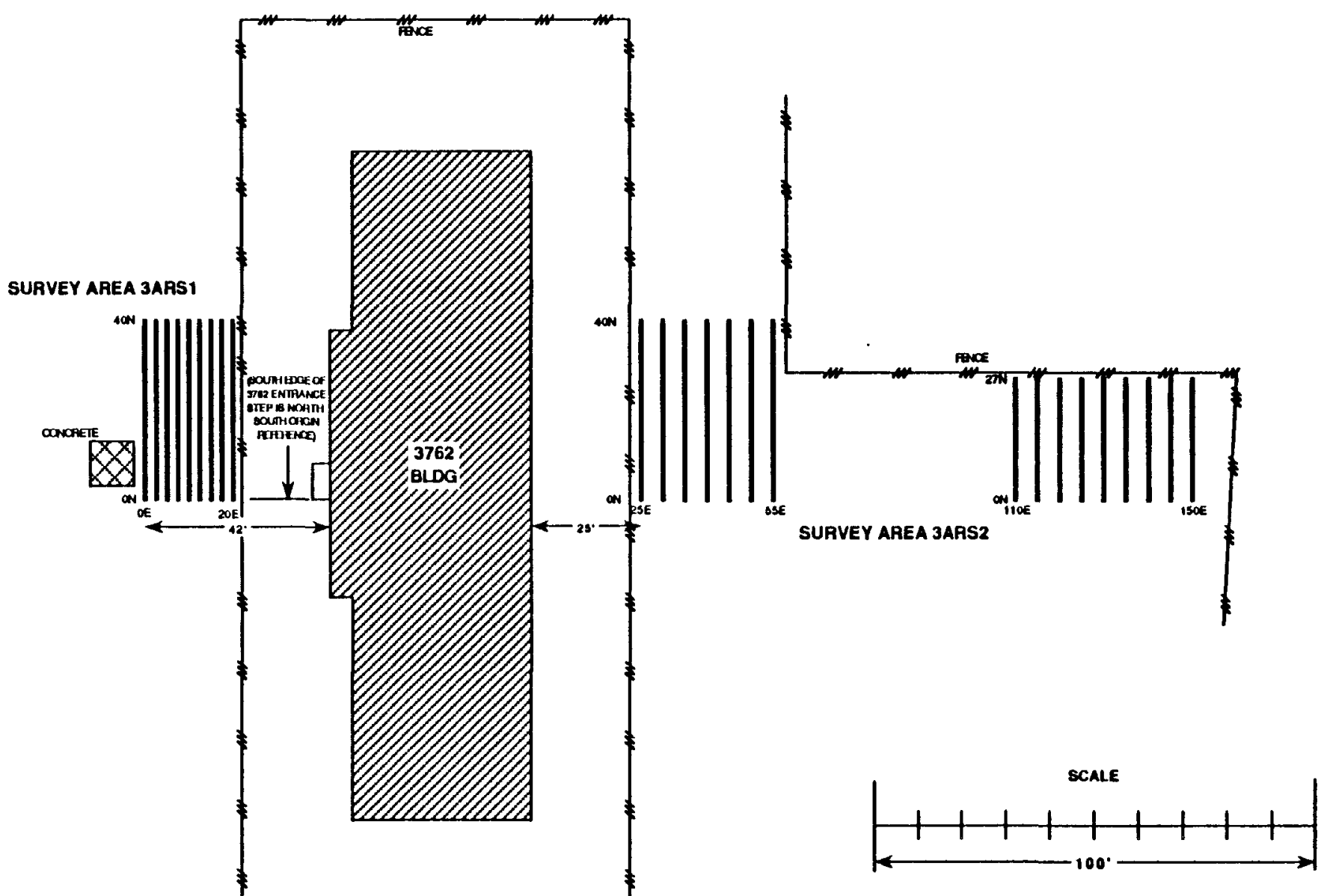

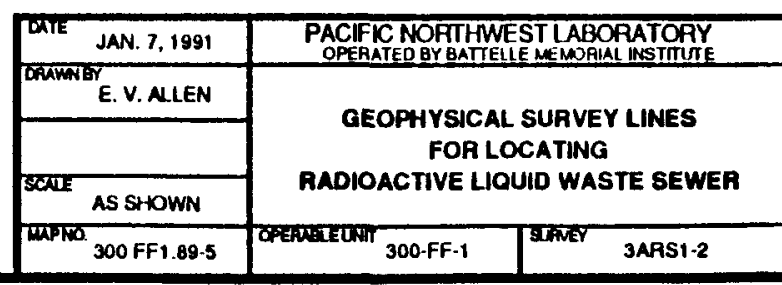




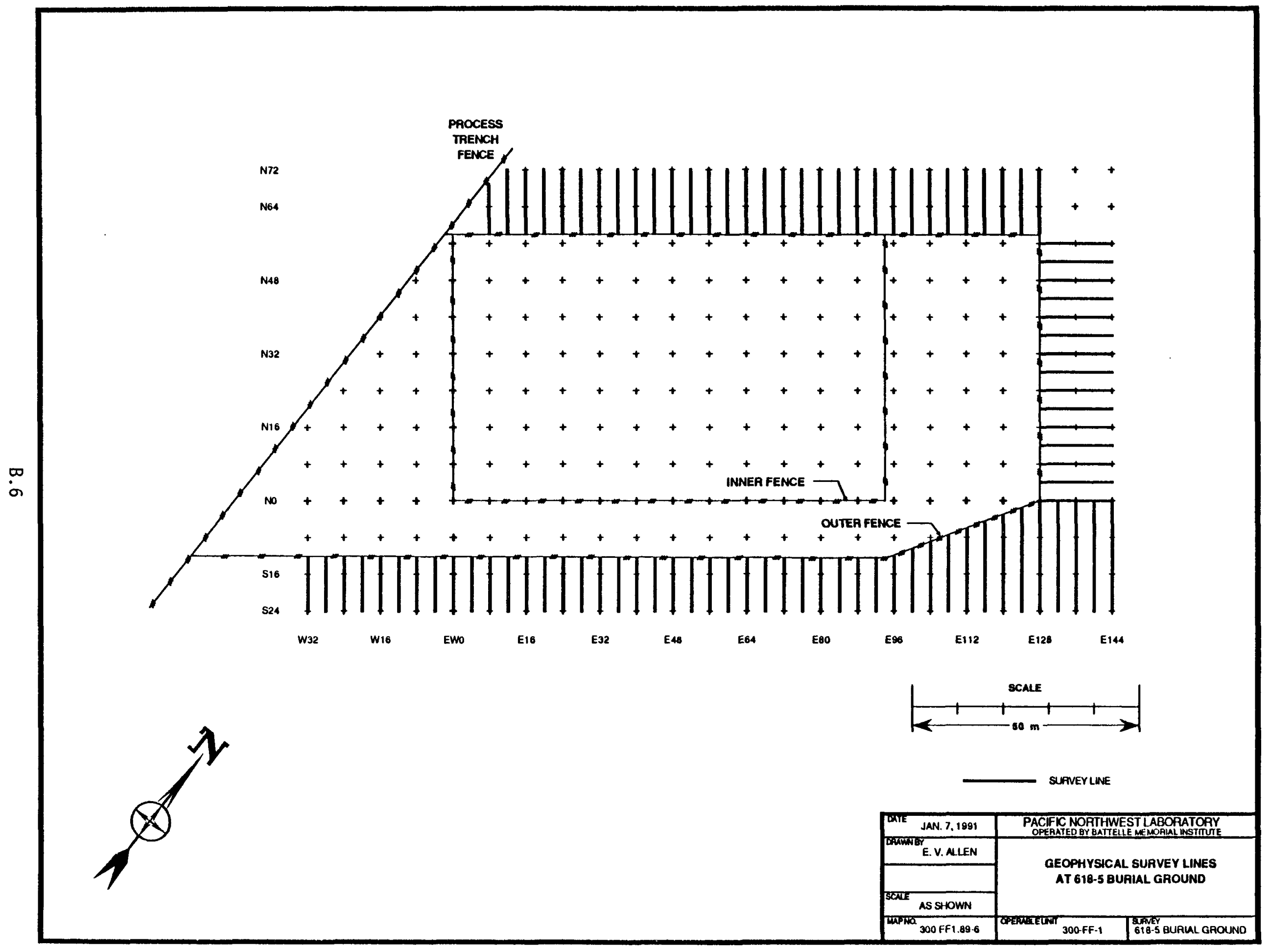




\section{APPENDIX C}

GPR PROFILES 
GPR PROFILES ACROSS PROCESS SEWER, AREA 3APSOI

PAGE 1 180

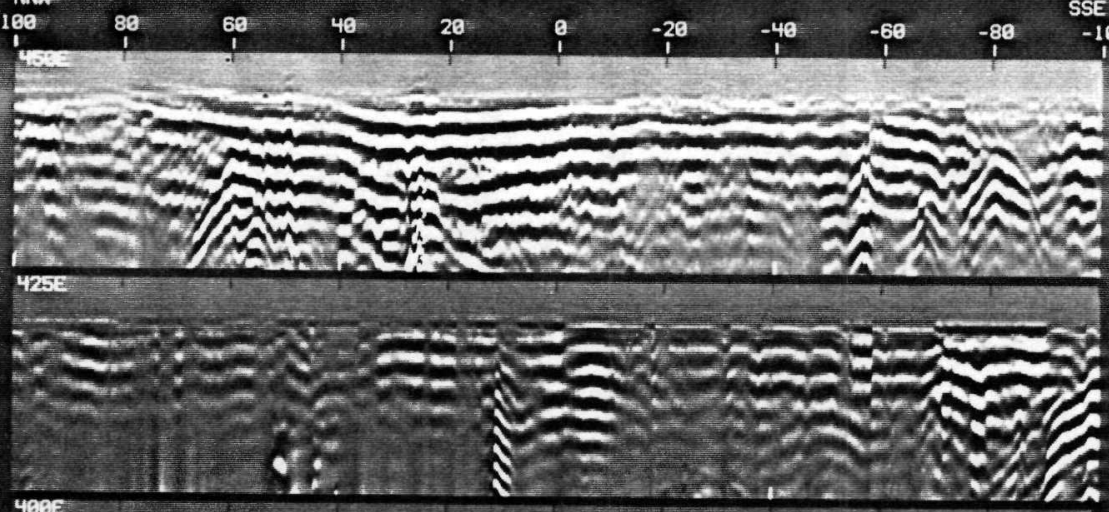

$400 \mathrm{e}$

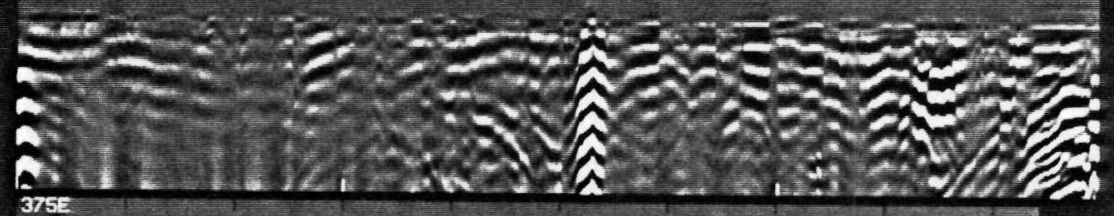
375
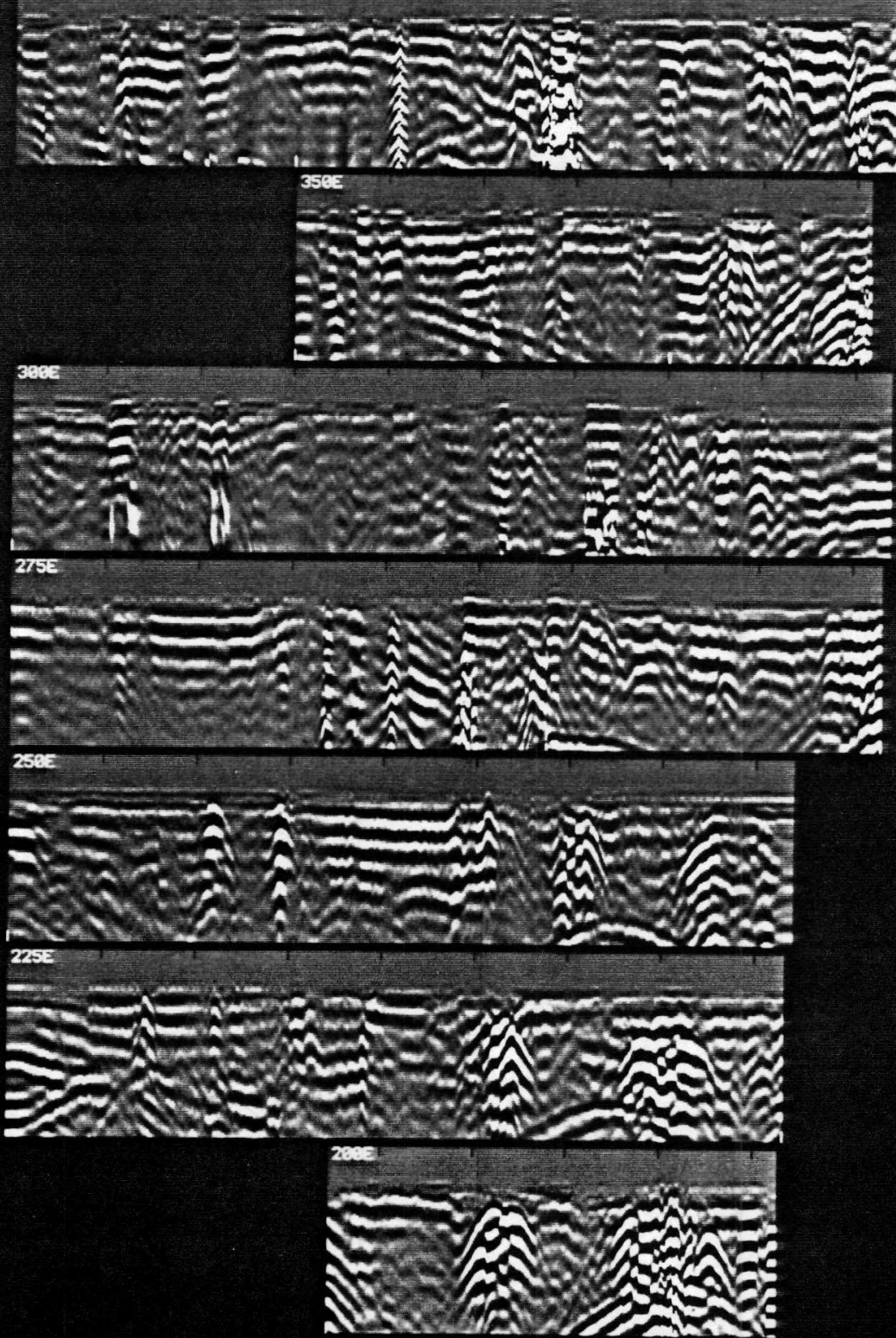
GPR PROFILES ACROSS PROCESS SEWER, AREA 3APSOI

PAGE 2 NM

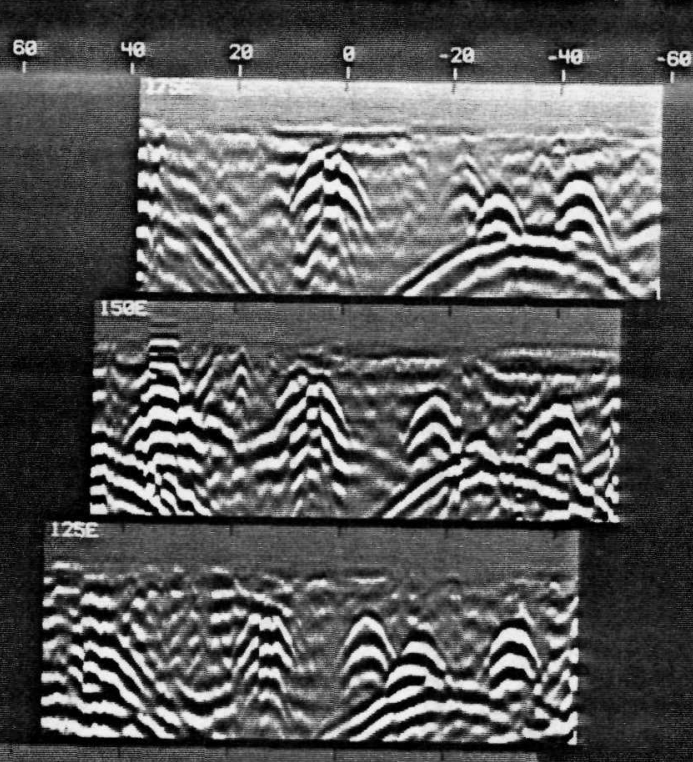

1808

mancin

1200

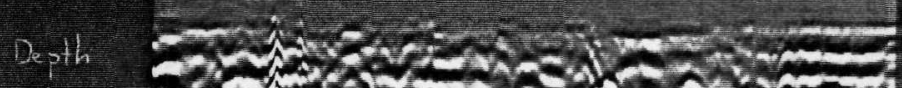

Y

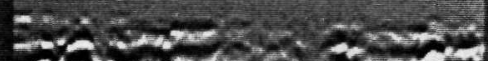

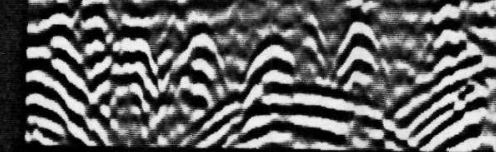

SEE

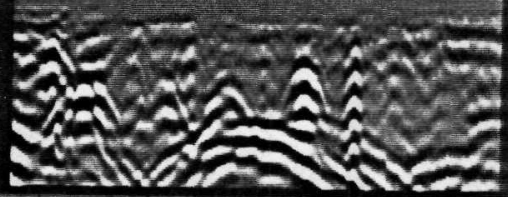

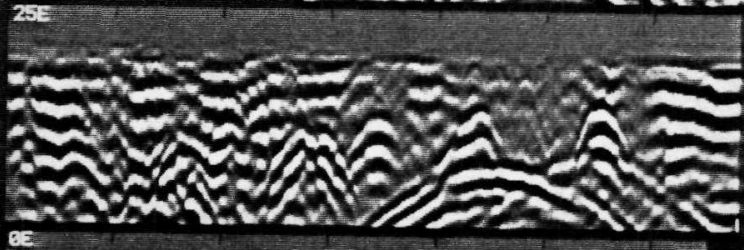

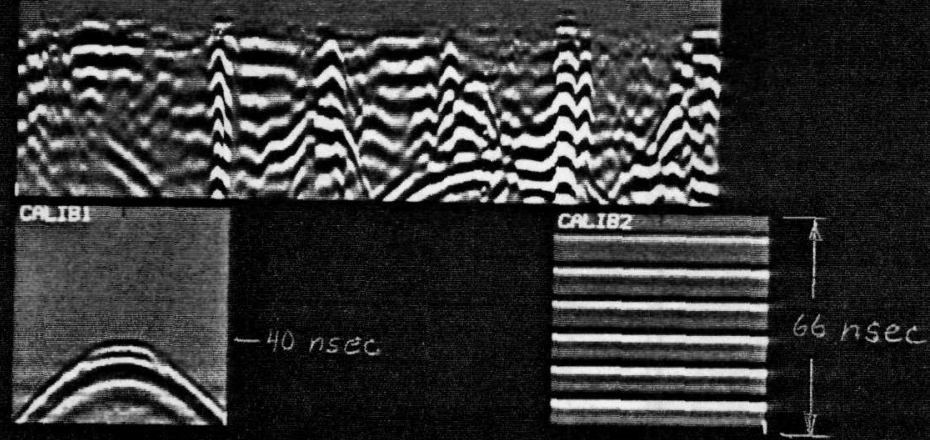


GPR PROFILES ACROSS PROCESS SEWER, AREA 3APSO2

PAGE 1. $\begin{array}{llllllllllll}M N E & 80 & 60 & 49 & 28 & 0 & -28 & -49 & -60 & -80 & -108\end{array}$

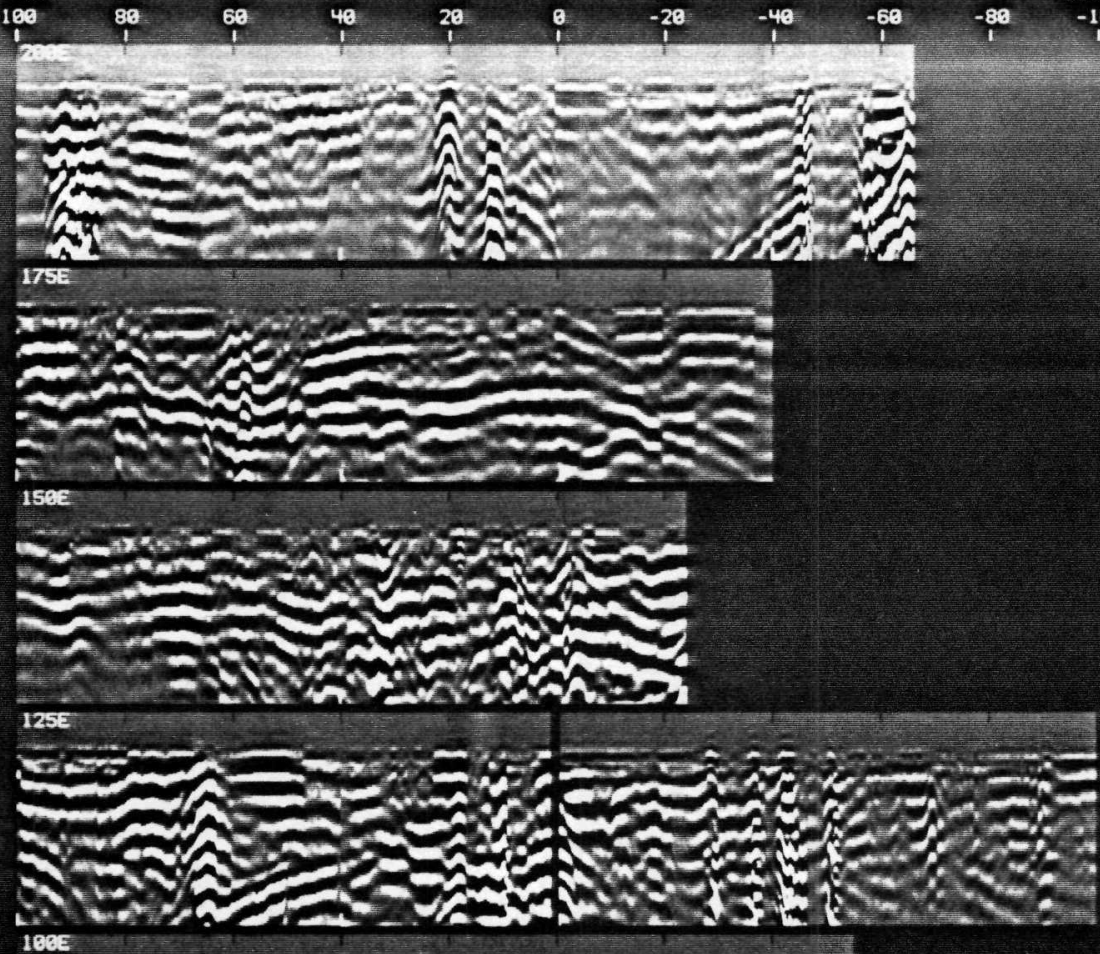

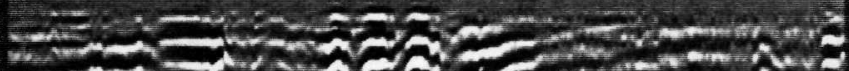

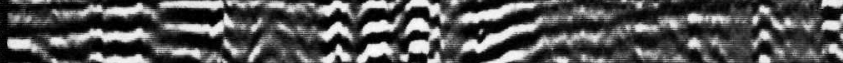

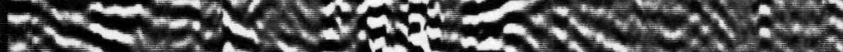

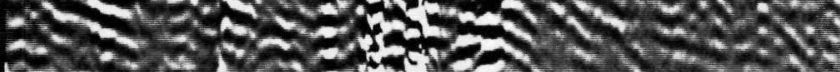
TSE

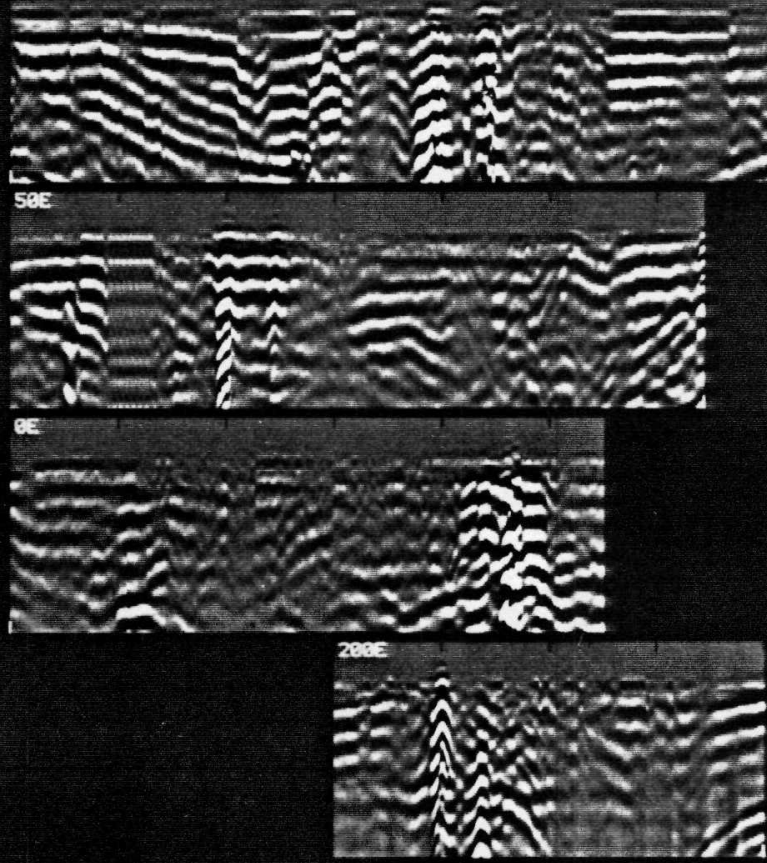


GPR PROFILES ACROSS RLW SEWER, AREA 3APRSI

PAGE 1

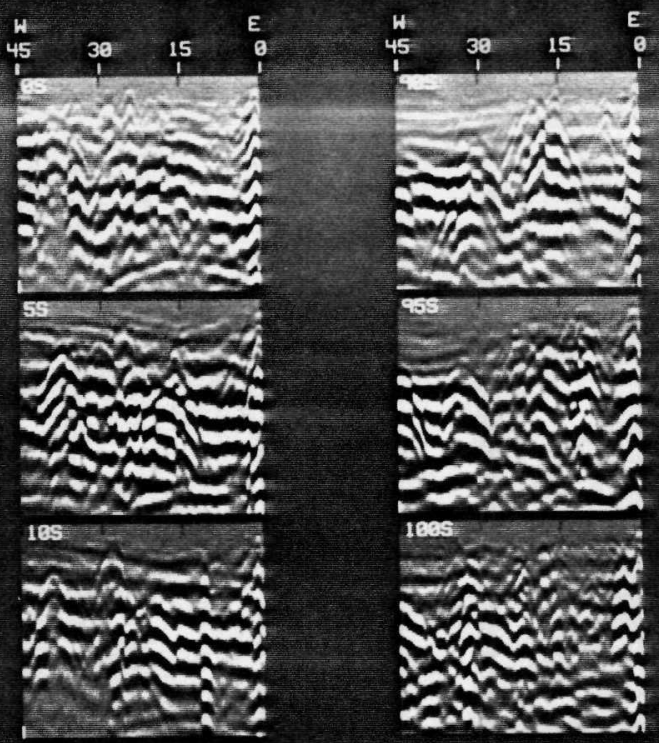

155.40

Yown

Uvisum

208

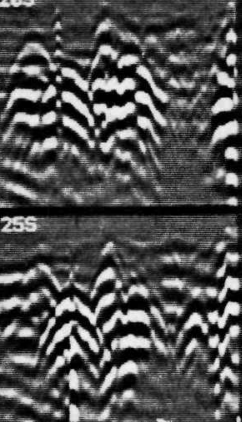

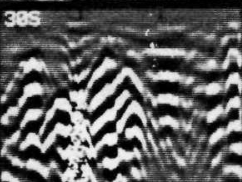

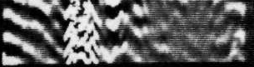

$355.0-1$

w - trest

Sathery

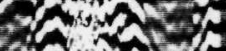

- 4 ir

- or. 0 .

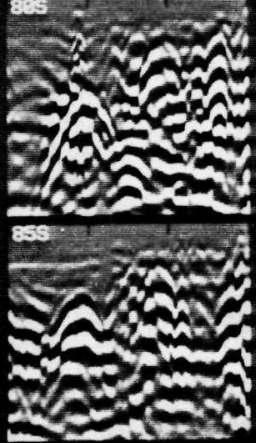


GPR PROFILES ACROSS RLW SEWER, AREA 3APRS1

PAGE 2

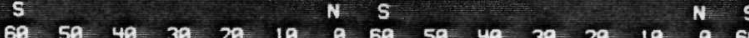

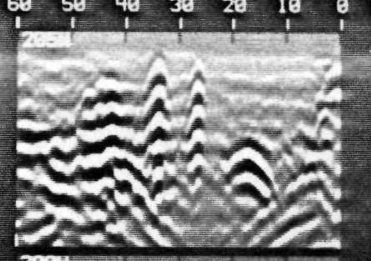
$203 \mathrm{H}$

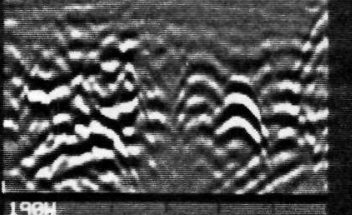
$199 \mathrm{H}$

ison. . s. $x=0$

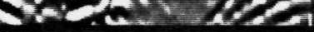

issh

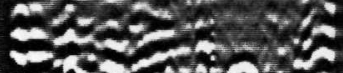
$\rightarrow$ a Whater. 1804 Dis.

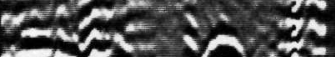
$=$ s. A 175

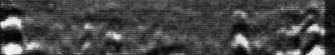

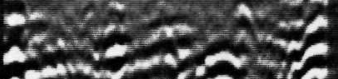
a

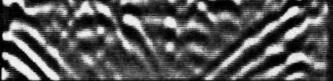
17en 110

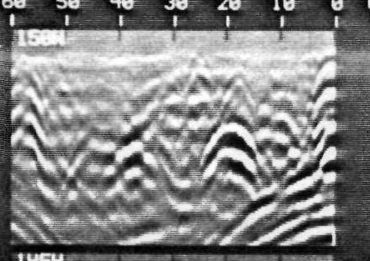
1454 1404 an

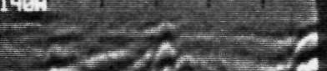

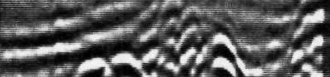

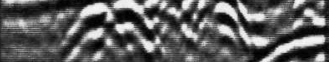

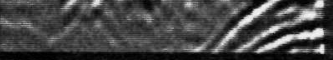
1354 (n) 1304

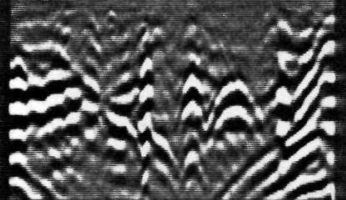
165

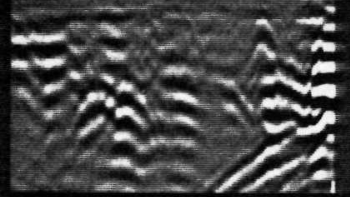
$115 *$

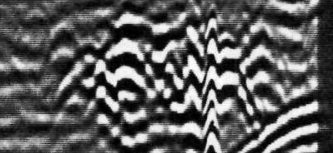

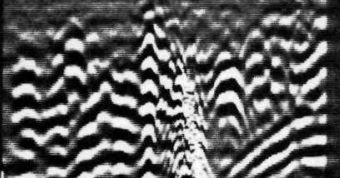
Hen

Nos 1604 1054 .

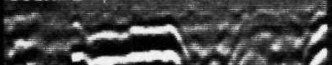
atoming 10 w

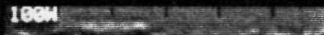

i. $20 \%$ Bvin wy 158

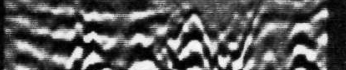
Cor and - everay?

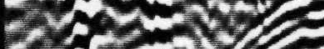
ast 30 (E) ( (2) $\begin{array}{llllllllll}28 & 18 & 0 & -10 & -28\end{array}$ D.pentay ty

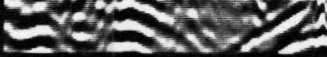
40\% $\mathrm{A}$. 约

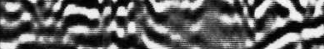
abrats 35u 政

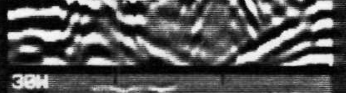
Tindy

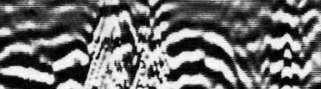

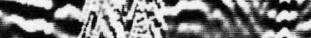

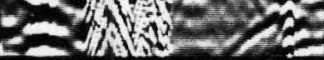
254 10 .

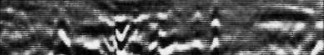

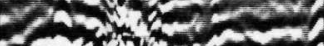

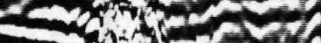

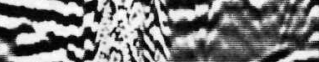

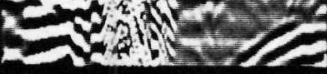
184

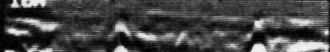
New

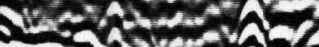

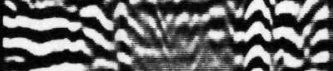
$\Rightarrow$ A.

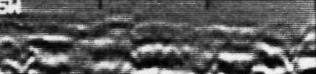

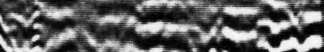
Her. and $3-1$ (rot)

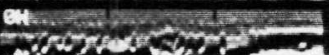

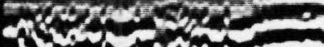

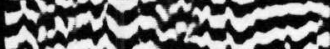
WNA Pind - 
GPR PROFILES ACROSS RLW SEWER, AREA 3APRS2

PAGE 1

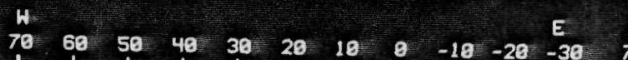
$\begin{array}{llllllllllll}40 & 69 & 50 & 40 & 30 & 28 & 10 & 9 & -10 & -20 & -30\end{array}$

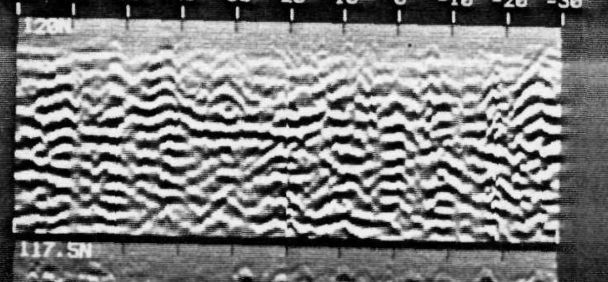

$117.5 n$

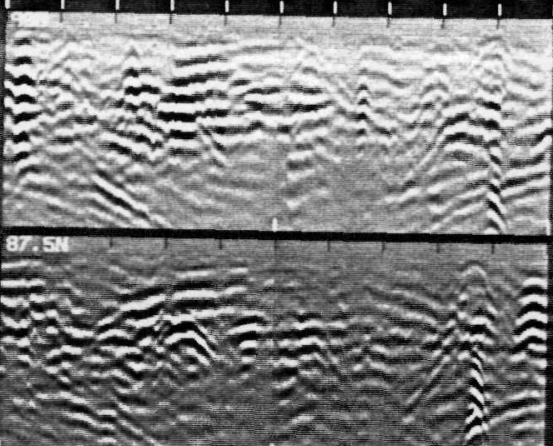

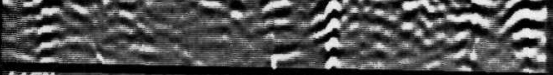
IISW

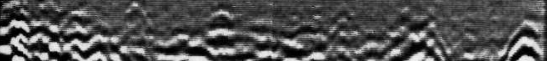

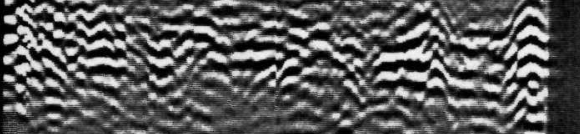

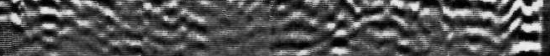

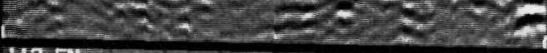

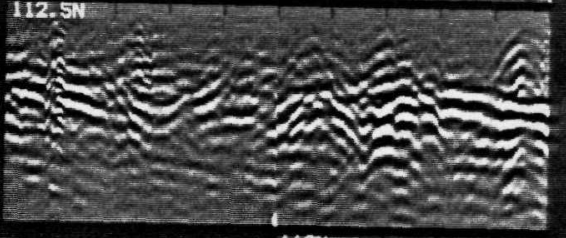

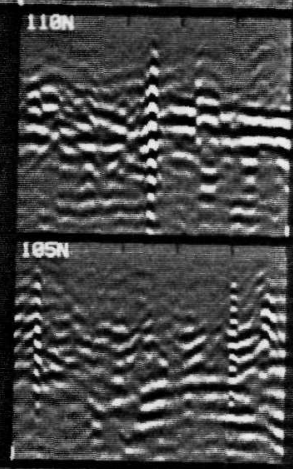
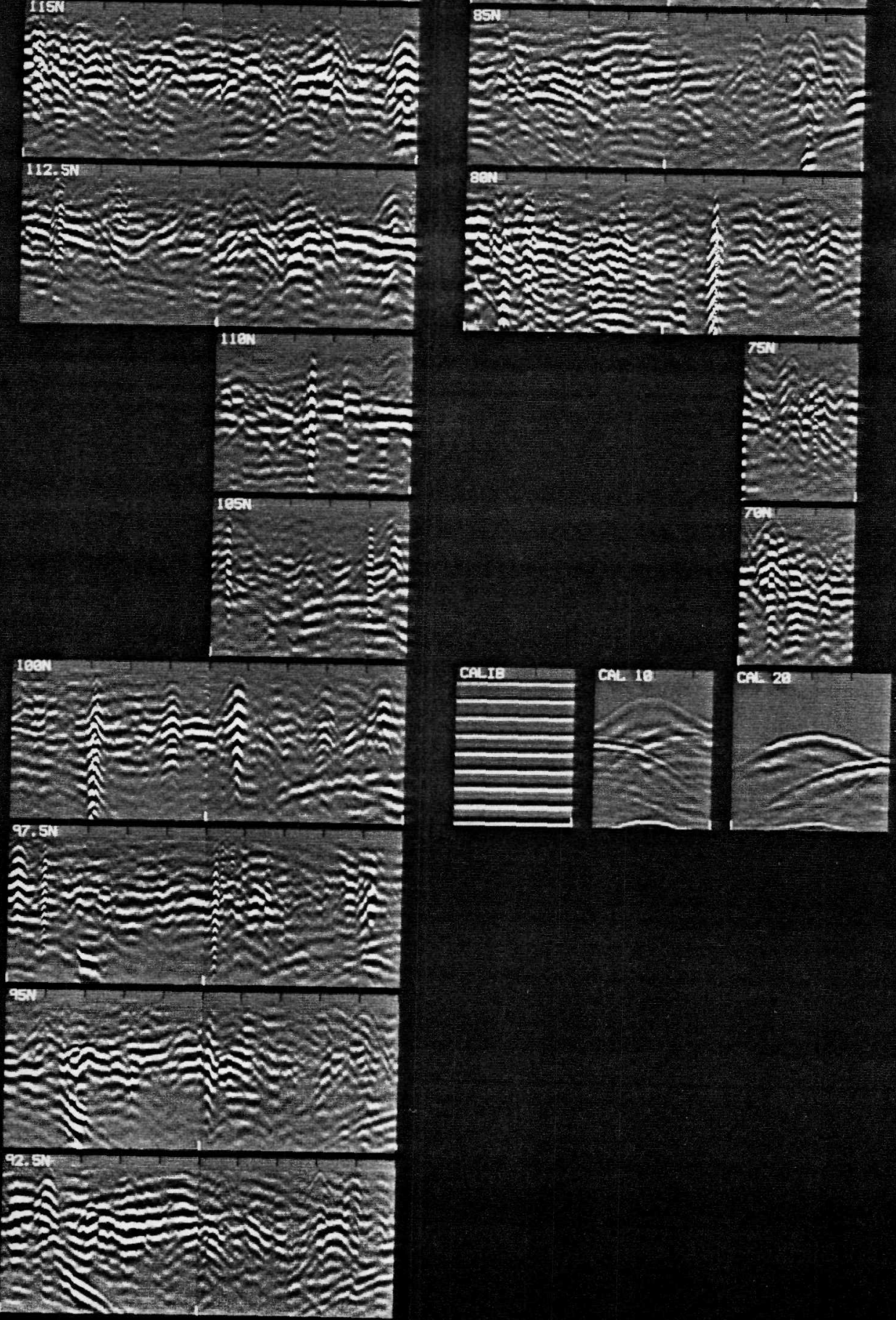

sises

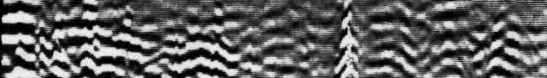

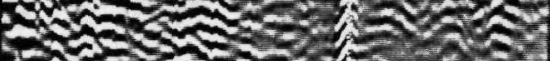

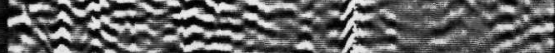

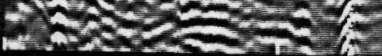


GPR PROFILES ACROSS RLW SEWER, AREA 3APRS2

PAGE 2 $\begin{array}{cccccc}1 & & & & & \\ 70 & 60 & 50 & 40 & 30 & 20 \\ 1 & 1 & 1 & 1 & 1 & 1\end{array}$

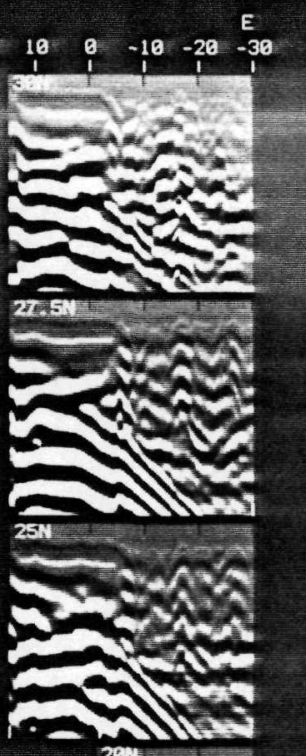

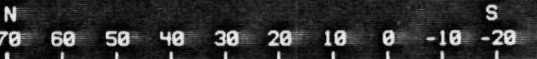
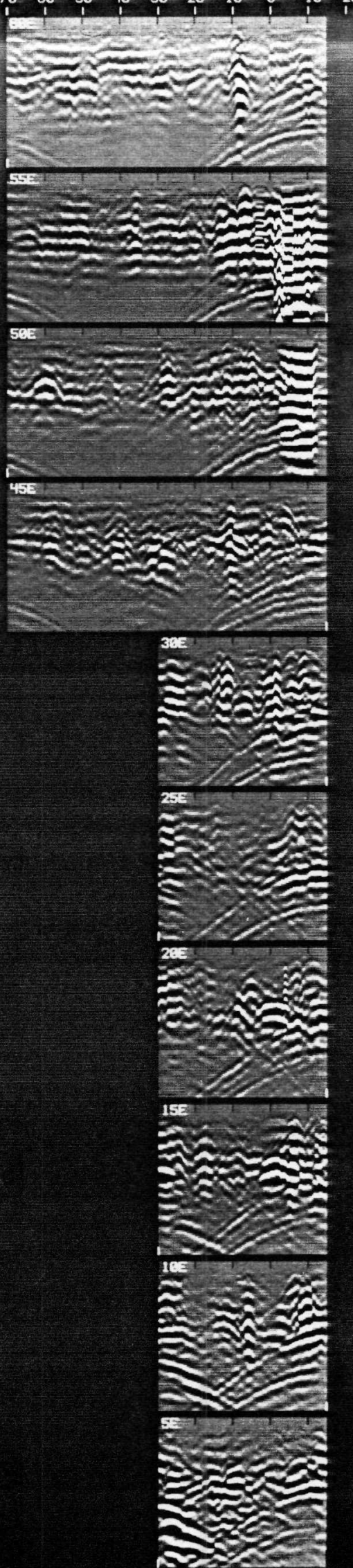


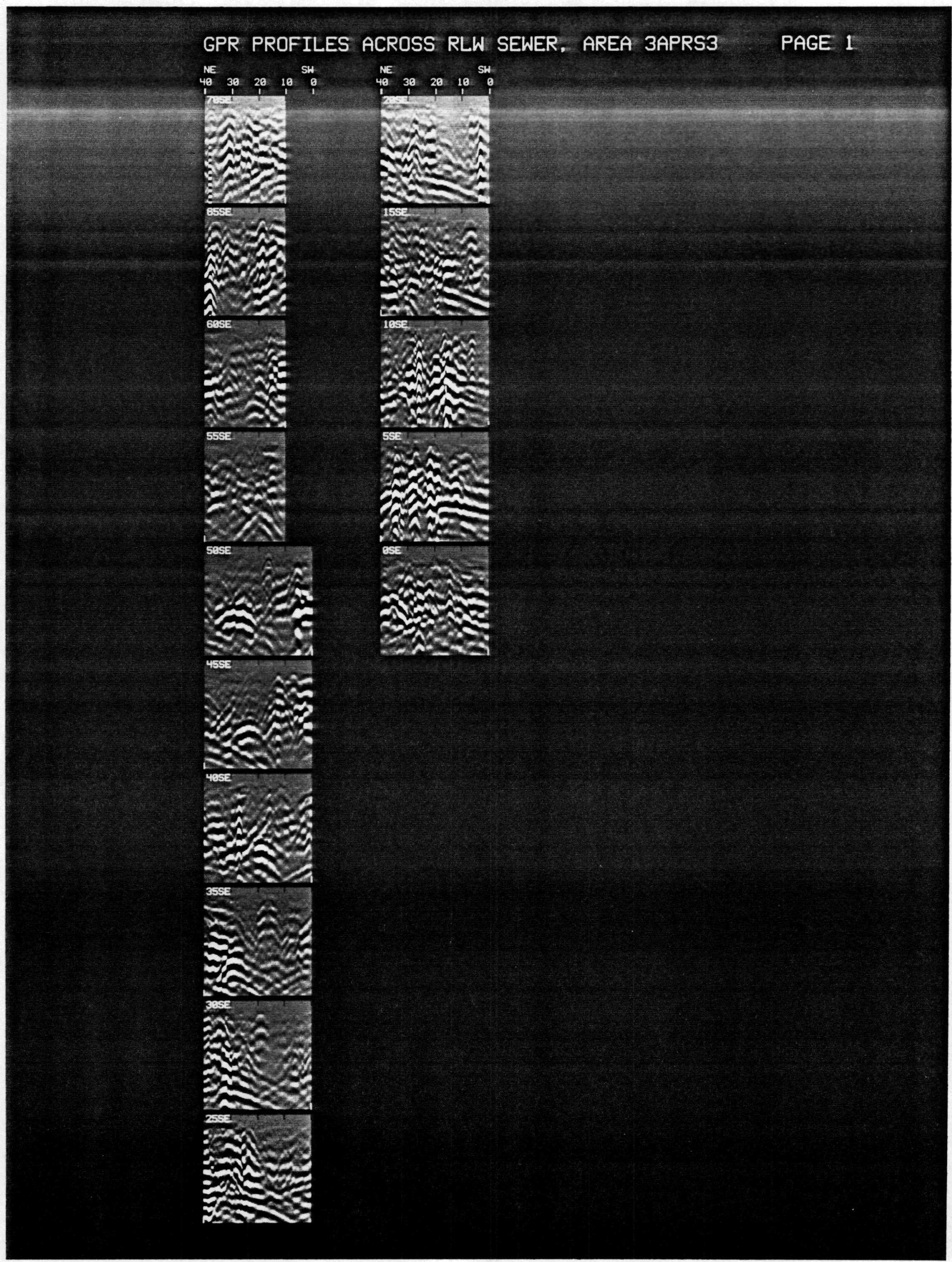


GPR PROFILES ACROSS PROCESS SEWER. AREA 3APRS4

PAGE 1 $\begin{array}{lllllll}0 & 10 & 20 & 30 & 40 & 50\end{array}$

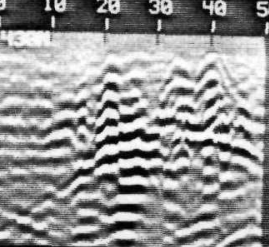
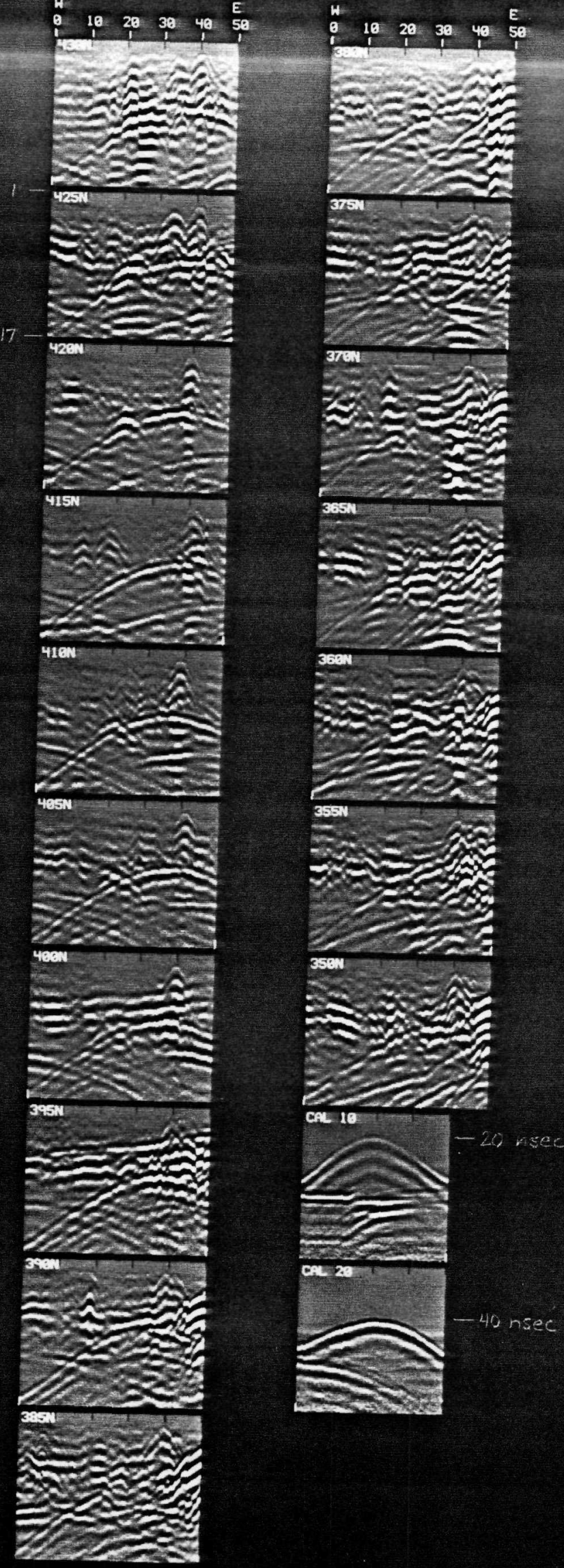
GPR PROFILES S AND E OF 307 PONDS, AREA 3APRS5

PAGE 1

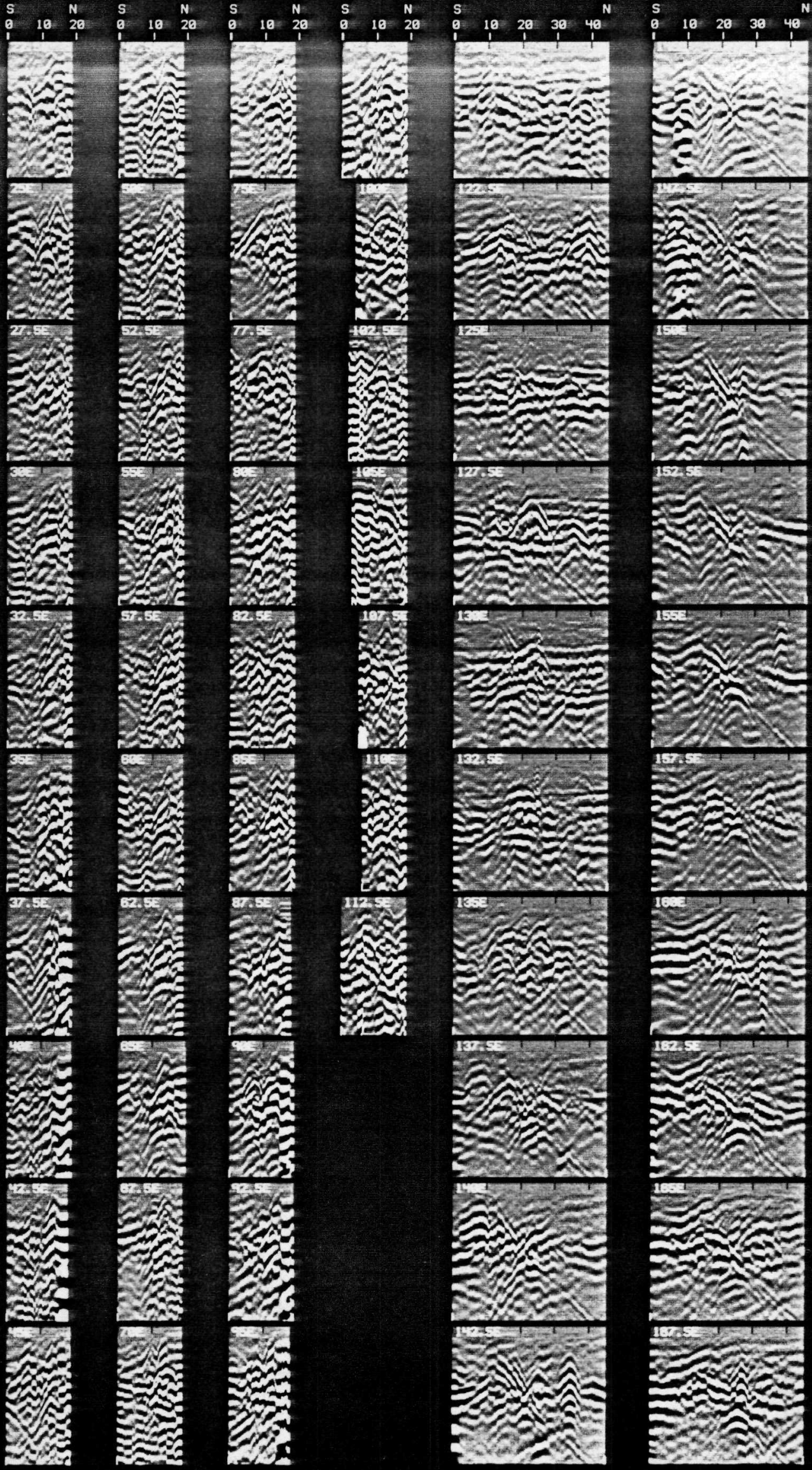


GPR PROFILES S AND E OF 307 PONDS, AREA 3APRS5

PAGE 2

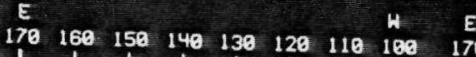

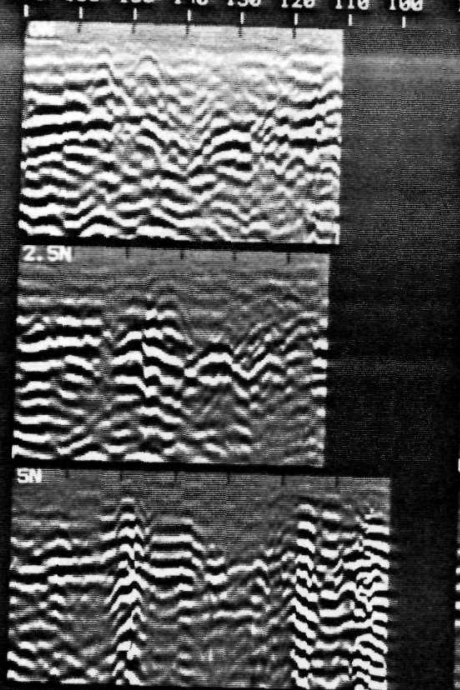

$7.5 \mathrm{~N}-\mathrm{x}$.

$2-2=020$

$x+20 x-5$

20. $20 \%$

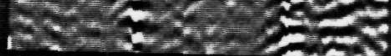
tow

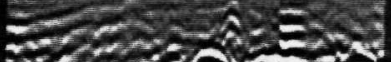

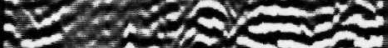

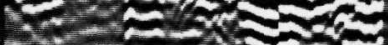

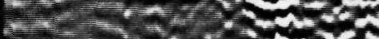

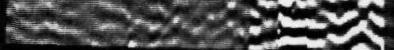
$12.5 \mathrm{y}$

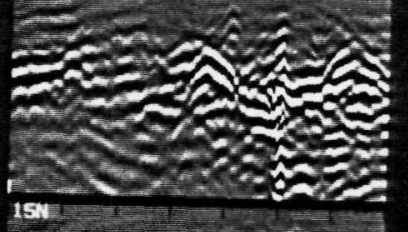

15N:

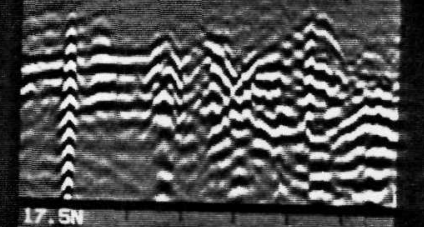

WN A A A A

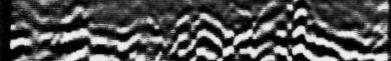

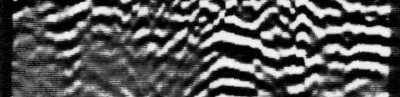

46.

200

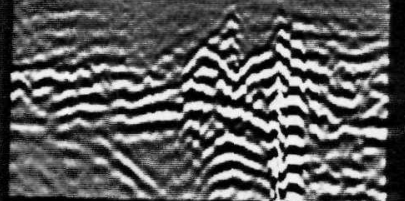

s. $3 \times 2000$

$2012=245$

\begin{tabular}{lllllllllllllll}
\hline 60 & 150 & 140 & 139 & 120 & 110 & 180 & 110 & 160 & 90 & 80 & 78 & 69 & 58
\end{tabular}

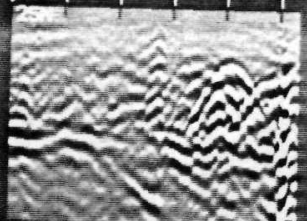

$2 \pi \cdot 5 \mathrm{n}$

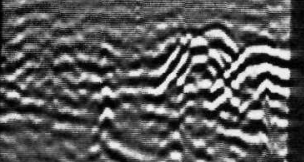

Nates

36\% ts

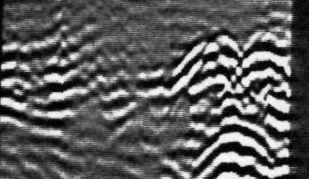

wis

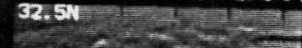

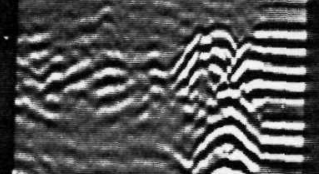

andana

35W :

2001904

s. $=219$

Sis we

37.5N

$-2=1 / \sin ^{2}$

$-2030$

Wis. $x_{2}=$

4ev

$3=2010$

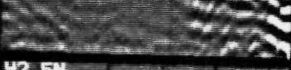

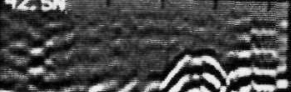

20180

is

4อง

W6r $=1,2$

andara

N-2.2/

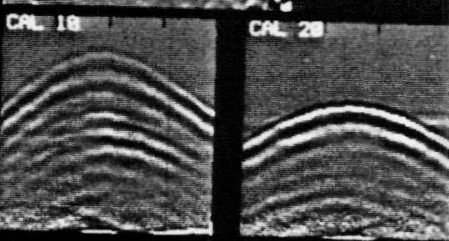

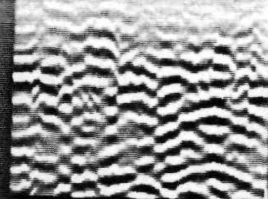

2.5n:

$\pm 1061$ 5 Nan?

ocent

$6+20$

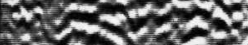
$-4 \times 1$ 2.10 an $7.5 \%$

20.25.2.

2500

$250-2$ $x+5=$

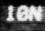

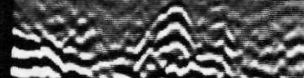
$0-12$ 9100 $x-2002$ 12.5W

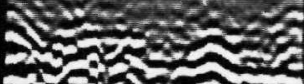
as N

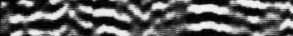
seten: $15 \mathrm{H}$

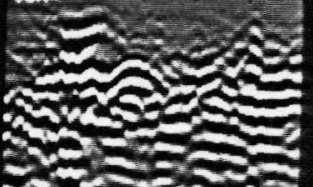

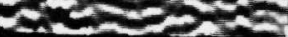

17.5

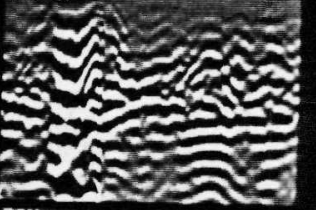

2en

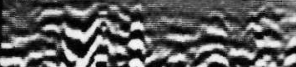

- 1.20

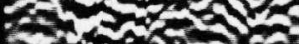

Nate

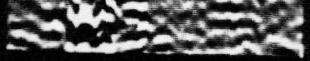


GPR PROFILES ACROSS RLW SEWER, AREAS 3ARS1, 2

PAGE 1
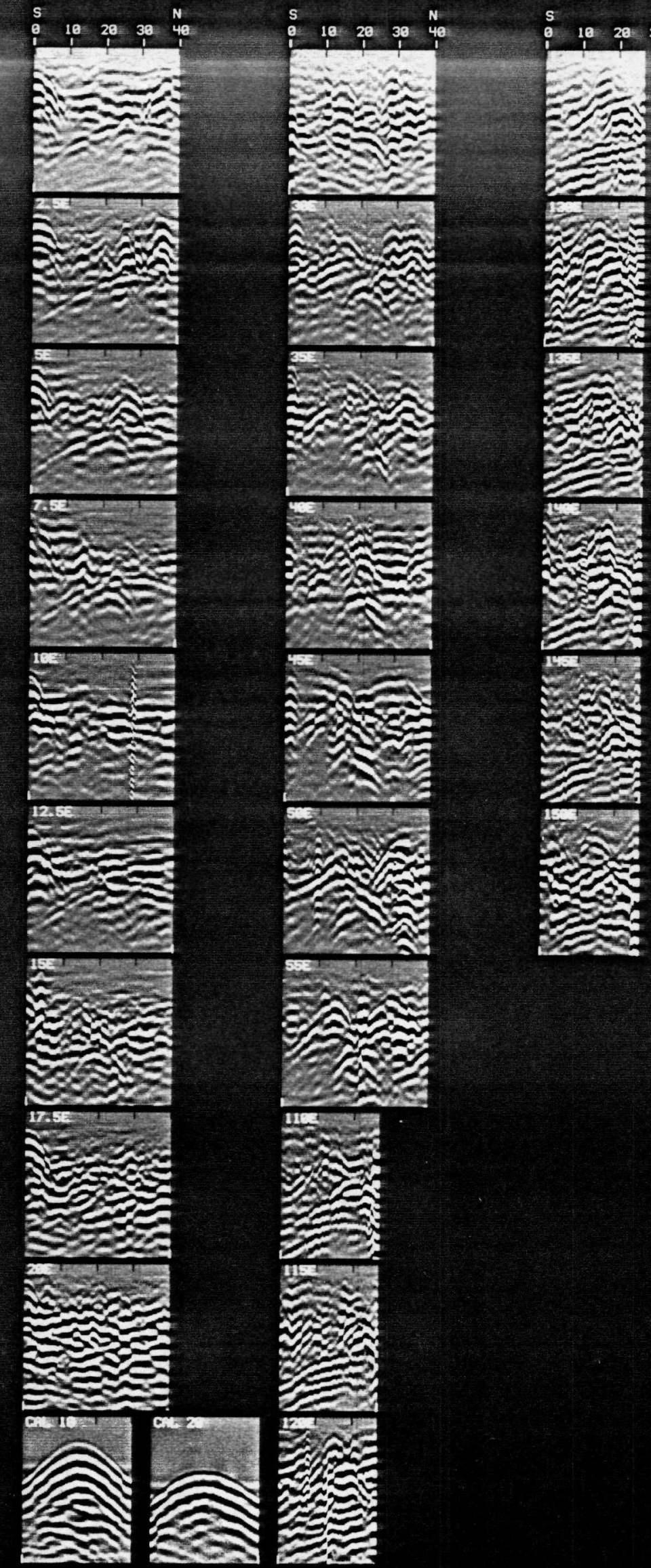
GPR PROFILES ALONG SOUTHEAST EDGE OF BG 618-5

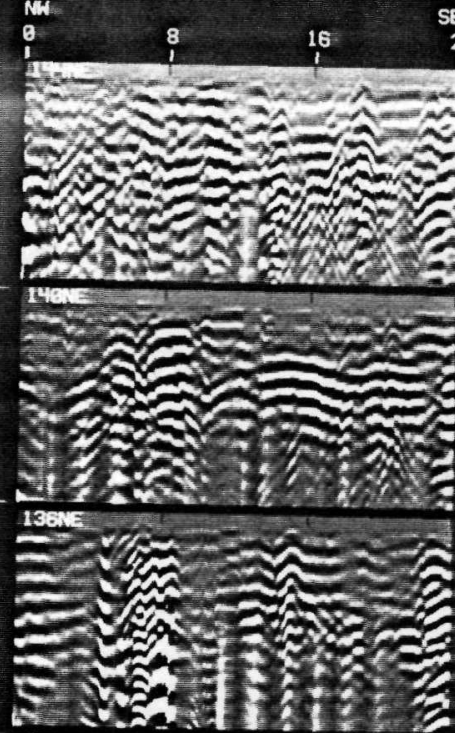
102is:

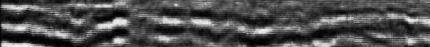

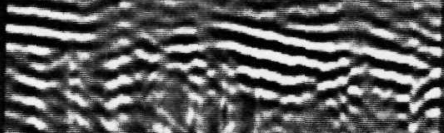

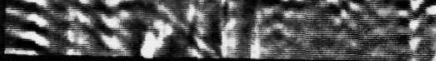
$128 \mathrm{Ne}$ E NH

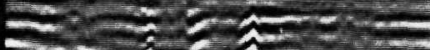

ThNon-

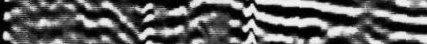

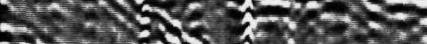

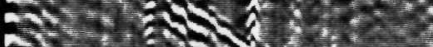
12412 in

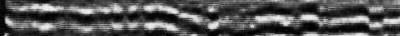

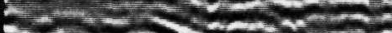
7.6.6-

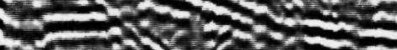

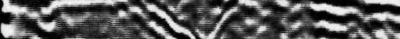
in

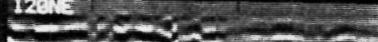

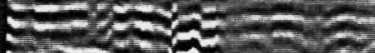

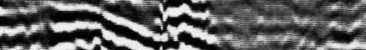
$20 \times 1-12$

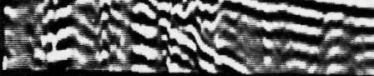
HEN

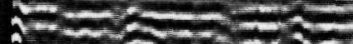

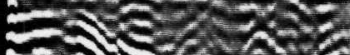
$\because 20$ ande $\because 215$

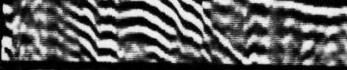

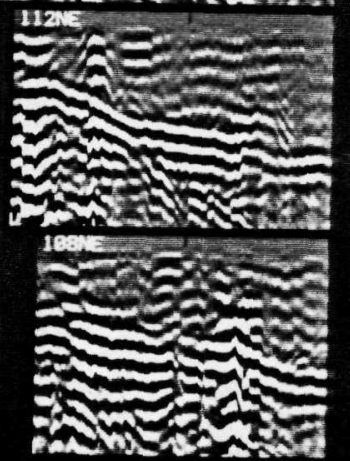
$240 \quad 8$

\section{1}

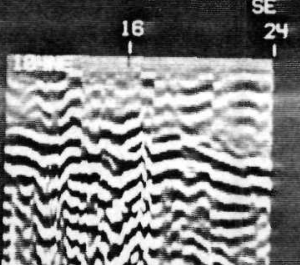
athatas

Iocme

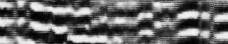

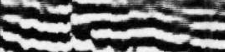

aminding

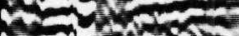

310

com

난,

$-2 a n=$

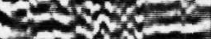

ovination

omitand

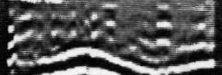

Sinnem

ANow

Nentans

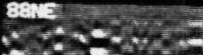

c.tan

6 rovise?

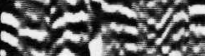

W. $x^{2}, 0$

$84 x^{2}$

$+2$

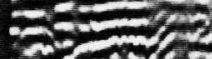

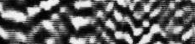

He INANo

$80+=$

$5-2=$

$\rightarrow$ atrons

satar

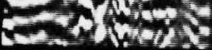

76 is

- iny

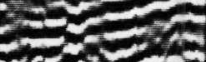

res

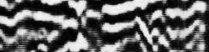

con A N

7213

SNwis

10

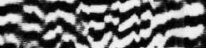

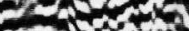

- 640 .

6eiry

2wotest

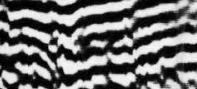

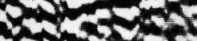

Lamishy
PAGE 1

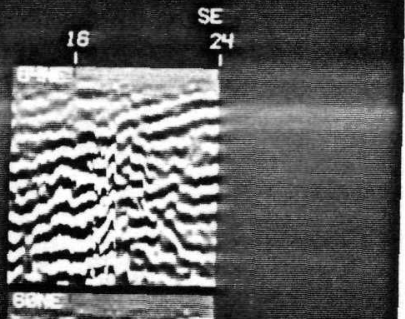

$\underbrace{}_{25 x}$

sertat

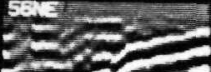

20

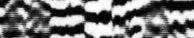
$20 \log 20$ $3 \sin x$

$52 \mathrm{at}$

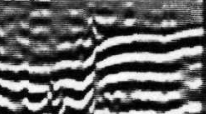

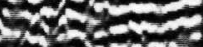

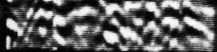

पele $2=x$

$20-1=$

inda

Brins

uniz

siste

$-201$

-101스.

avoris

wenes

$-\infty$

r.t.m.

36:

280

$-5$

5 mas

- 10

1200 .

3250

zaven

N

Datow

cour

cotat

2000

$20 x=25$

$x=$

x-50a

-

NAs 
GPR PROFILES ALONG SOUTHEAST EDGE OF BG 618-5

PAGE 2 M

SE

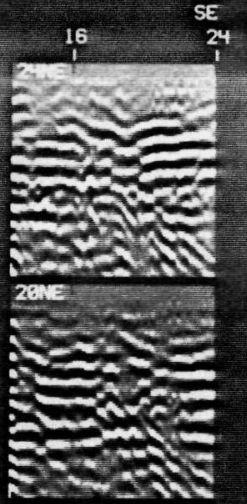

SE

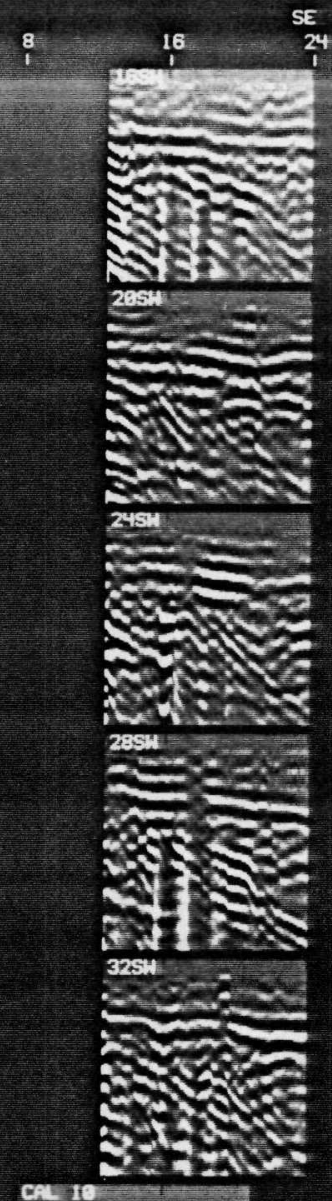

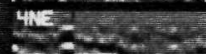

Cit 10

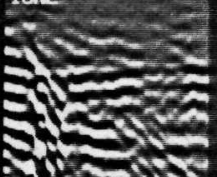

- Avalis

I2NE

wis $x=1 x$

$\approx \approx$

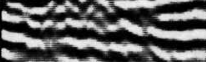

Print

BNE

intin

nomisonic

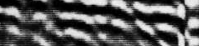

tivi

$5 x \ln =$

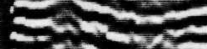

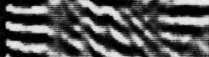

in

ente.

vitis

$20 \sin$

1

Syla

Non

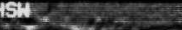

$x=1-1=$

$25=$

con

atrats

gsu

sin ans

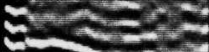

4000

$\sin 2$

$-2 \times 1 \times$

Andx

lest eving 4

ancoras

anses

$21 \times 12$

ats

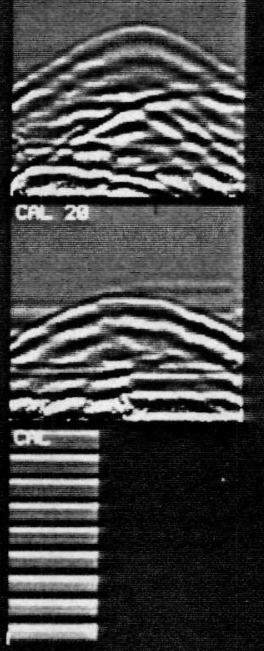


GPR PROFILES ALONG NORTHEAST EDGE OF BG 618-5

PAGE 1
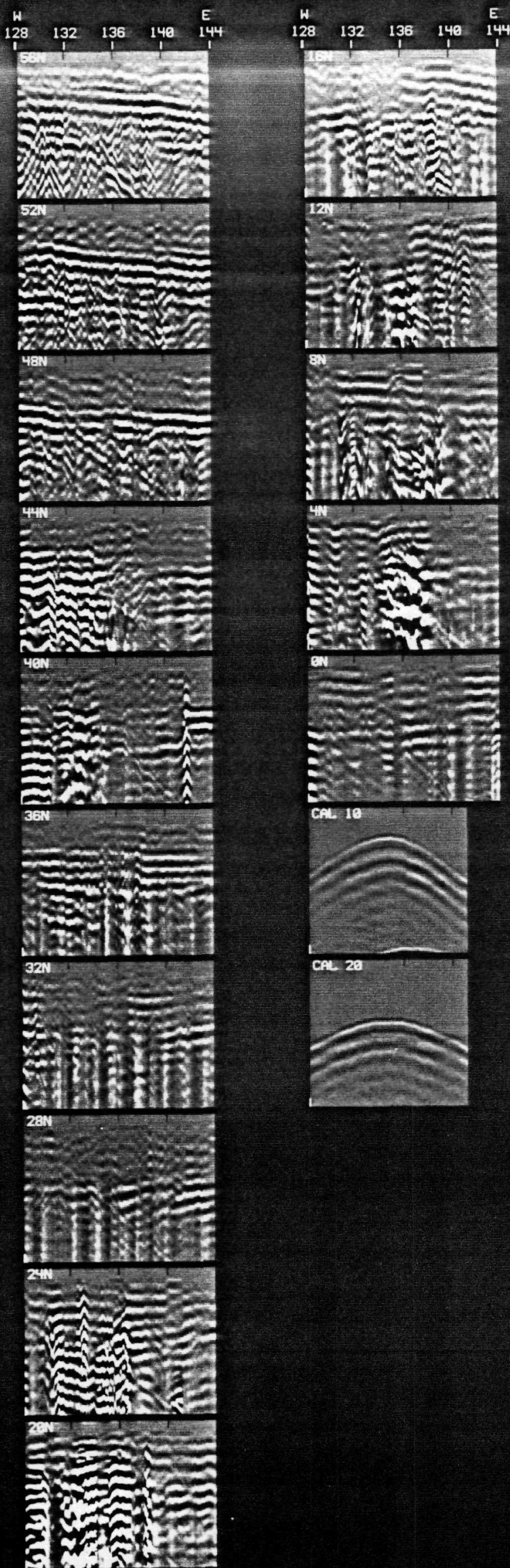
GPR PROFILES ALONG NORTHWEST EDGE OF BG 618-5 PAGE 1

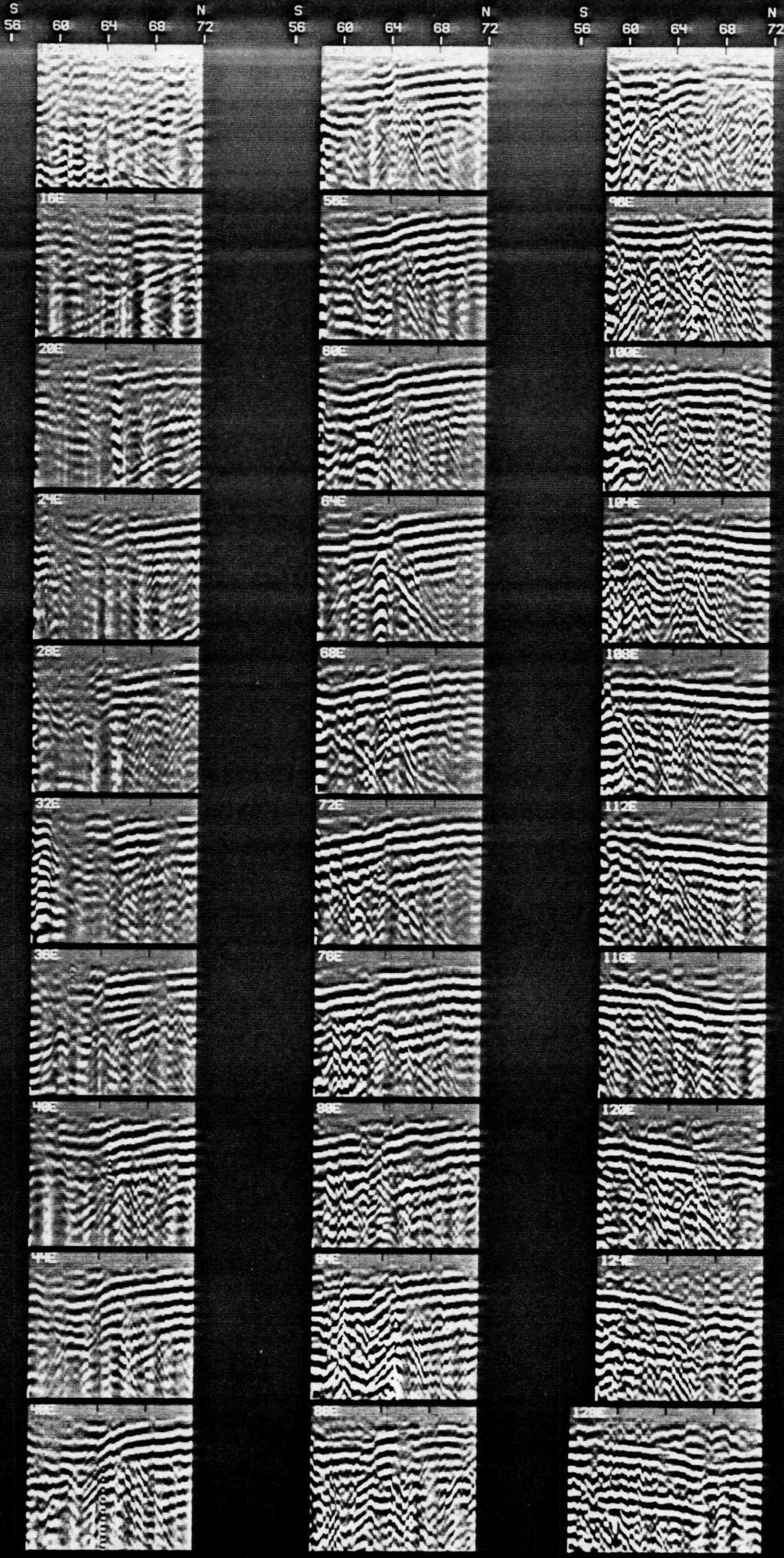


APPENDIX D

LARGE-SCALE SUMMARY MAPS 


\section{APPENDIX E}

\section{EMI PROFILES}


APPENDIX E

\section{EMI PROFILES}

\section{EXPLANATION OF VERTICAL SCALE}

As stated in Section 4.4 of the text, the numbers shown on the vertical axes of the EMI profiles are raw digital data values that are proportional to the calibrated meter indications of the EM31 ground conductivity sensor. Although the corresponding conductivity values have no significance in this application, they can be obtained for each of the following profiles by multiplying the numbers shown on the vertical axis by a scale factor. The appropriate scale factors are as follows:

EM31 Sensitivity

Setting (mmhos/m)

10

30

100

300

\section{Scale Factor}

0.005

0.015

0.050

0.150

The EM31 sensitivity settings that were used in the surveys are noted on the profile pages.

E.1 
SURVEY LINE OE
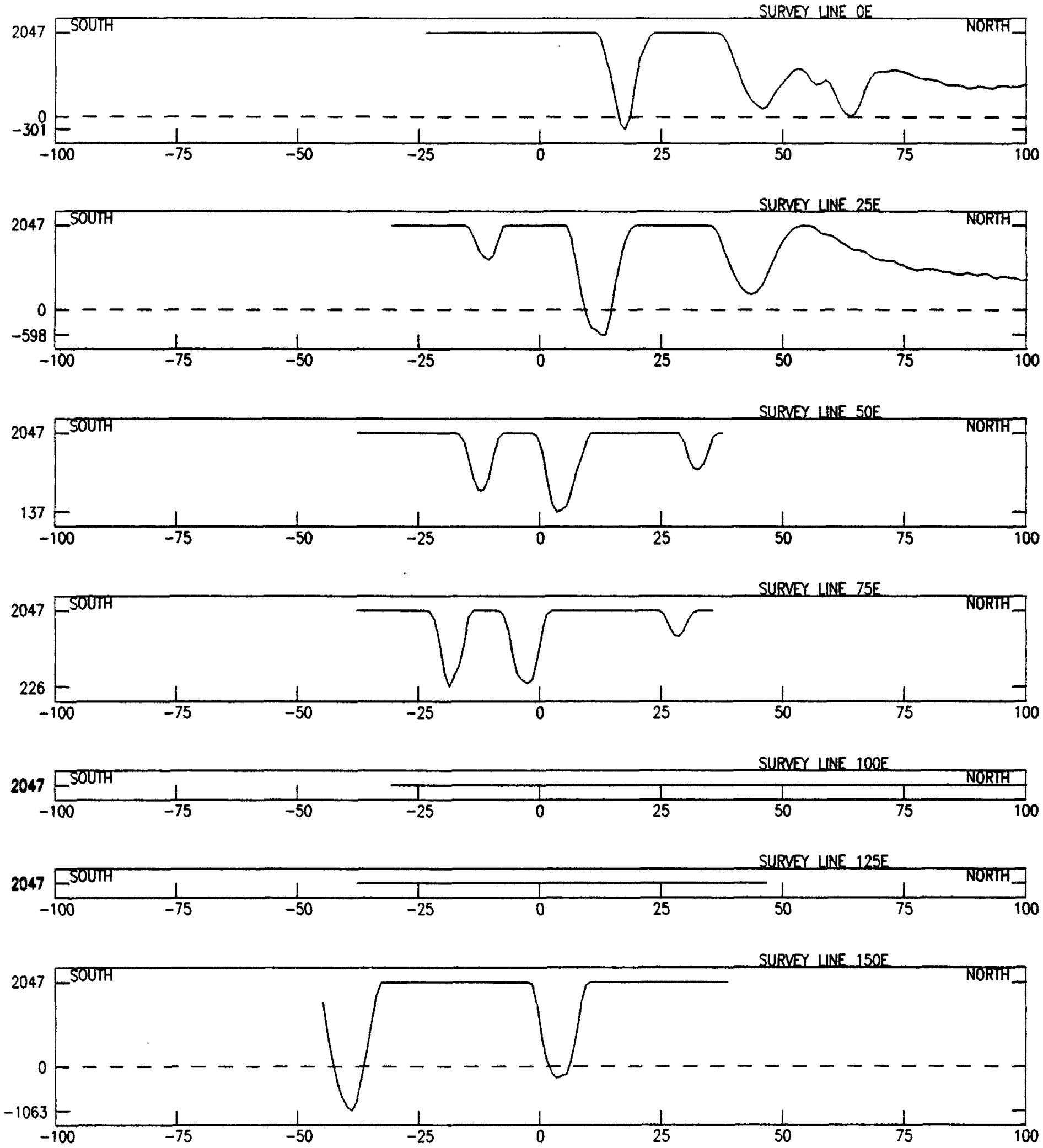

E.2 
SURVEY LINE $175 E$

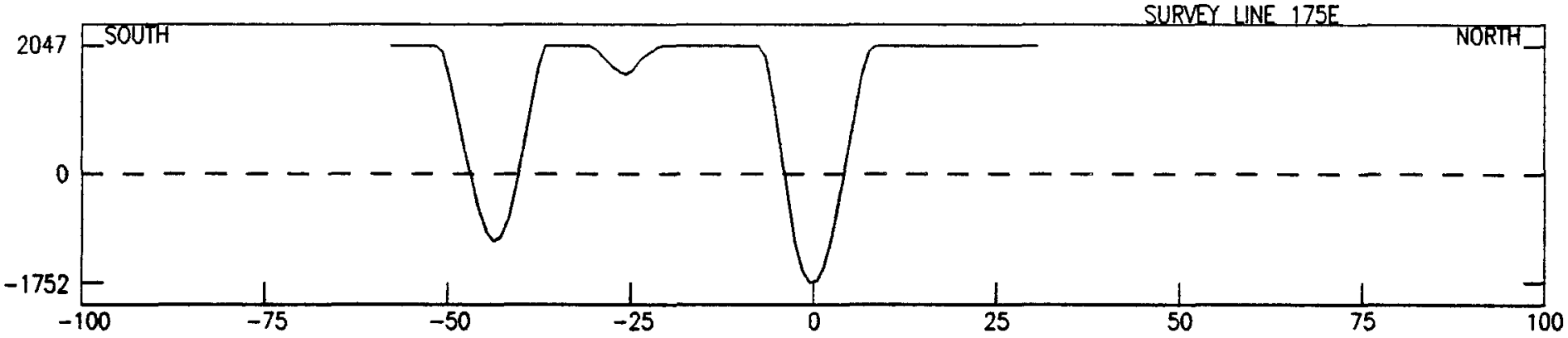

SURVEY LINE 200E

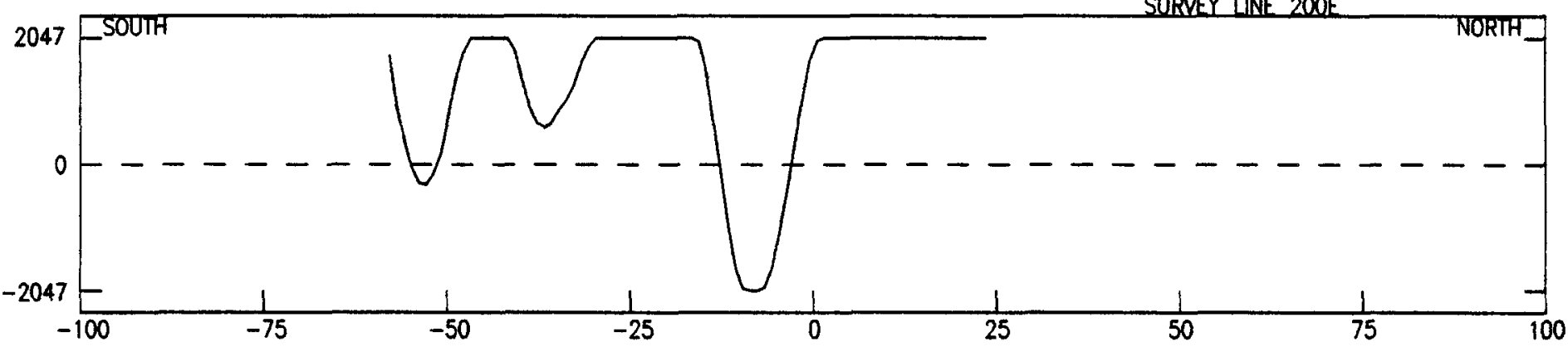

SURVEY LINE 225E

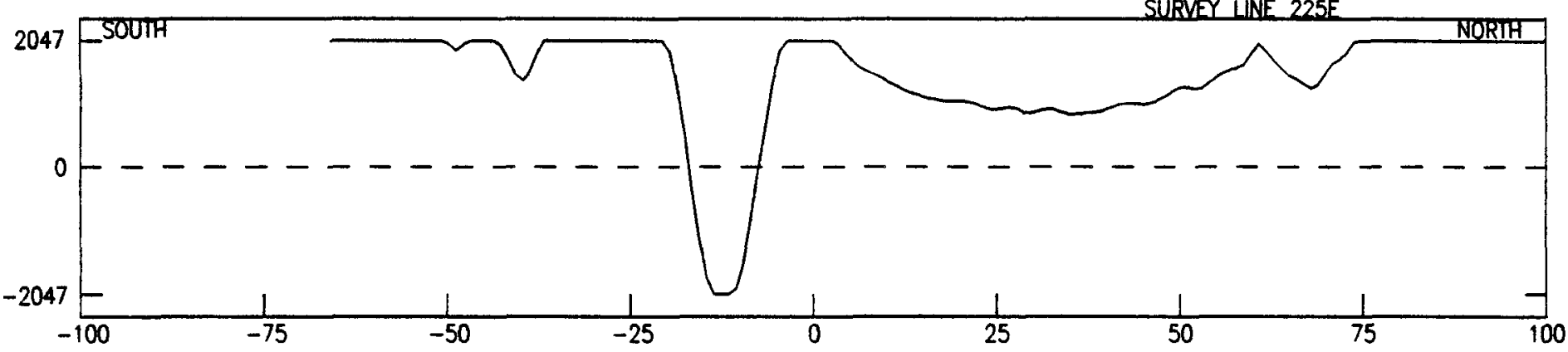

SURVEY LINE 250E

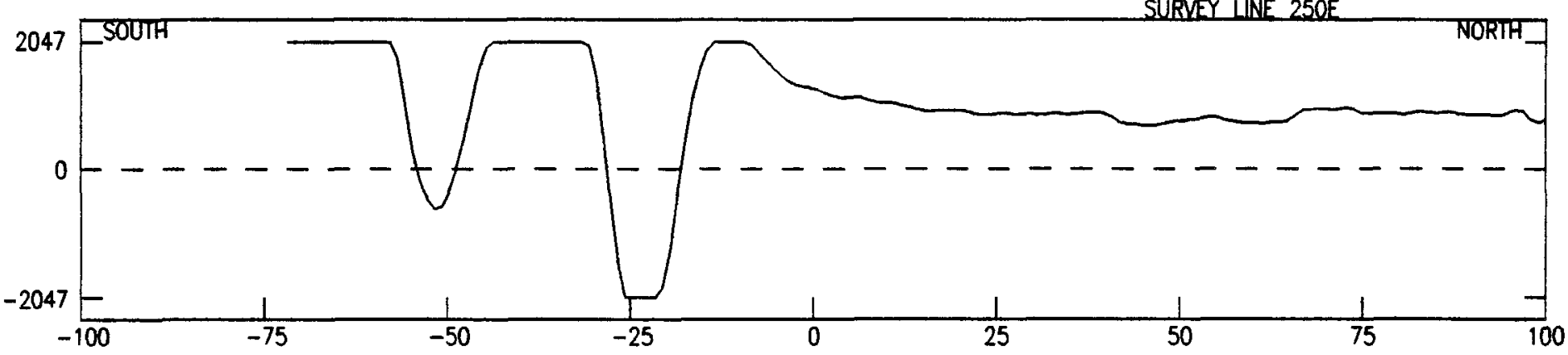

SURVEY LINE $275 E$

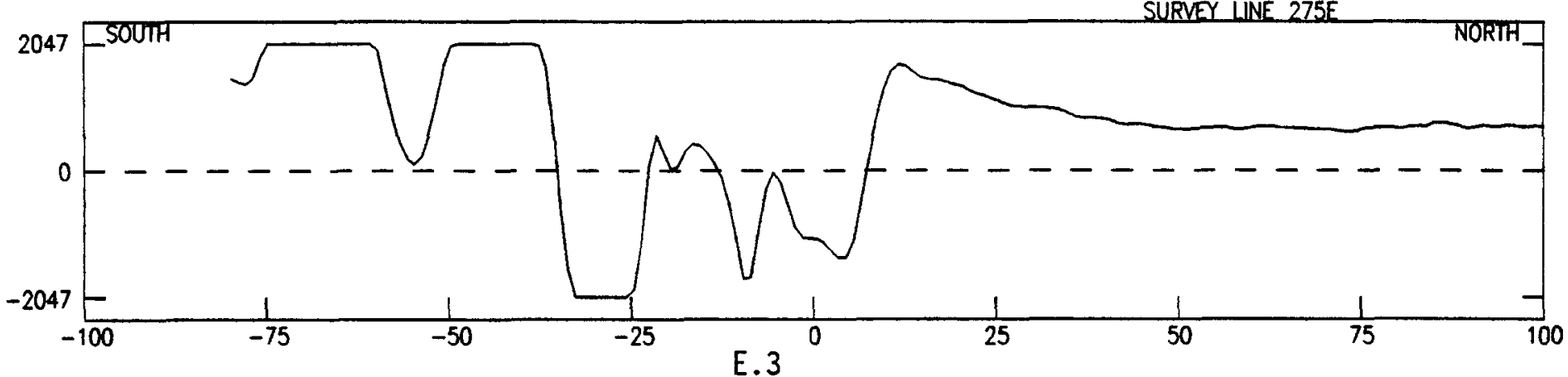



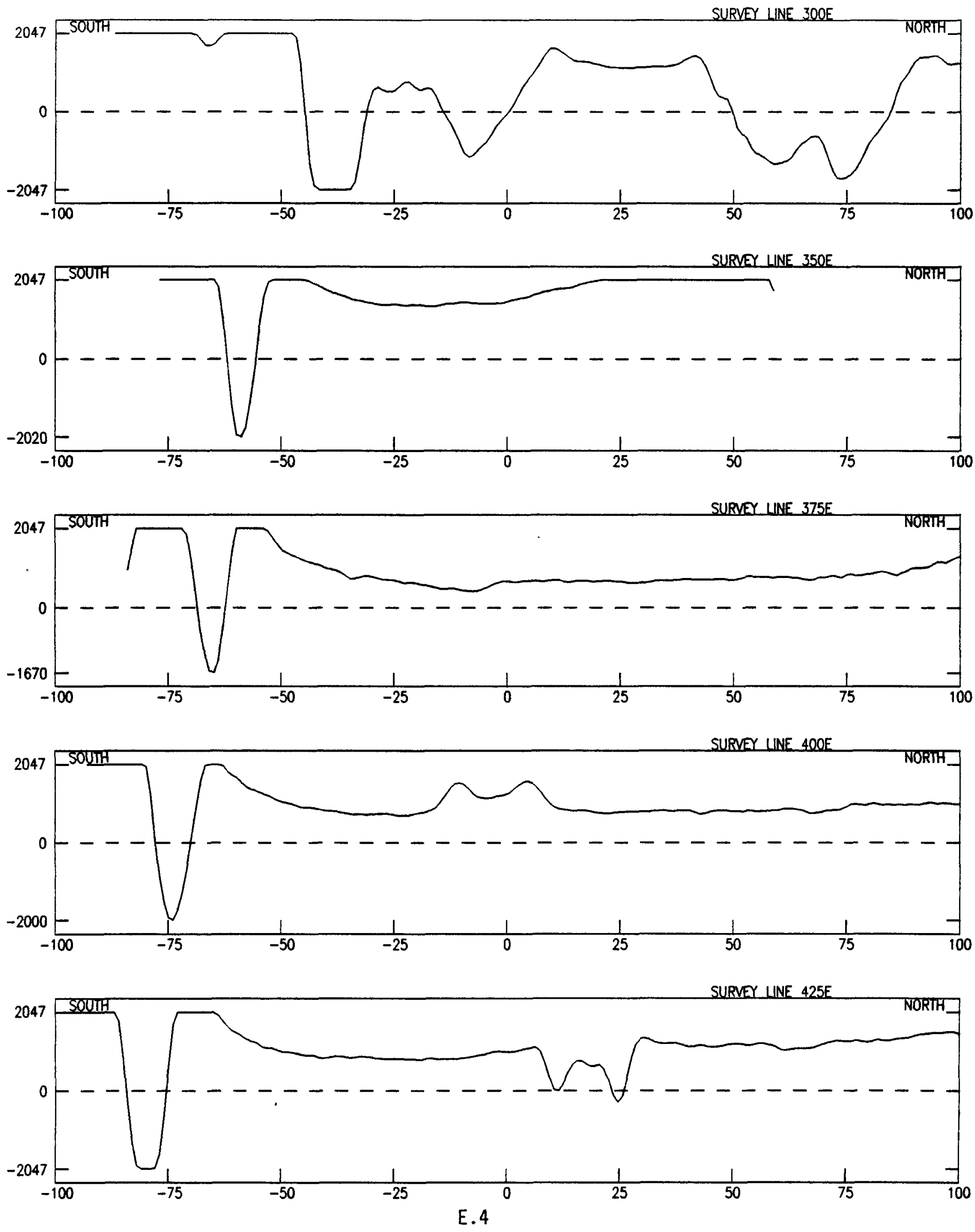

Sensitivity Setting $=10 \mathrm{mmhos} / \mathrm{m}$ except as noted.

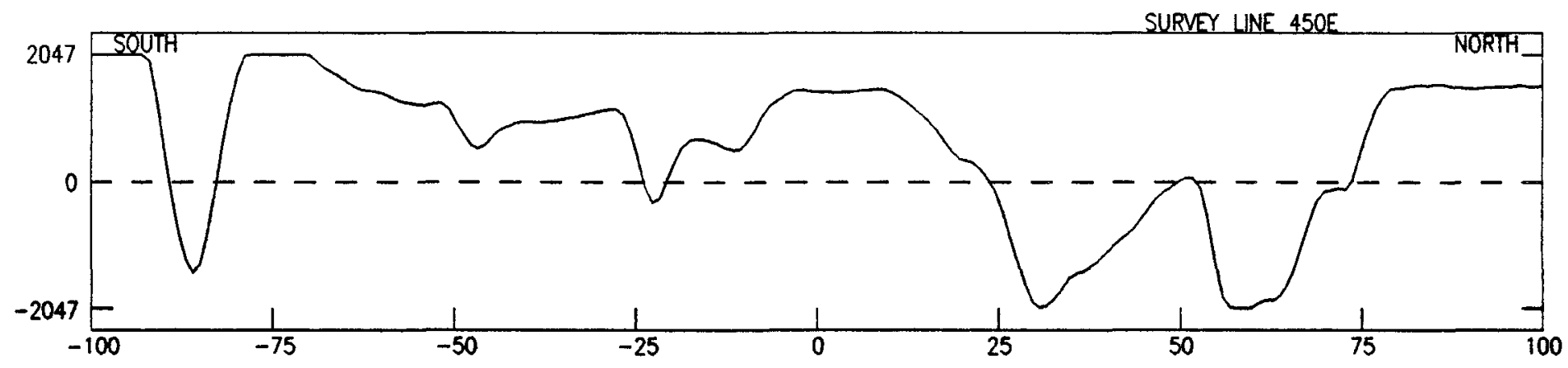


SURVEY LINE 200E

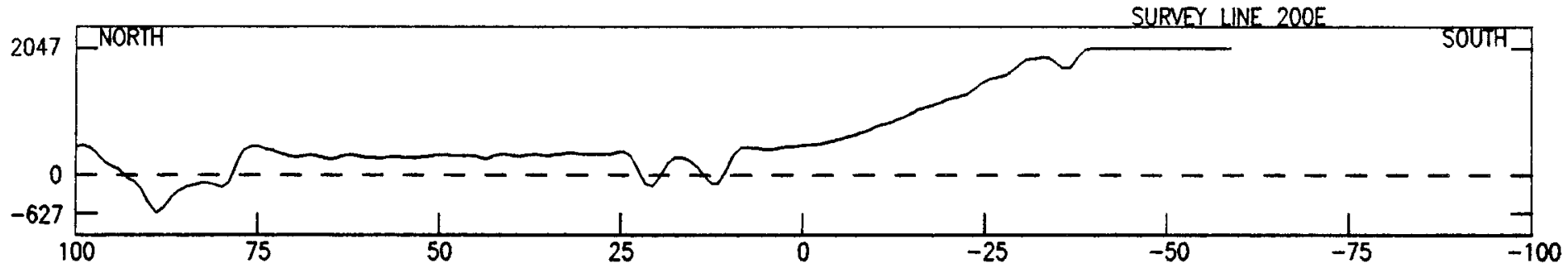

SURVEY LINE 175E
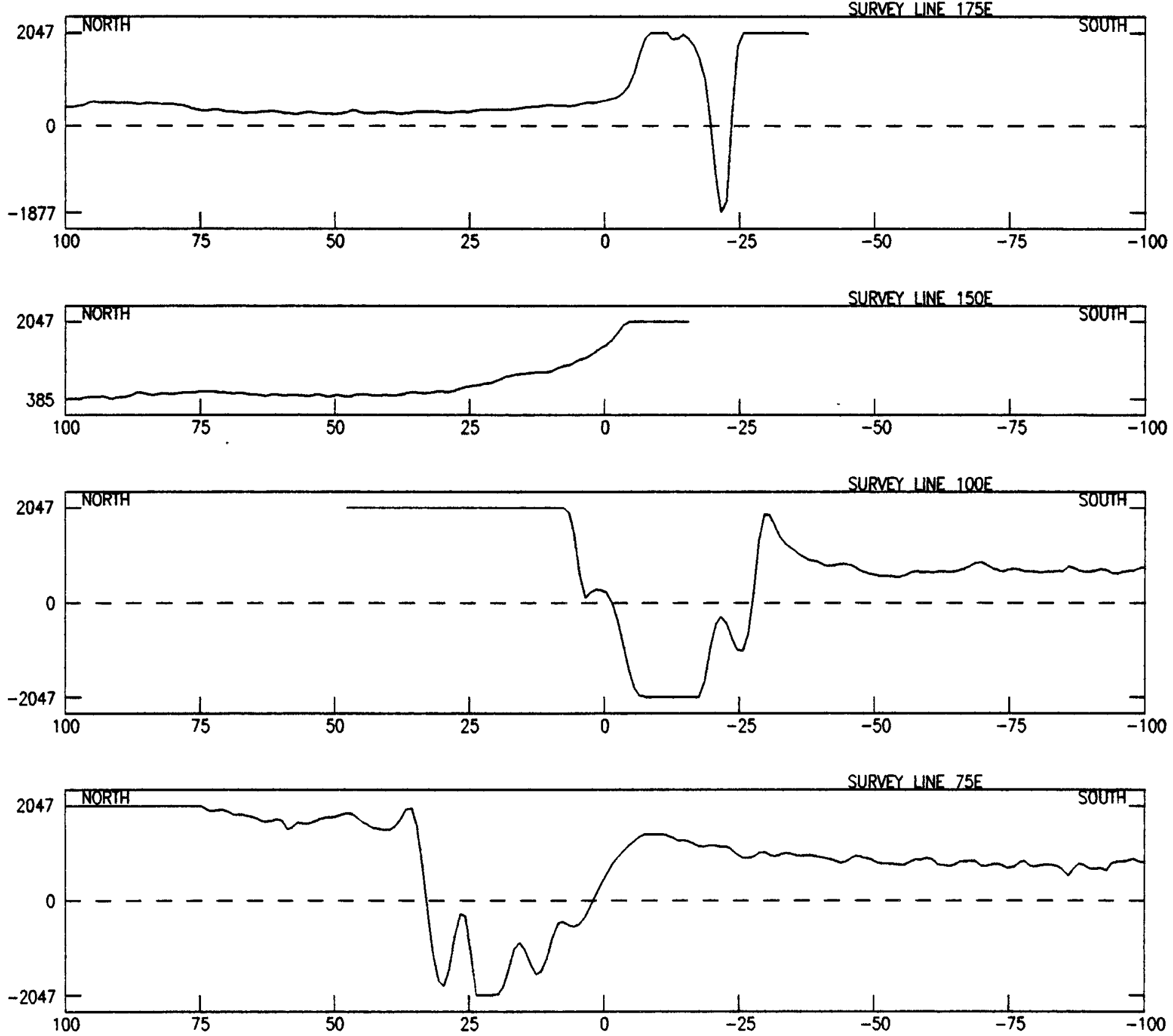

E. 6 
EM31 PROFILES ACROSS PROCESS SEWER TO POND \#1, AREA 3 APSO2

SURVEY LINE 50E

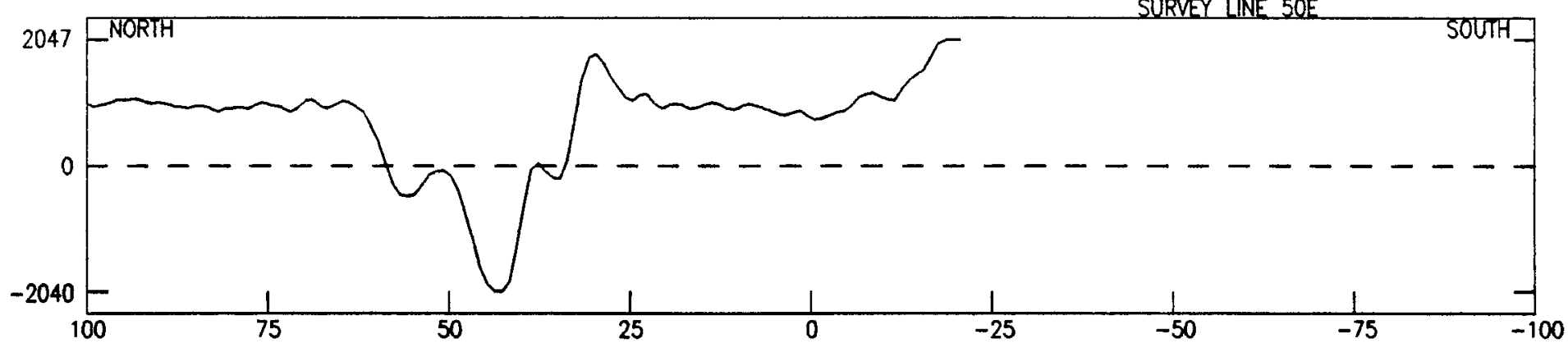

SURVEY LINE OE

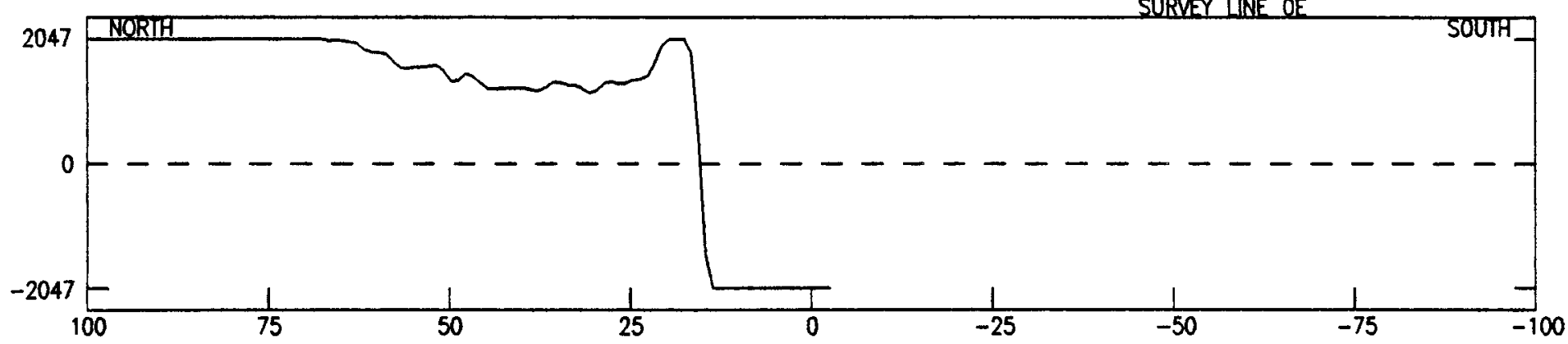

200 ROI. $90 \mathrm{H}$

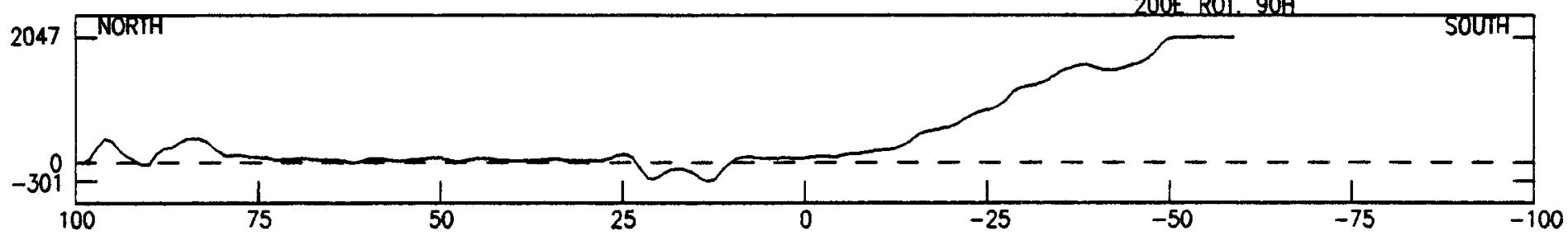

200E ROT. $90 \mathrm{~V}$

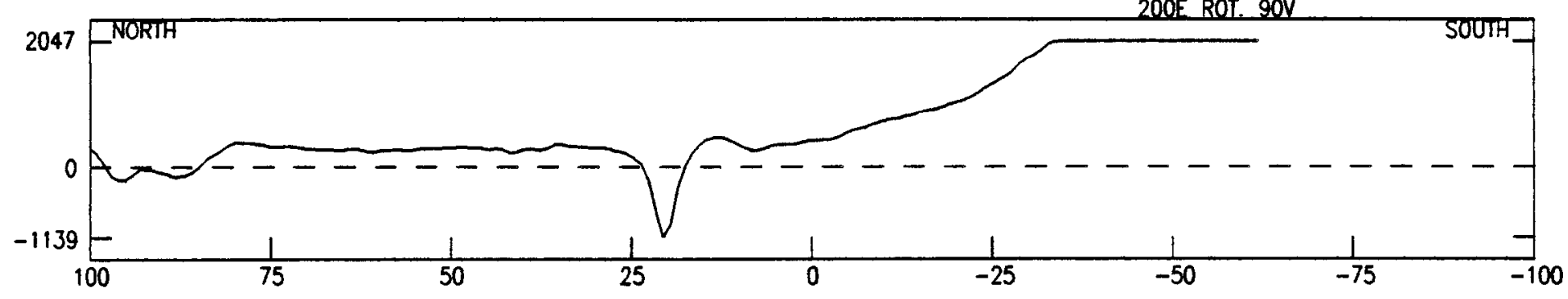

200 E ROT. $90 \mathrm{HV}$

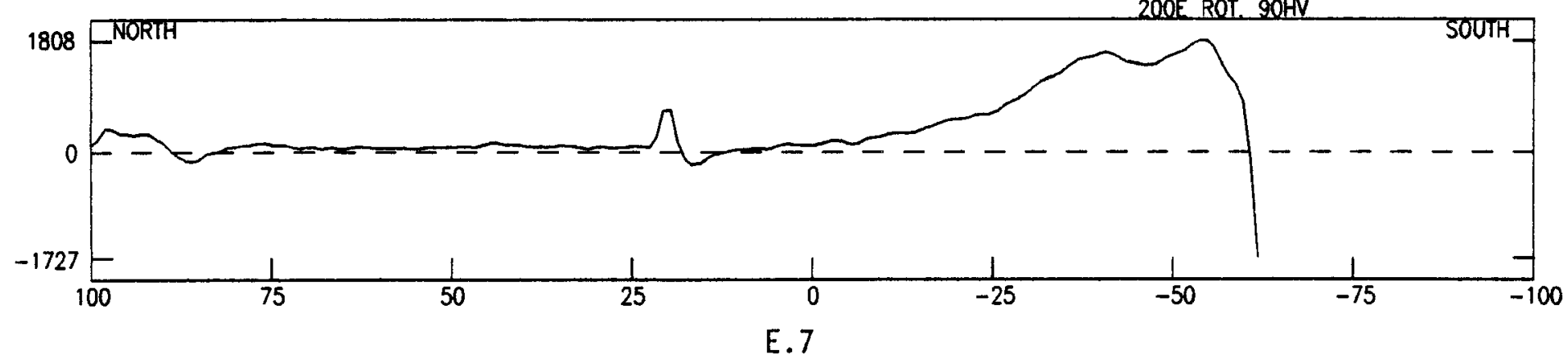



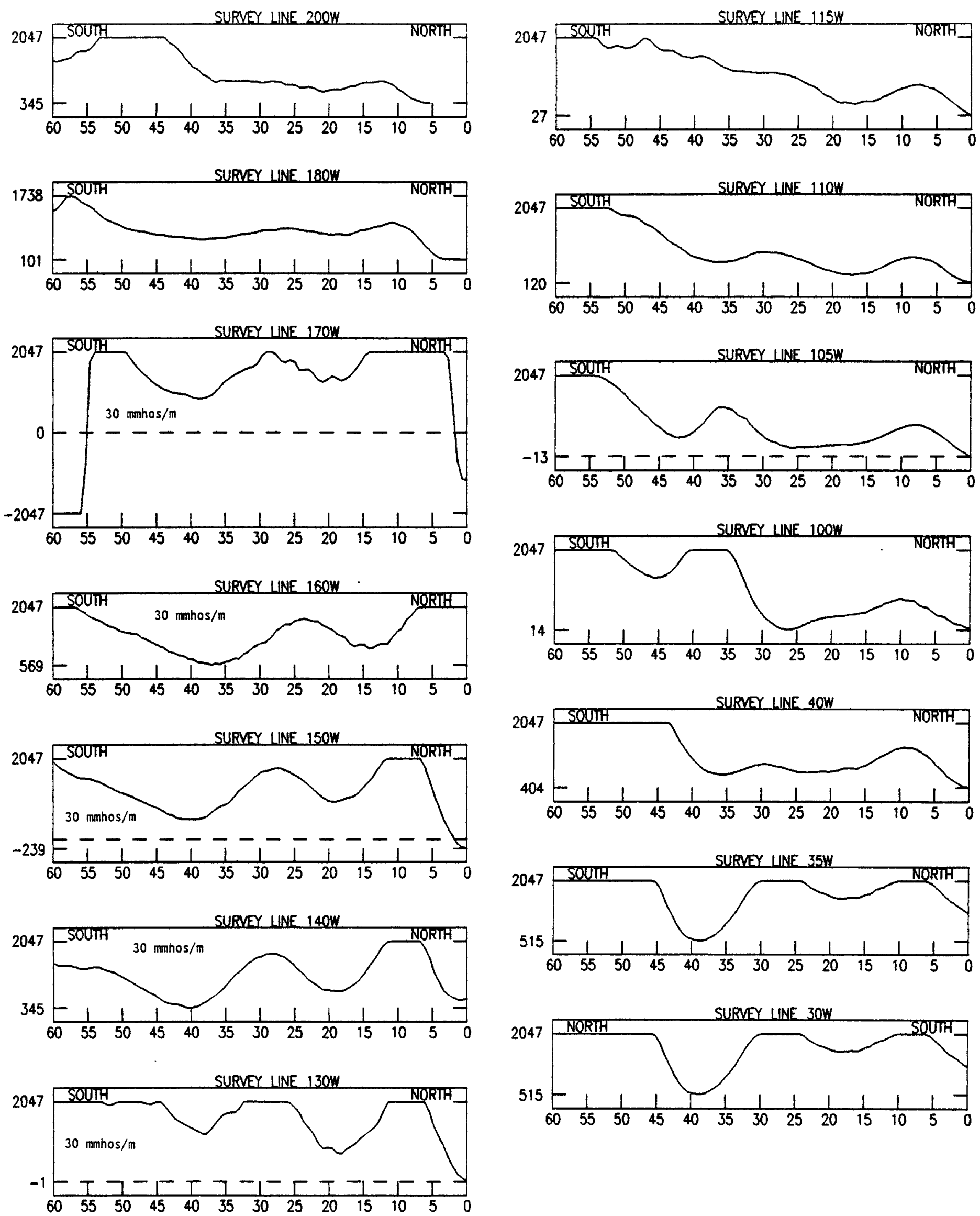

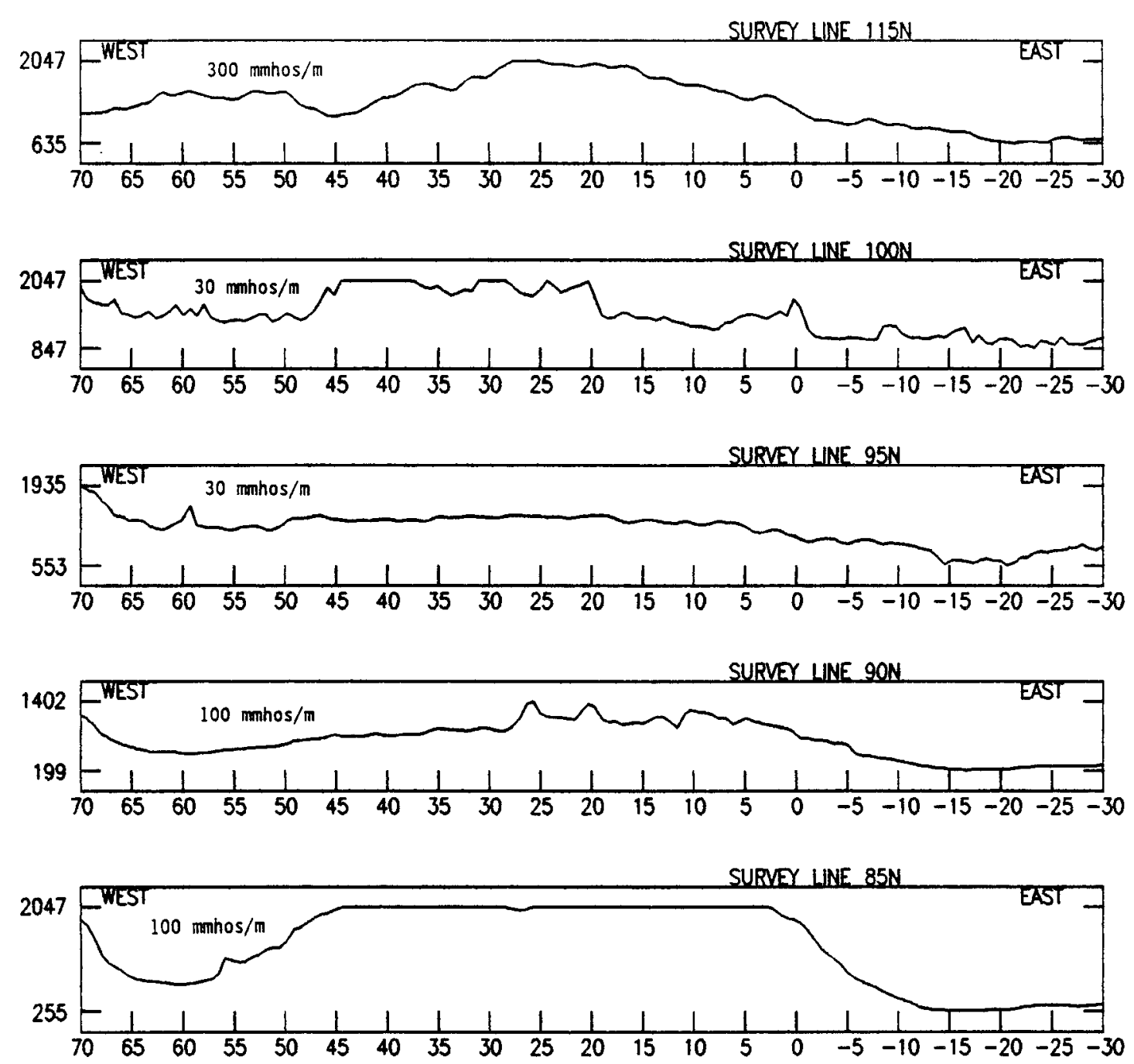

E.9 
EM31 PROFILES ACROSSS 307 TRENCH LINES, AREA 3APRS2 Sensitivity Setting $=30 \mathrm{mmhos} / \mathrm{m}$ except as noted.
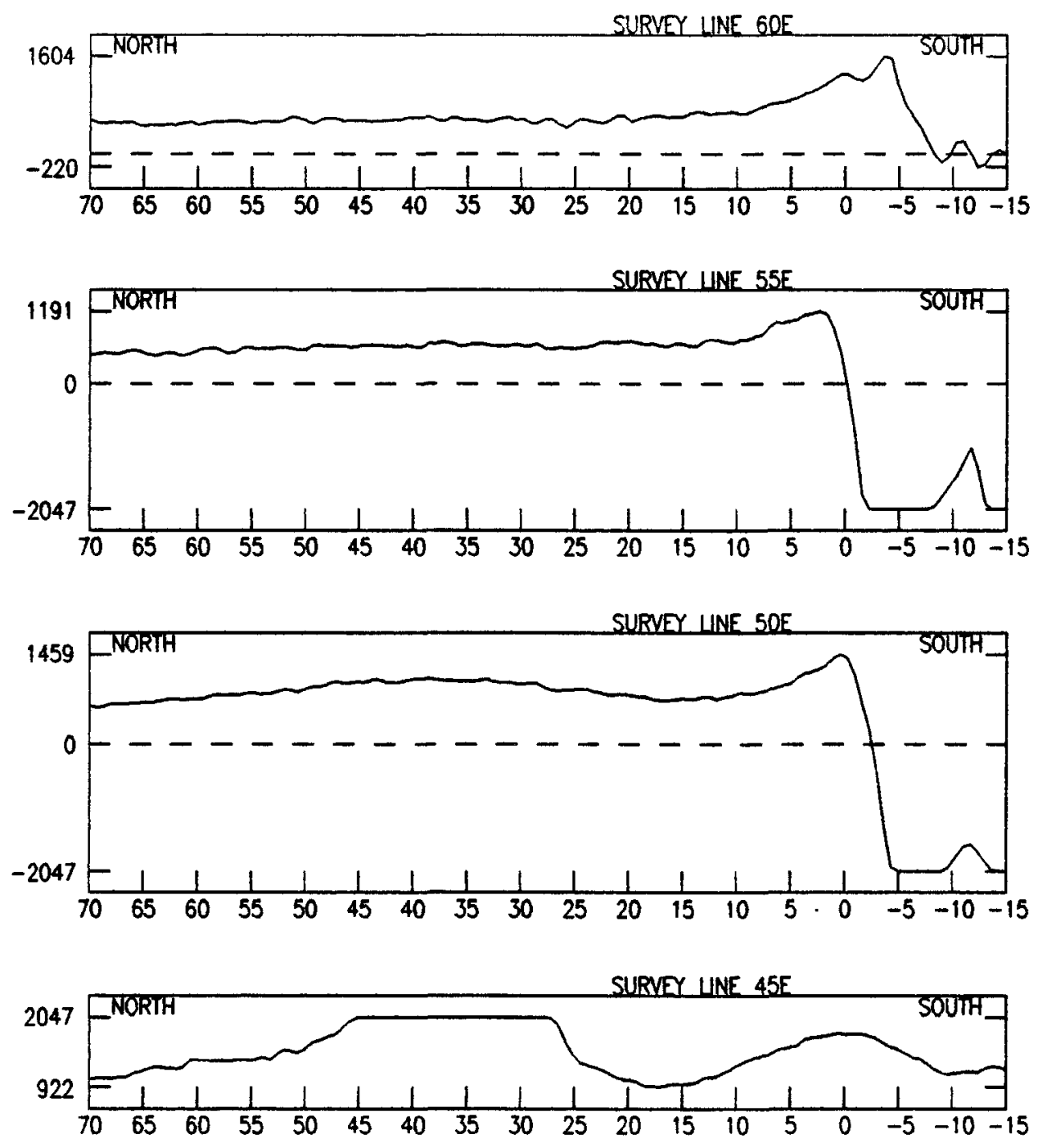

SURVEY LINE 45E

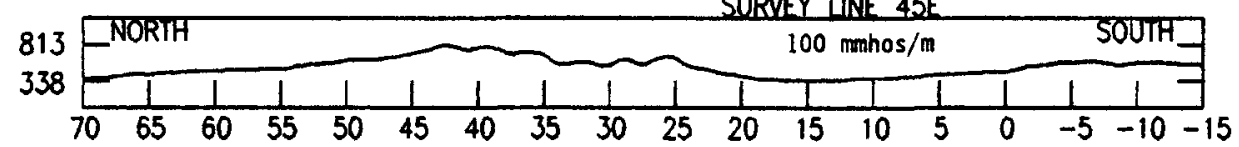


EM31 PROFILES ACROSS RLW SEWER FROM 324 BLDG, AREA 3APRS3

PAGE 1 Sensitivity Setting $=30 \mathrm{mmhos} / \mathrm{m}$ except as noted.
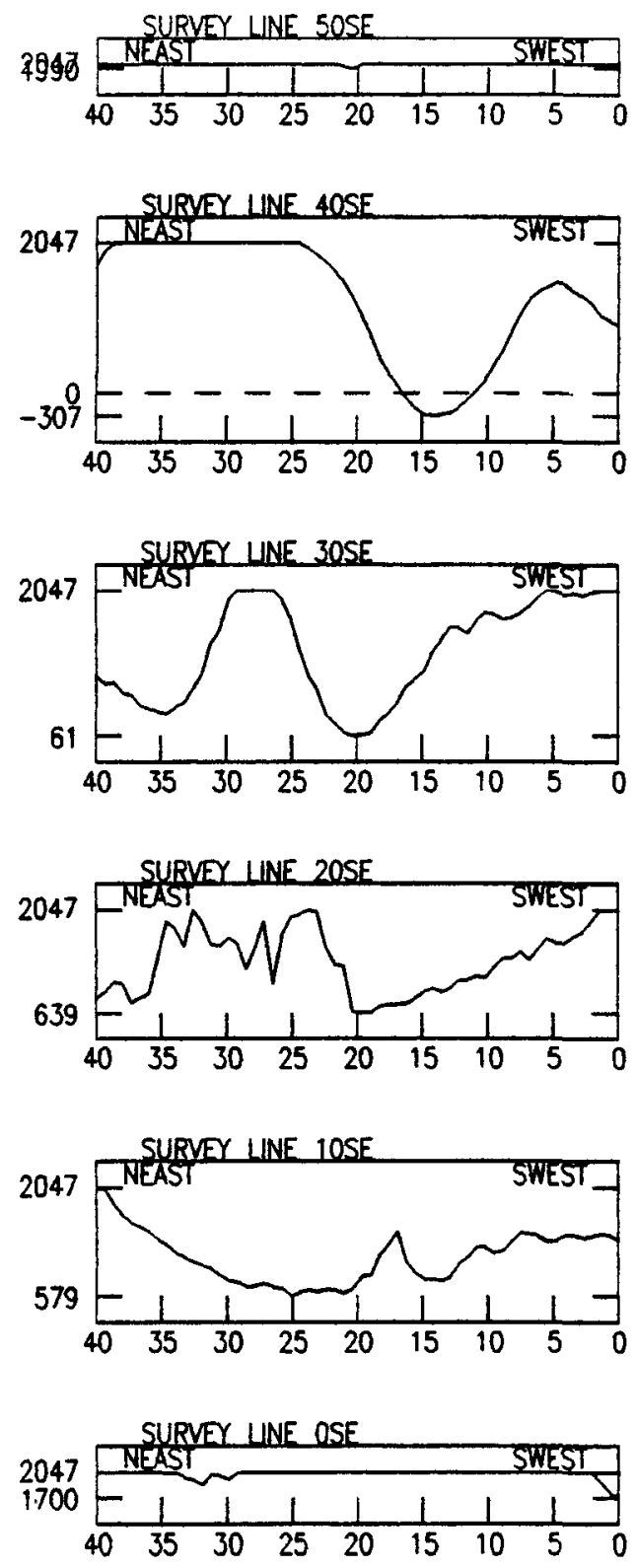

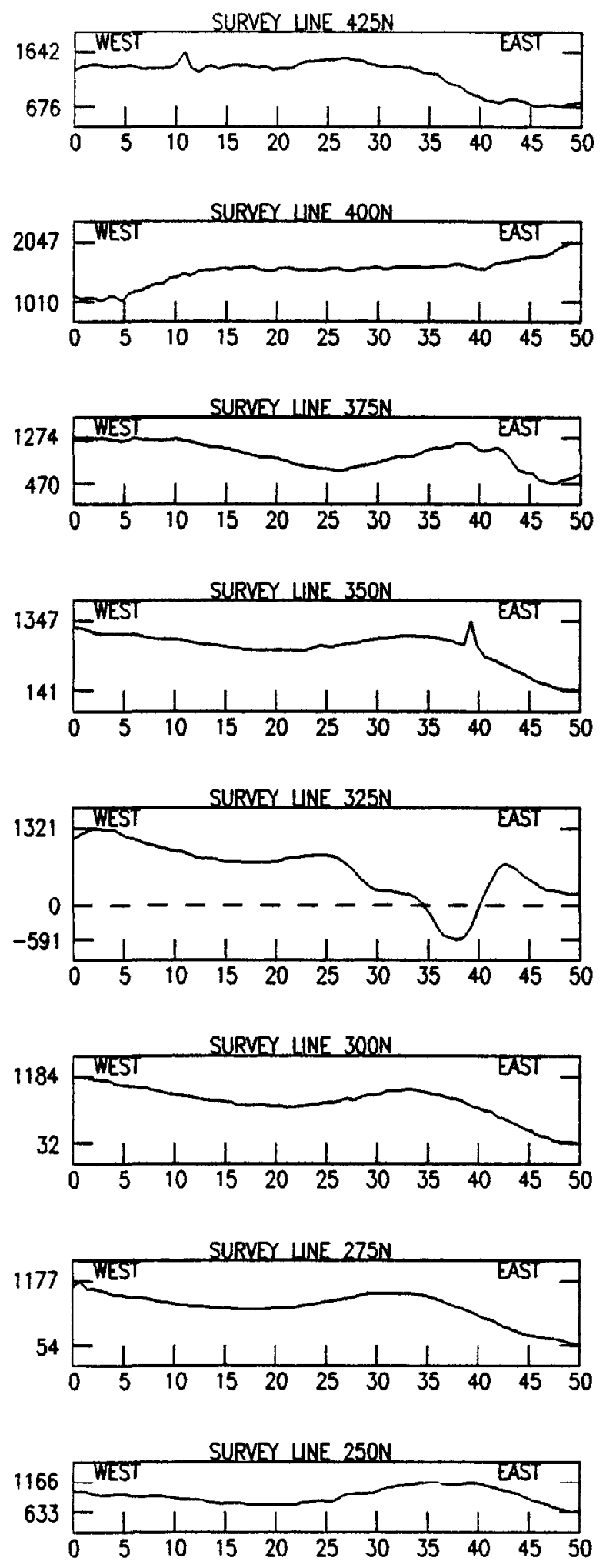
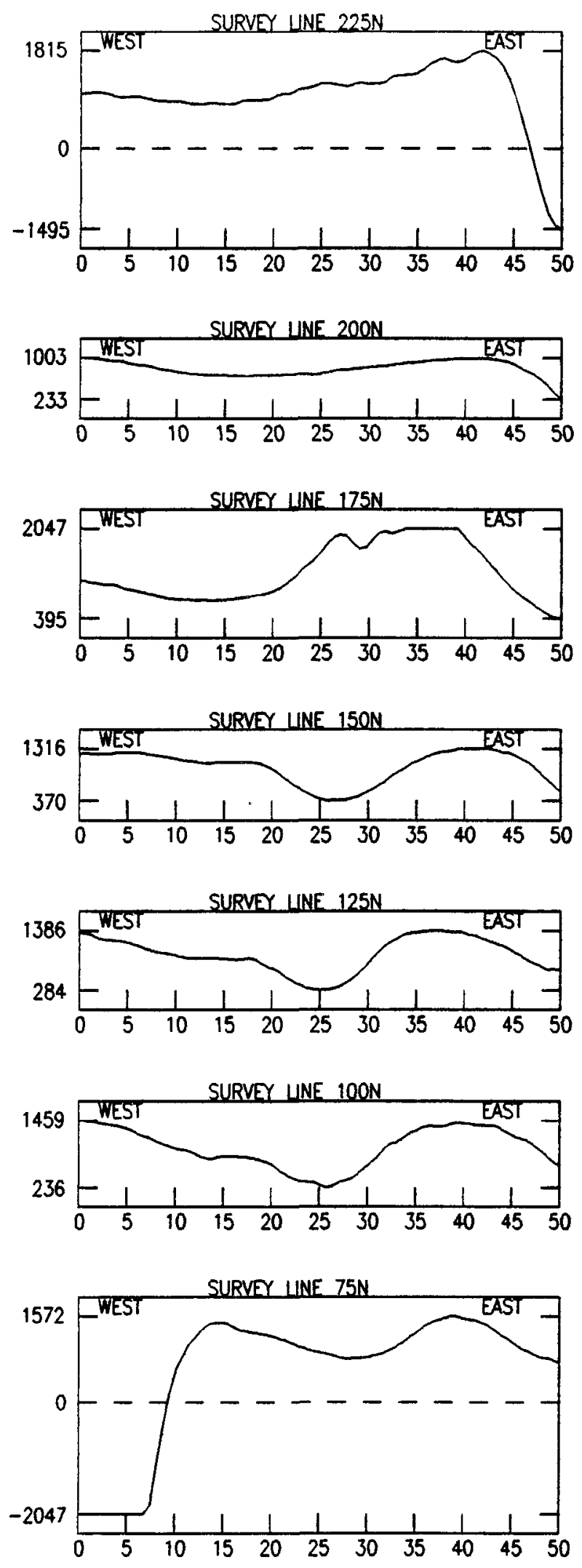
EM31 PROFILES ACROSS RLW SEWER FROM 309 BLDG, AREA 3APRS4

PAGE - 2

\section{Sensitivity Setting $=30 \mathrm{mmhos} / \mathrm{m}$ except as noted.}

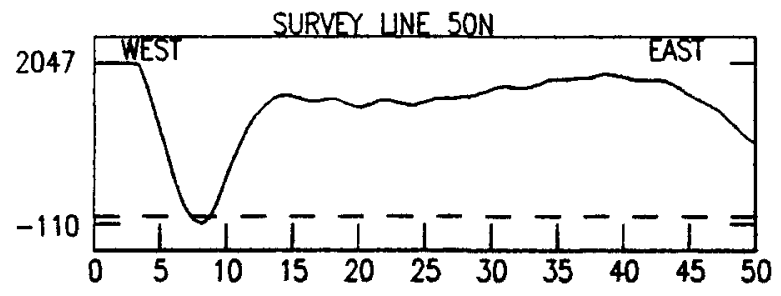

SURVEY UINE ON

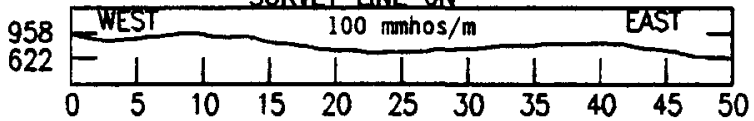

\section{E. 13}


APPENDIX $F$

GEOPHYSICAL SURVEYS TO LOCATE BURIED LITHIUM ALUMINATE RODS 


\section{कै: Battelle \\ Pacific Northwest Laboratories P.O. Box 999 \\ Richland, Washington U.S.A. 99352 \\ Telephone (509) \\ Telex 15-2874 \\ $375-3808$}

August 10, 1988

Mr. Doug Lenkersdorfer

Westinghouse Hanford Company

3200 George Washington Way

MS HO-20

Richland WA 99352

Dear Mr. Lenkersdorfer:

SUBJECT: Geophysical Surveys to Locate Buried Lithium Aluminate Rods

On July 26, 1988, we performed ground-penetrating radar (GPR) and metal detector surveys of a site believed to contain a buried deposit of zirconiumclad lithium aluminate rods. These rods were considered to be waste materials and were buried in an undocumented location sometime during the 1967-1970 time period. The objective of our geophysical surveys was to locate these materials. This letter report describes the work that we performed and outlines the results that we obtained.

The approximate location of the burial site was pointed out by Bob Hall, a former Hanford worker. He believed that his estimate of the location was accurate to within a hundred feet or so, but acknowledged the possibility that it could be in error by much more than that. Following a plan of attack developed during a site visit by Bob Hall, Farley George, you, and me, we defined a 265-ft (north-south) x 105-ft (east-west) survey area that covered the area thought to contain the buried rods. The site is located approximately $1000 \mathrm{ft}$ north of the 300 Area fence, just to the east of two long, north-south oriented process trenches. As shown in Figure 1, most of the survey area was located inside the fence enclosing the process trenches.

Our initial action in performing the surveys was to establish a reference grid on the ground surface. We did this by spray painting footage marks along the periphery of the survey area. These marks allowed us to define a set of parallel survey lines, or tracks, along which we made our measurements.

For the radar survey, we used a Geophysical Survey Systems, Inc., (GSSI) radar unit with a $120-\mathrm{MHz}$ (nominal) antenna (GSSI Model 3110) which transmits and receives radar signals in a frequency band of approximately 50-200 $\mathrm{MHz}$. Using the survey grid, we collected radar reflection data along parallel north-south survey lines spaced $5 \mathrm{ft}$ apart. The data were recorded on tape in digital form and were subsequently computer processed in our laboratory. 
Mr. Doug Lenkersdorfer

August 10, 1988

Page 2

For the metal detector survey, we used a Fisher M-Scope, Model TW-6. This instrument was originally marketed as a pipe and cable detector, but in recent years it has proven to be highly effective in detecting buried metallic waste materials at depths of a few feet. In this case, it was assumed that the targets of interest would be relatively shallow. The metal detector was carried by hand along the parallel survey lines until a response was obtained. Then the operator concentrated on the area of the response in order to completely define the outline of the metallic material. The outline was spray painted on the ground before the survey was continued.

Figure 2 shows the radar data collected in this survey. Each of the small images in this photograph is called a radar profile and represents one track or survey line. The horizontal dimension in a given profile corresponds to the distance along the survey line. The vertical dimension corresponds to signal travel time or depth. Thus, a radar profile can be regarded as a vertical cross-sectional view of the ground under the survey line. The maximum penetration depth shown in these profiles is approximately $16 \mathrm{ft}$. The depth calibration is based on an estimate of the dielectric constant of the ground at this location, so may be in error by 10-15\%. Excavation of one of the objects detected by the radar and measurement of its depth would provide the ground truth needed to improve the accuracy of the depth scale.

Figure 3 is a map which summarizes the results of the radar and metal detector surveys. It shows two significant subsurface features, either one of which could represent the deposit of lithium aluminate rods. The first is a shallow north-south oriented trench located along the west edge of the survey area. The waste materials are concentrated in the deepest part of the trench, a 140ft-long section extending from 100 South to 240 South in the survey-area (and map) coordinate system. The maximum depth of the trench is approximately $5 \mathrm{ft}$, but some of the waste materials seem to be as shallow as 2 or $3 \mathrm{ft}$. As shown on the map, the west edge of the trench is clearly outside the boundary of our survey area. Its width, however, is limited by the presence of the process trench which is located only 5-10 ft to the west of our 0 East baseline. The radar reflections, as shown in Figure 2, suggest that the metallic components of the waste deposit are not massive or densely packed, but rather of a relatively small size and widely distributed. This interpretation is supported by the fact that, given their depth of 2-5 ft, the objects shown by the radar were too small to be detected by the metal detector. An exception is the object or collection of objects shown on the map as a nearly circular metal detector response at coordinates $2275,4 \mathrm{~W}$.

The second significant feature is a small pit, 3-4 ft deep, lacated just to the east of the fence at coordinates 205-224S,91-105E. The waste materials contained in it are at approximately the same depth as the materials in the larger trench, but as indicated by the strong metal detector response, apparently represent a denser concentration of metallic materials. 
Mr. Doug Lenkersdorfer

August 10, 1988

Page 3

The black dots which are scattered across the map show the locations of isolated objects that were detected by the radar. Most of these objects are small and are buried at depths of 2-3 ft or less. Presumably, they are pieces of debris that have been deposited randomly during the various soil-moving operations that have taken place at this site.

The results just described offer two good possibilities for the location of the deposit of lithium aluminate rods, but do not provide any clear indication as to which of the two is the correct one. In an attempt to obtain additional information which could help to resolve the issue, we returned to the site on August 9 and performed a set of magnetic measurements along traverse lines $5 \mathrm{~W}$, $O E, 5 E, 95 E$, and $100 E$. The instrument used was a Geonics G-816 proton precession magnetometer. The resulting magnetic profiles are'shown in Figure 4. The lithium aluminate rods would not be expected to produce a magnetic anomaly because they do not contain ferromagnetic material. Thus, their location might be indicated by the absence of a magnetic anomaly where the metal detector and/or radar showed a large deposit of metallic material. Unfortunately, all of the magnetic profiles show anomaly amplitudes of a few hundred gammas ( 1 gamma $=.00001$ gauss), indicating that both waste deposits contain some ferromagnetic material.

In summary, each of the two waste deposits found at this site contains a substantial amount of metallic material; thus, either deposit could contain the zirconium-clad lithium aluminate rods. The magnetic data suggest, however, that the lithium aluminate rods are: 1) mixed with other waste materials, 2) enclosed in ferromagnetic containers, or 3) not present within the surveyed area. Excavation is needed to ascertain the contents of these waste deposits.

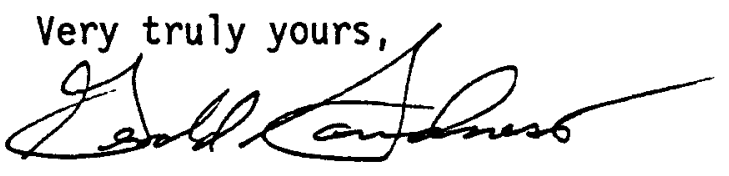

Gerald A. Sandness, Ph.D. Senior Research Scientist Electro-Optic Systems Section

GAS:klk

Enclosures 


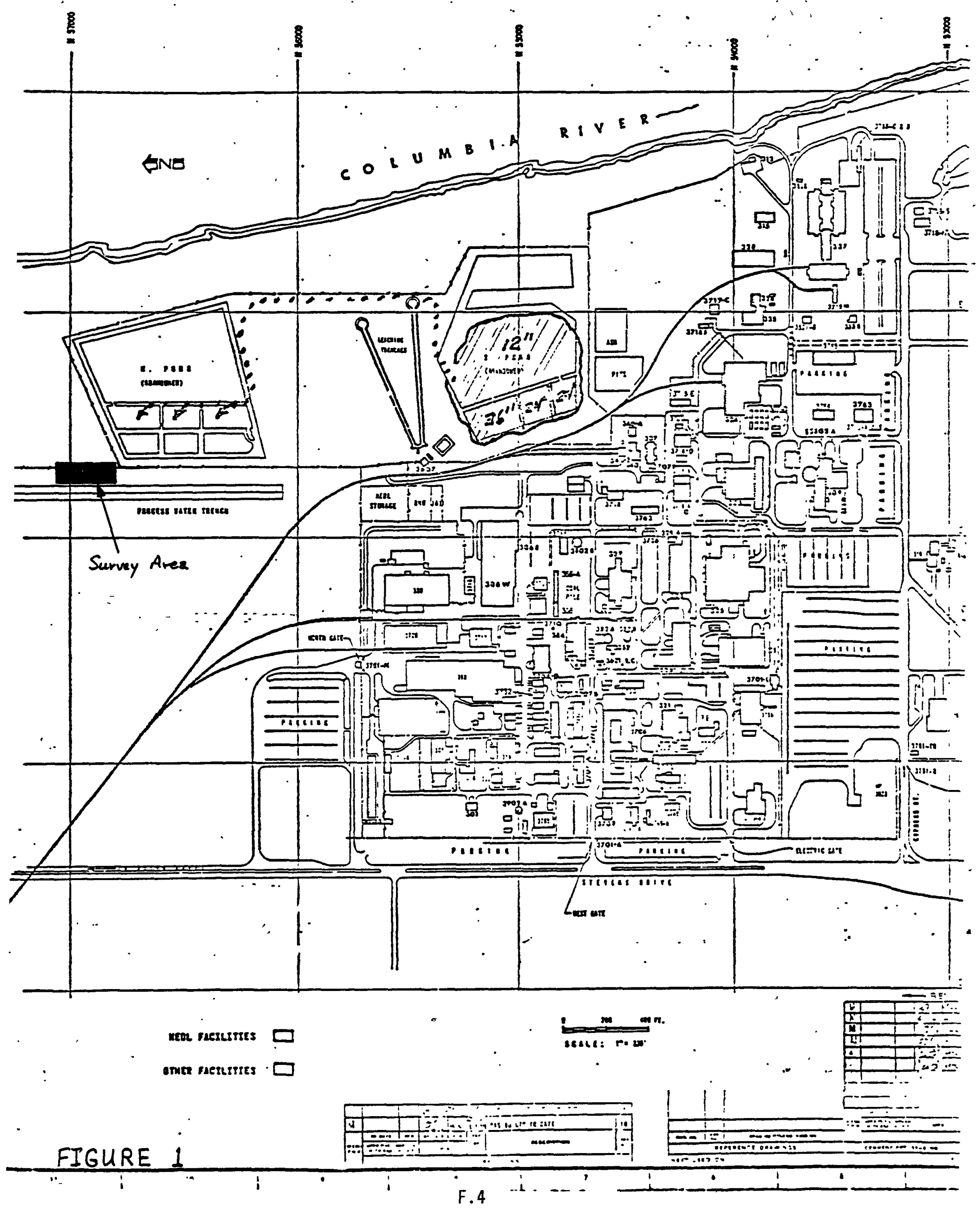




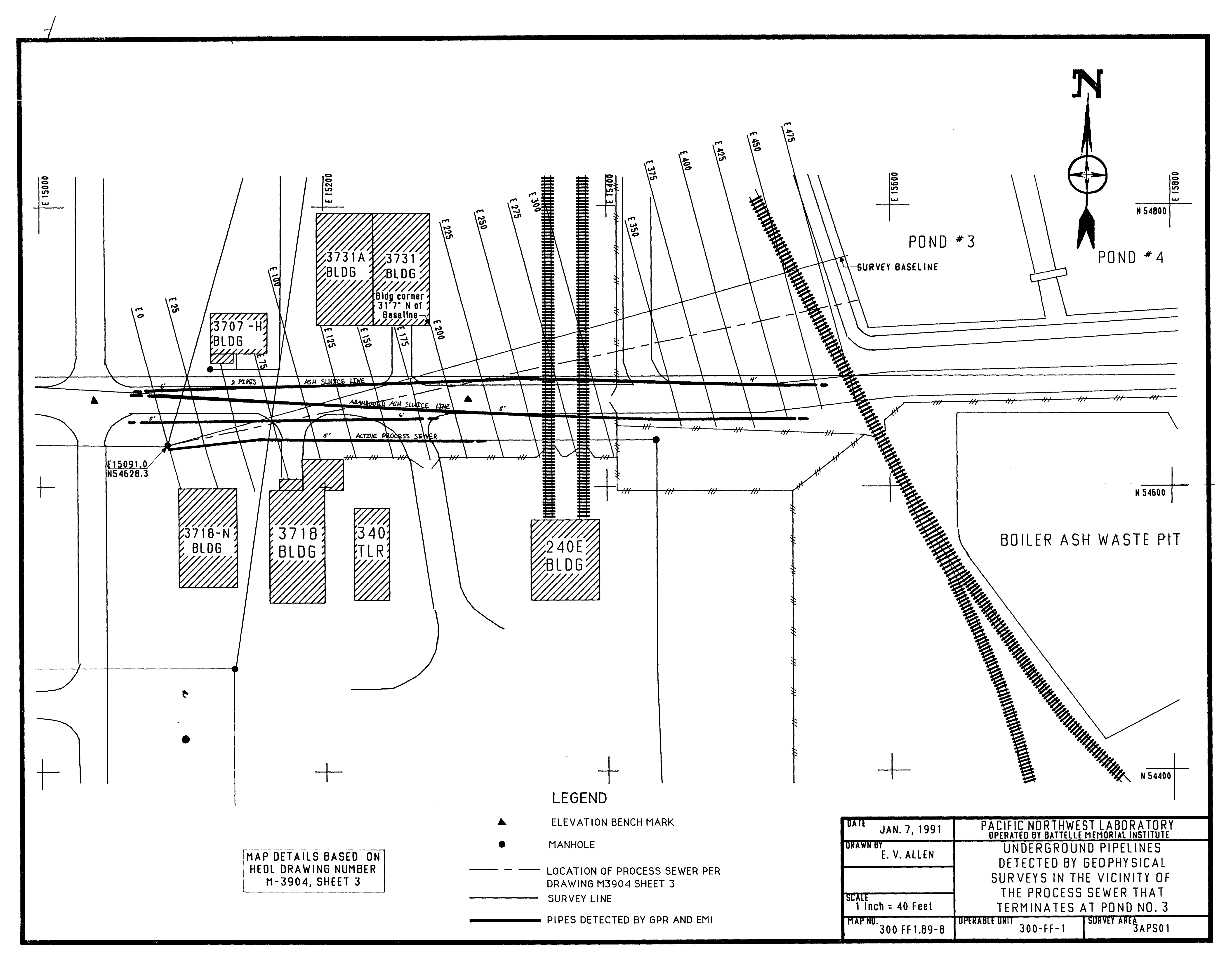




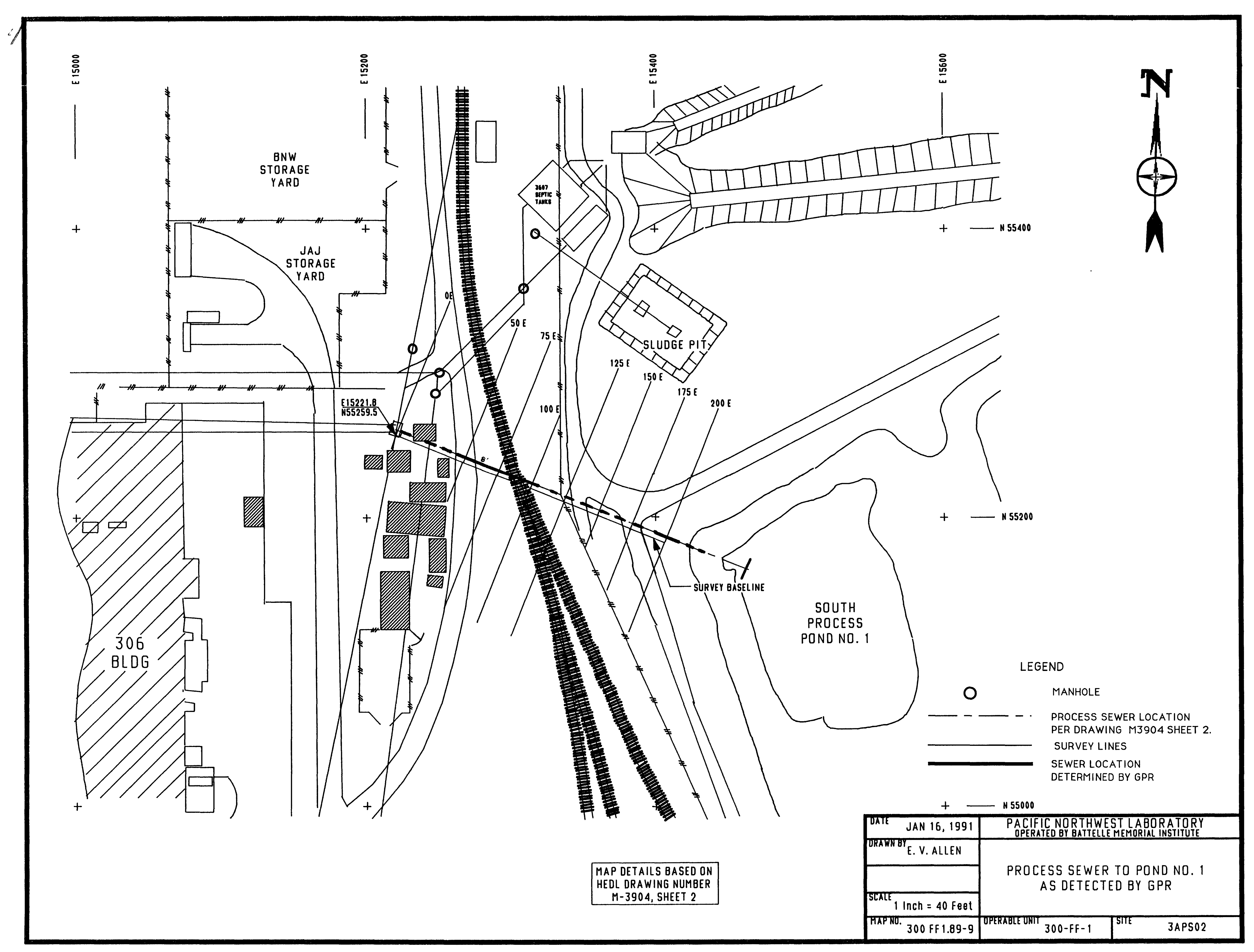




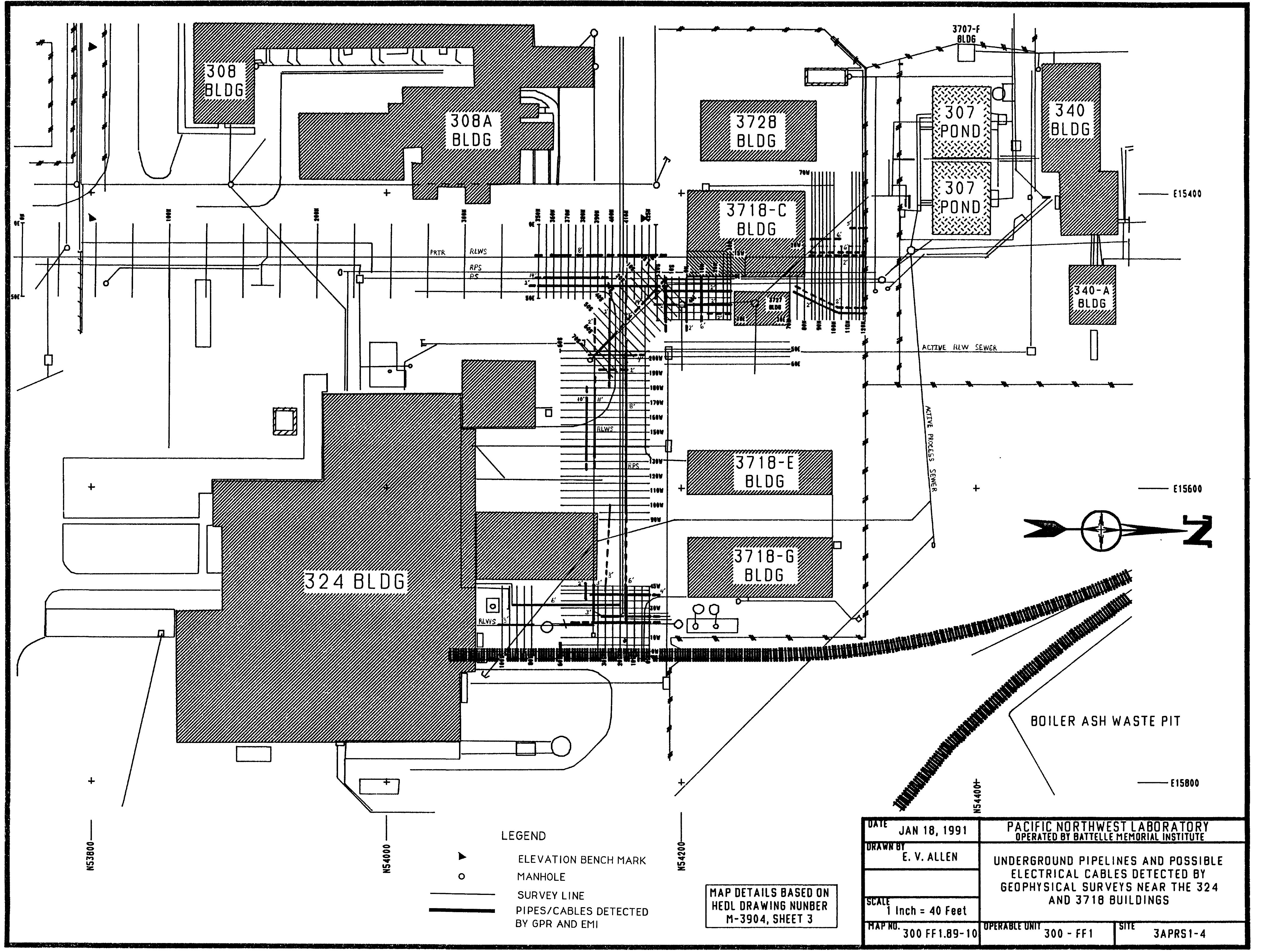




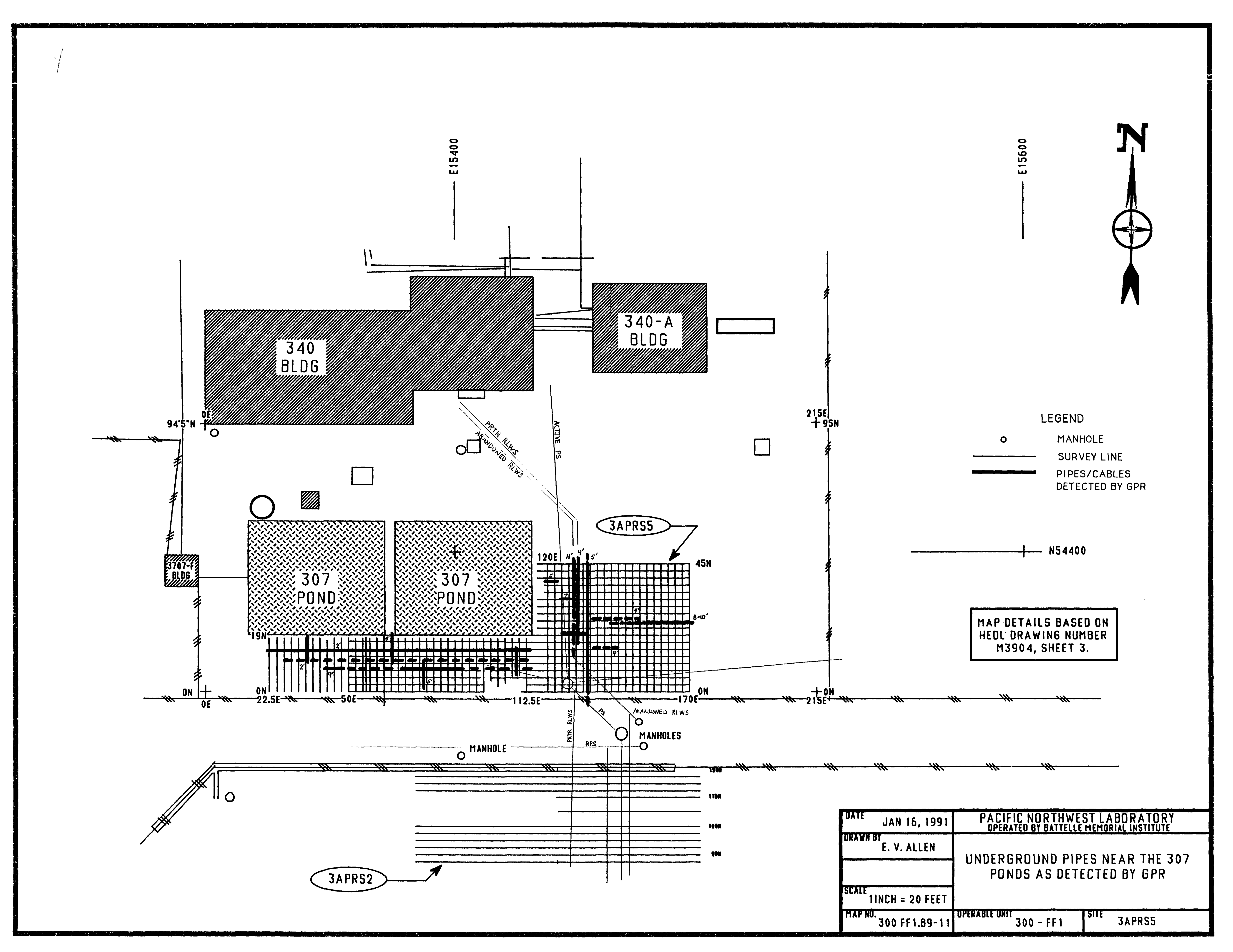




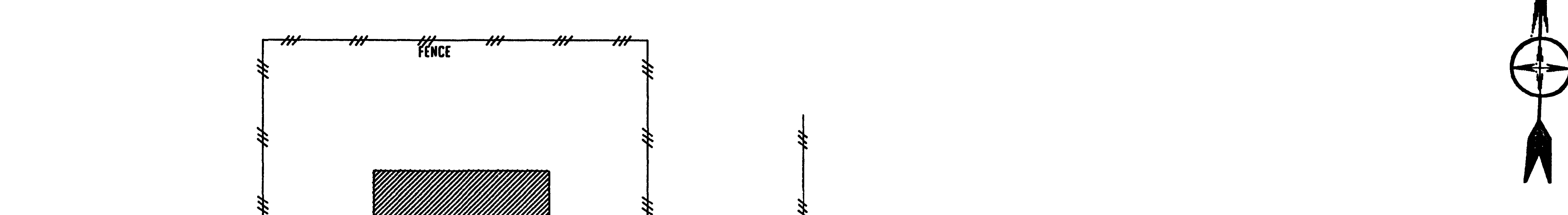

SURVEY AREA 3ARSI

1.

COCCRETE

.

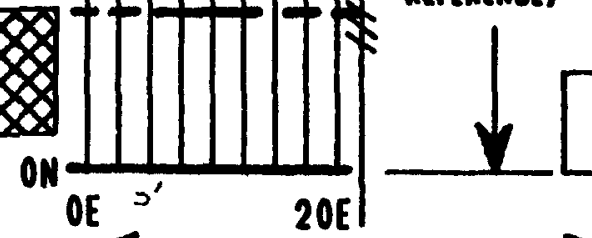

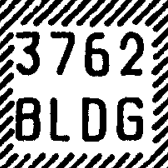

SURVEY AREA 3ARSP

次

ON 25

AREA JARS

LEGEND

SURVEY LINE

PIPES/CABLES
DETECTED BY GPR

\begin{tabular}{|c|c|}
\hline UAIE JAN. 18, 1991 & $\begin{array}{l}\text { PACIFIC NORTHWEST LABORATORY } \\
\text { OPERATED BY BATTELEMEMORML INSTITUTE }\end{array}$ \\
\hline E. V. ALLEN & \multirow{2}{*}{$\begin{array}{l}\text { UNDERGROUND PIPES AND POSSIBLE } \\
\text { ELECTRICAL CABLES DETECTED BY } \\
\text { GPR NEAR THE } 3762 \text { BLDG. }\end{array}$} \\
\hline דיזיר מ & \\
\hline RAPHO. 300 FF $1.89-12$ & SURVET \\
\hline
\end{tabular}




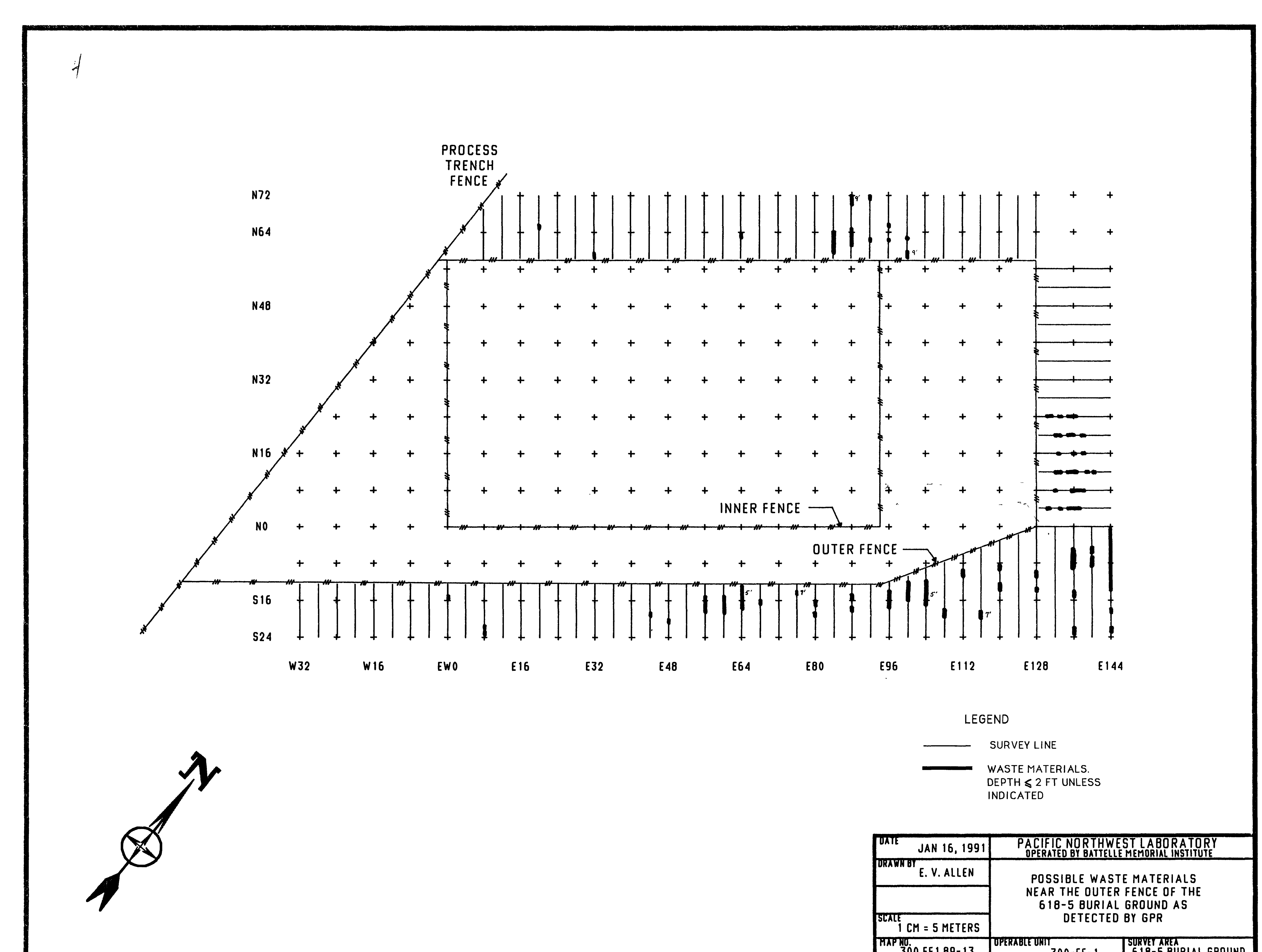




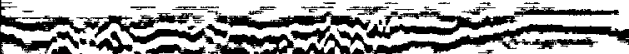

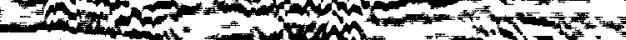

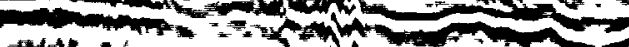

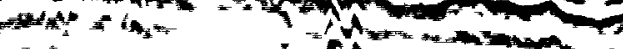
*.

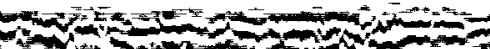

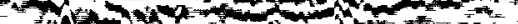

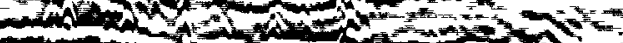

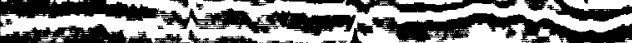

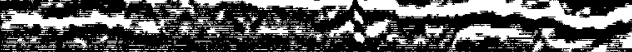

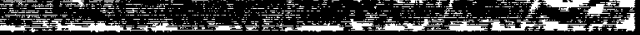

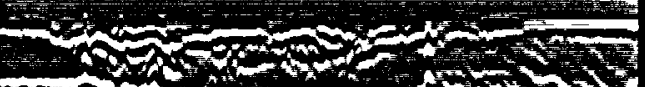

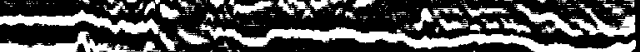

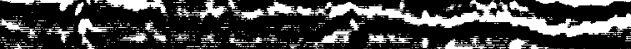

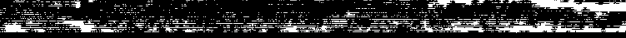

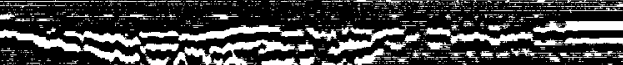

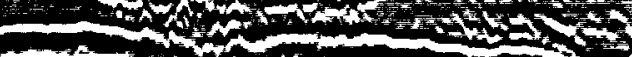

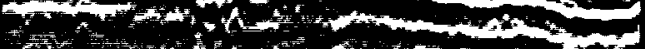

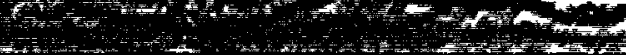

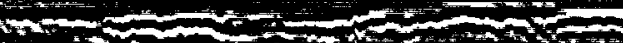

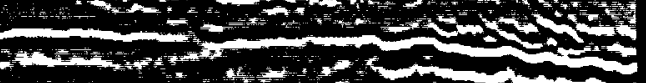

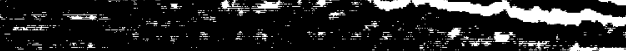
$\rightarrow$
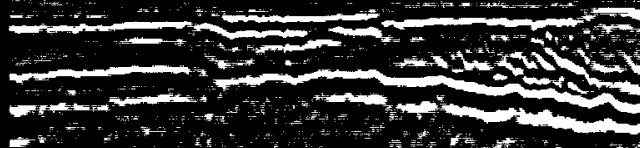

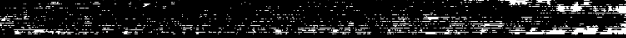
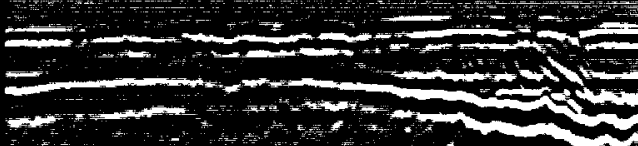

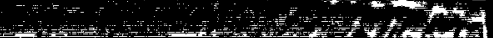

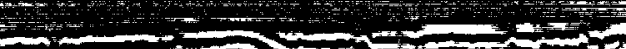

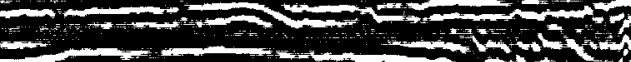

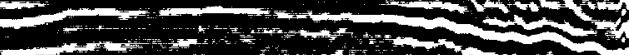

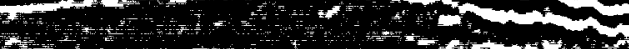

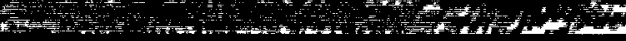

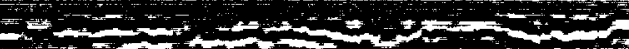

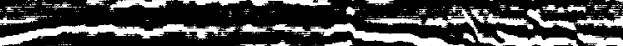

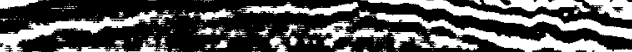

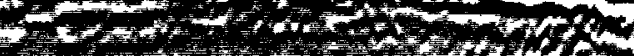

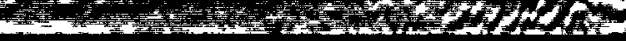

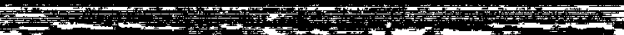

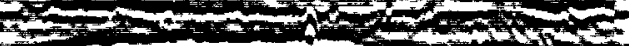

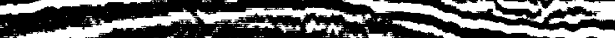

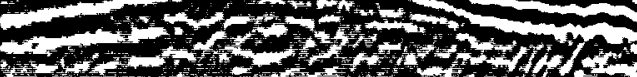

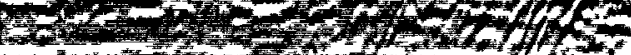

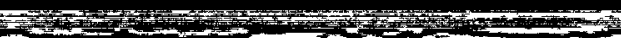

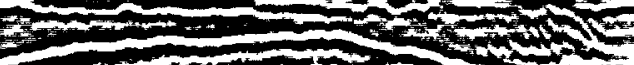

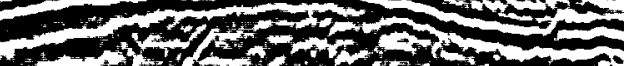

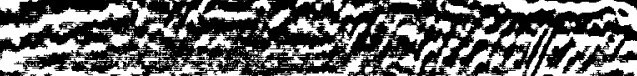
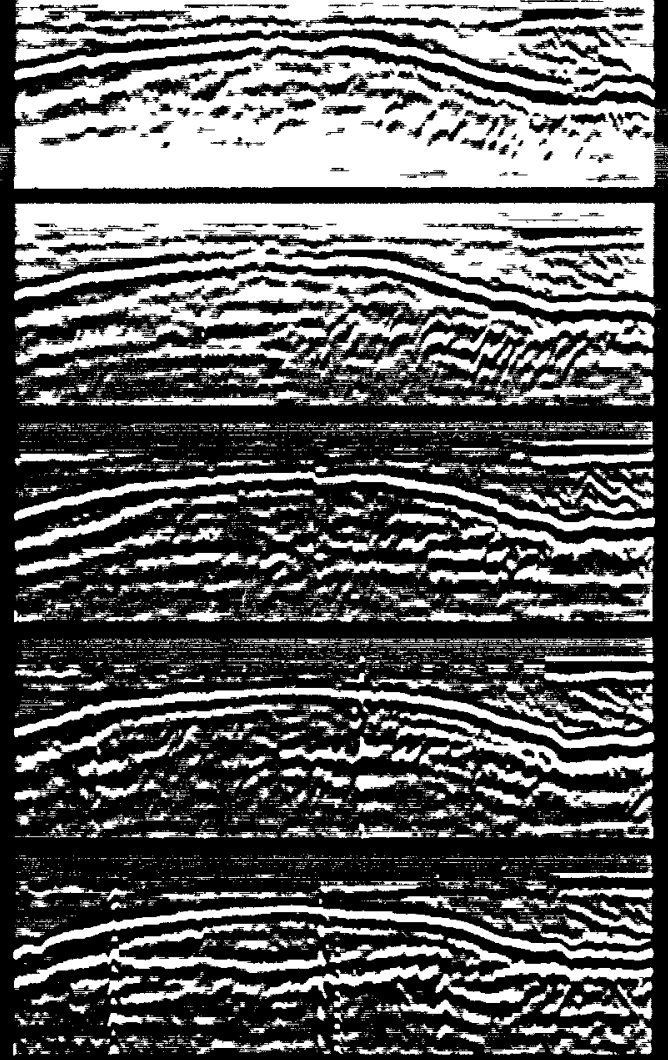

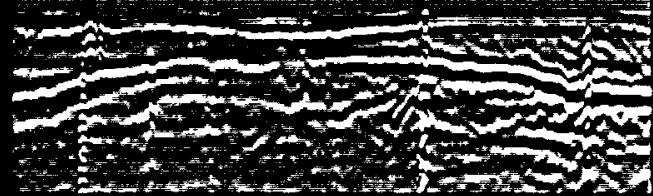

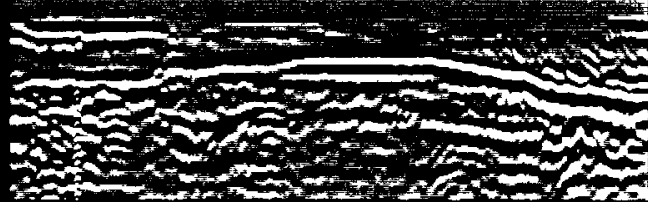

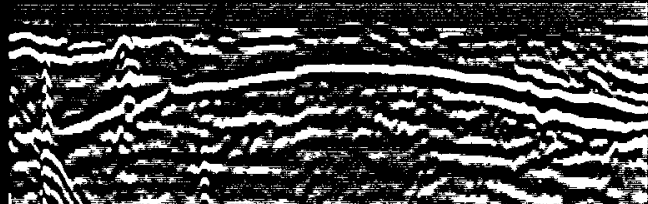

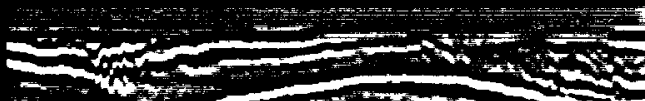

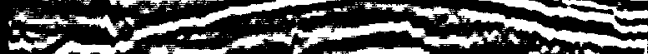
$-1+2+2=2+20$

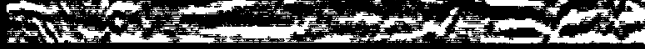

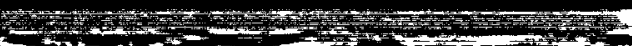

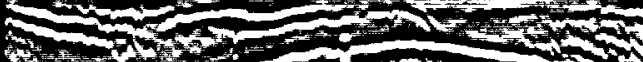

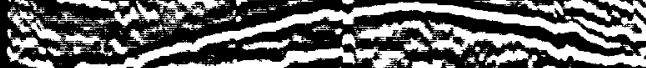

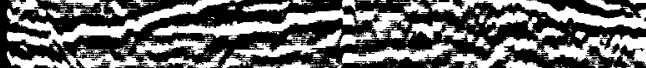

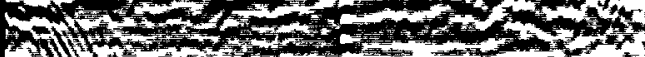
13

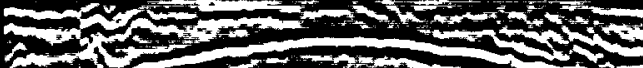

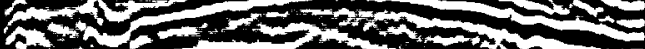
20200000 2 


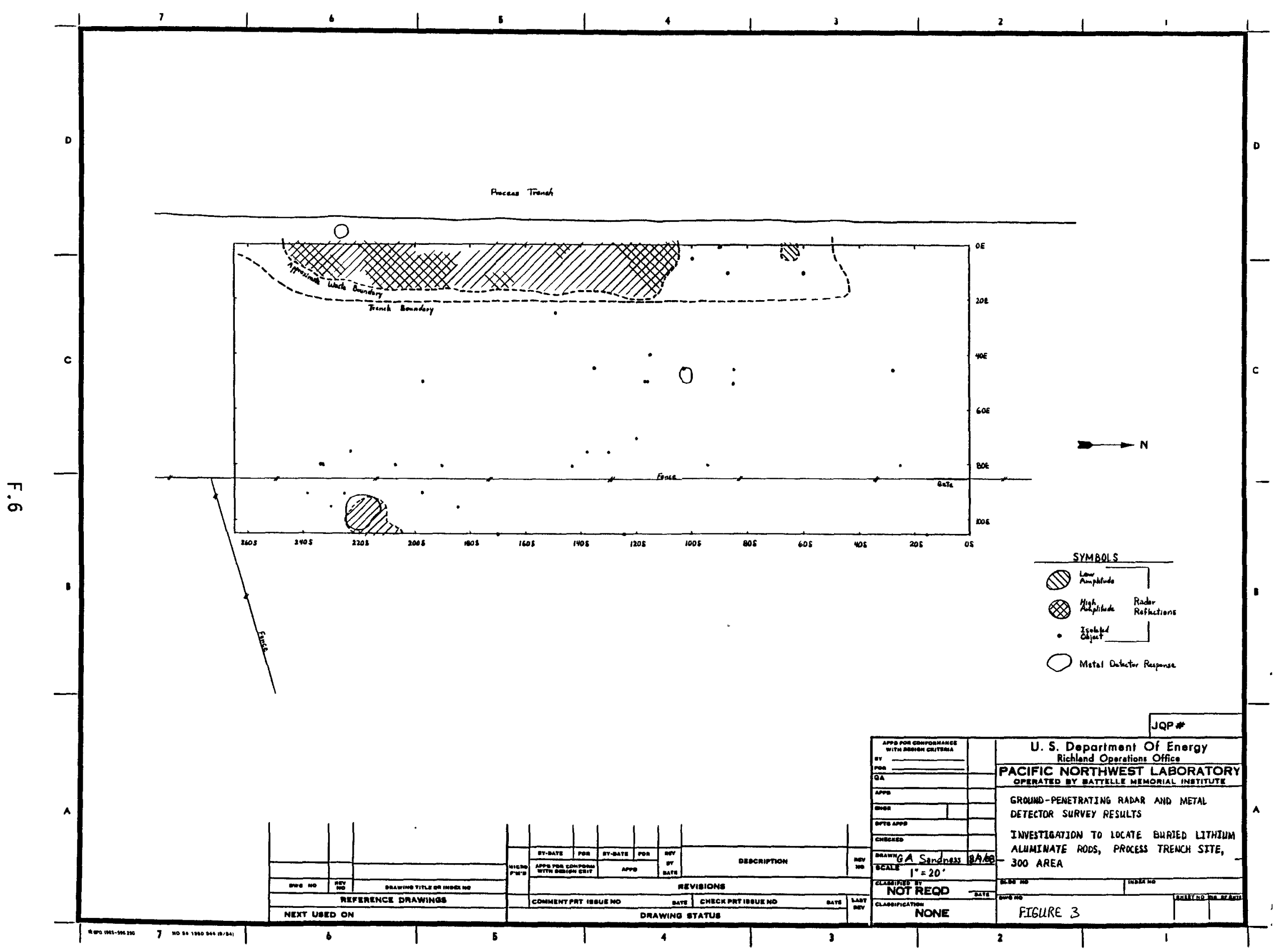




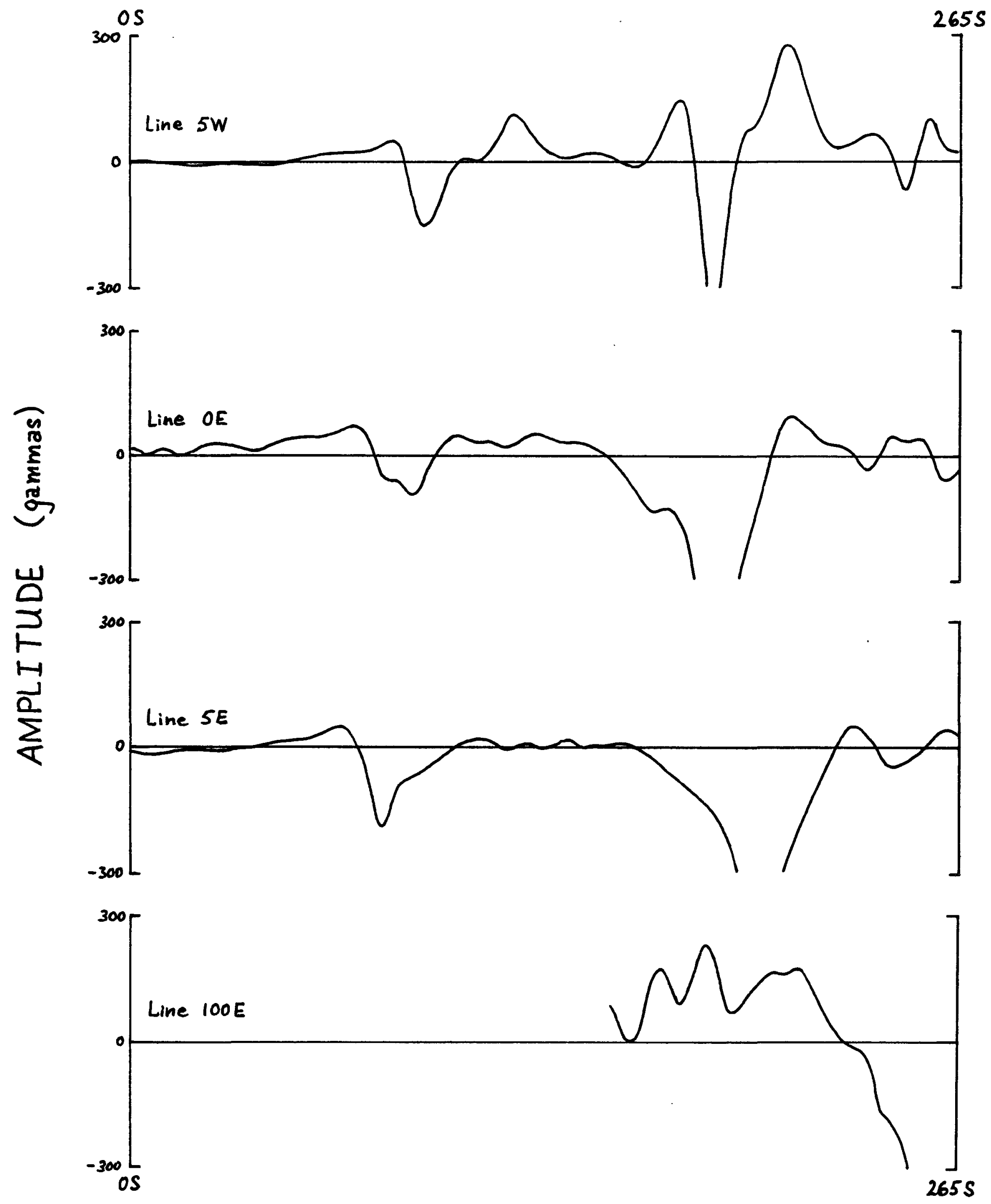

FIGURE 4. MAGNETIC PROFILES 


\section{DISTRIBUTION}

No. of

Copies

OFFSITE

2 DOE/Office of Scientific and Technical Information

C. Cline

Mail Stop PV-11

State of Washington Department of Ecology

01ympia, WA 98504-8711

P. T. Day

U.S. Environmental Protection Agency

Room 178, Federal Building

Richland, WA 99352

2 D. R. Einan

U.S. Environmental Protection Agency

Room 178, Federal Building

Richland, WA 99352

2 L. Goldstein

Mail Stop PV-11

State of Washington Department of Ecology

01 ympia, WA 98504-8711

\section{ONSITE}

4 DOE Richland Operations Office

D. L. Clark

R. K. Stewart (2)

K. M. Thompson
No. of

Copies

24 Westinghouse Hanford Company

M. R. Adams

R. A. Carlson

E. M. Greager

L. C. HuTstrom (20)

T. M. Wintczak

29 Pacific Northwest Laboratory

E. V. Allen

C. A. Brandt

M. A. Chamness

P. G. Doctor

J. W. Falco

J. S. Fruchter

W. R. Gorst

J. M. Hales

P. C. Hays

D. A. Kane

G. V. Last (2)

K. B. 01 sen

T. J. Peters

W. T. Penne11

G. A. Sandness (5)

R. L. Skaggs

C. Taylor

S. S. Teet

Publishing Coordination

Technical Report Files 